\title{
Origin of the balanomorph barnacles (Crustacea, Cirripedia, Thoracica) - new evidence from the Late Cretaceous (Campanian) of Sweden).
}

\author{
Andy S. Gale ${ }^{1}$ and Anne M. Sørensen ${ }^{2}$ \\ ${ }^{1}$ School of Earth and Environmental Sciences, University of Portsmouth, Burnaby \\ Building, Burnaby Road, Portsmouth P01 3QL UK \\ ${ }^{2}$ Department of Geography and Geology, University of Copenhagen, $\varnothing$ ster \\ Voldgade 10, DK-1350, Denmark
}

New material of thoracican cirripedes, traditionally assigned to the Brachylepadomorpha and basal Balanomorpha, is described from abundant isolated plates collected from sediment deposited between boulders on a rocky coastline of Late Campanian age (c. $80 \mathrm{Ma}$ ) at Ivö Klack in Scania, southern Sweden. Two new genera, Epibrachylepas and Parabrachylepas (type species $P$. ifoensis Withers, 1935) are described, as is a new species, Epibrachylepas newmani. Pachydiadema cretacea Withers, 1935 and Brachylepas guascoi (Bosquet, 1857) are redescribed on the basis of extensive new material. It is concluded that the long-held homologies between lateral plates of pedunculate cirripedes and balanomorphs are incorrect, and a new nomenclature is proposed for the latter group. Cladistic analysis based on 40 morphological characters of 12 species yields a consensus tree showing successive Brachylepas species and Pachydiadema as sister taxa to the crown group balanomorphs, which are here called the Plesion Neobalanomorpha nov. Both the "Brachylepadomorpha" and the "Brachylepadidae" are paraphyletic, and together with P. cretacea, form a morphocline leading from pedunculate ancestors (Pycnolepas articulata), through to basal sessile forms (B. naissanti, B. guascoi) and on to taxa identified as basal balanomorphs (Parabrachylepas, Epibrachylepas, Pachydiadema). The functional significance of the progressive changes is discussed with reference to 
living taxa. It is suggested that the radiation of the Neobalanomorpha, dominant shallow water thoracicans in the Cenozoic, postdated the K-Pg near-extinction of more basal sessile barnacle groups.

Key words: Cirripedia balanomorpha Cretaceous phylogeny, taxonomy

\section{Introduction}

One of the major questions in thoracican cirripede phylogeny is the evolution of the sessile balanomorphs (acorn barnacles) from a stalked ancestor (Darwin 1854; Anderson 1983; Newman 1987), specifically, the timing and precise order of appearance of the morphological changes involved in the evolution of this group. Although these changes can be considered usefully from theoretical and functional viewpoints applied to living species (Anderson 1983), the fossil record to date has failed to provide much evidence of balanomorph origins. The group appeared suddenly, with a full suite of derived characters, in the late Palaeocene of Australasia (Buckeridge 1983). However, Withers (1935) had described a large barnacle from the Campanian of Sweden as a member of the extant, basal balanomorph genus Catophragmus (Pachydiadema) cretacea (see also Newman et al. 1969; Foster \& Buckeridge 1987). Buckeridge (1996) reexamined Wither's material and cast doubt on the balanomorph affinities of this taxon, preferring to consider it "a brachylepadomorph or heavily armoured scalpellomorph".

Another fossil barnacle group which has claimed a place as potentially ancestral to the balanomorphs are the brachylepadids, a dominantly Cretaceous, sessile group with two constituent genera, Brachylepas and Pycnolepas (Withers 1935). Pycnolepas ranges from the Late Jurassic to the Miocene (Jagt et al. 2007), whereas Brachylepas is Late Cretaceous in age (Zullo et al. 1987). A living brachylepadid, Neobrachylepas, was described from vent faunas in the Pacific (Newman \& Yamaguchi 1995). Brachylepadids lack a peduncle, and the large capitular plates (rostrum, carina, 2 terga, 2 scuta, 2 upper latera) are surrounded 
by whorls of small, imbricating, scale-like plates. Woodward (1901) was the first to recognise the similarities between the only known articulated specimen of brachylepadid (Fig. 3) and basal balanomorphs. The idea was taken up again by Newman (1987) who constructed elaborate homologies beween the imbricating plates in Brachylepas and the primary wall plates in basal balanomorphs. Brachylepas has subsequently been placed close to the base of both the verrucomorph and balanomorph barnacles (Anderson 1983; Newman \& Buckeridge 1992). Brachylepas, however, remains poorly known, with only a single articulated specimen, and four species known from only a small number of isolated plates. A fourth species, B. americana, is known from abundant isolated plates (Zullo et al. 1987).

The Cretaceous locality of Ivö Klack in southern Sweden, from which Withers (1935) described cirripede material, represents a rocky shoreline cut in Precambrian gneiss, overlain by carbonate gravels made up of the skeletal remains of the diverse invertebrates which lived on and around the large boulders (Surlyk \& Christensen 1974; Surlyk \& Sørensen 2010). The sediment dates to the upper lower Campanian, at about $80 \mathrm{Ma}$. The faunas are exceptionally diverse, and dominated by echinoderms, bivalves, serpulids, brachiopods and bryozoans, and rare vertebrates (Gale 1997; Surlyk \& Sørensen 2010; Sørensen \& Surlyk 2010; 2011a,b; Sørensen et al. 2012, 2013). The recent discovery by Dr. Martin Röper (Germany) of a pocket of exceptionally well preserved material in cavities between the gneiss boulders has provided new insights into the fauna, and yielded a very large number $(>3,000)$ of cirripede valves, which include over 25 species (Gale \& Sørensen submitted). This locality is referred to here as the Röper Lense. The fauna includes four species which resemble Brachylepas, and two new genera are described in this paper. Additionally, the new collection provided over 200 plates of Pachydiadema cretacea.

Although disarticulated, the sheer abundance and exceptional preservation of the plates, plus the presence of early ontogenetic stages for some taxa, provides important new insights into cirripede evolution at a critical time in their history, 
and in a rocky coastal environment which is where the group has enjoyed its greatest success (Stanley \& Newman 1980).

The relationships of thoracican cirripedes has been recently revolutionised by molecular studies (Pérez-Lodosa et al 2008), which suggest extensive paraphyly exits amongst the scalpellomorphs, with three separate clades, and confirms the sister relationship of verrucomorphs and balanomorphs. Their cladogram places the putative ancestor of the verrucomorphs, Neoverruca (Newman \& Hessler 1989) within the basal scalpellomorphs. This study concentrates on the fossil evidence for the origin of the balanomorphs.

\section{Homology and terminology of thoracican skeleta}

\section{General morphology}

In stalked (pedunculate) cirripedes, the body is divided into a flexible peduncle, and a crown of larger plates called the capitulum (Fig. 1A). The peduncle is usually armoured with large numbers of peduncular scales, and the capitulum is tall, laterally compressed and formed of two rings of plates. The upper ring comprises an unpaired carina and and paired scuta and terga. The aperture is on the occludent margin formed by the paired scuta and terga. The lower ring is made up of a variable number of lateral plates, which have been classified as laterals (in contact with scuta and terga), including rostrum, rostrolaterals, carinolaterals and in some taxa sub-rostra and and sub-carina. The homology of these plates, at least within the extant stalked cirripede families Calanticidae and Scalpellidae, is well established, and the pattern of overlap is consistent (Newman et al. 1969; Newman1987). The number and relative size of these lateral plates is quite variable, and taxa such as Pollicipes and Capitulum have smaller plates intercalated between the larger, homologous ones (Fig. 2A,B).

In sessile barnacles (Verrucomorpha, Brachylepadomorpha, Balanomorpha) the peduncle is absent, and the capitulum is either attached directly to the 
substratum (e.g. derived balanomorphs, verrucomorphs) or elevated above it by whorls of smaller, imbricating plates (brachylepadomorphs, basal balanomorphs, basal verrucomorphs). Balanomorphs possess a primary wall made up of four to eight plates, which are thought to be individually homologous with the lateral plates of pedunculate cirripedes (Fig. 1B1; Darwin 1854; Newman et al. 1969). In Brachylepas, only the rostrum and carina are enlarged, and the gap between these is infilled by smaller plates (Figs 2D, 3). It is contentious as to whether these are homologous with either lateral plates or peduncular scales (see below).

\section{Plates of the primary wall}

Homology of lateral plates between scalpellomorphs and balanomorphs has a long history, commencing with Darwin (1854), who identified lateral, rostrolateral and carinolateral plates in both groups; this has proved to be one of the widely accepted truths of barnacle phylogeny (Anderson 1994; Fig. 1B1). However, in 8 plated balanomorphs the carinolatus (CL) is overlapped by the plate traditionally designated as the upper latus (L). As L has been incorporated into the operculum and subsequently lost (see Fig. 2) the argument runs that the plate must be either 11 or CL.; it cannot be the former, as it is overlapped by RL (see Yamaguchi \& Newman 1990 for an extended discussion) and must therefore be CL. The conclusion of Yamaguchi \& Newman was that replication of CL had taken place, and that the 8 plated balanomorph wall plesiomorphically comprises R-RL-CL1-CL2-C (Fig. 1B2; see also Ross \& Newman 2001; Jones 2000).

The origin of balanomorphs in the genus Brachylepas, originally proposed by Woodward (1901), resurrected by Newman (1987) and discussed here presents some problems for these proposed homologies, because Pycnolepas and Brachylepas lack all lateral plates except the upper latus (Withers 1935), which articulates closely with the operculum, lying over the scutal-tergal contact (Fig.2C-D). They possessed 3-4 whorls of small, imbricating plates set in up to 40 columns which form a skirt around the rostrum and carina, and are clearly 
peduncular scales; new plates formed adjacent to the rostrum and carina, along the vertical ridges (e.g. B. naissanti - Fig. 3).

Newman (1987) attempted to recognize homologues of scalpellomorph lateral plates among the scales occupying the gap between the rostrum and carina in $B$. naissanti (Fig. 3) and identified RL, CL, rl1 and l1. However, these plates are; 1) not differentiated morphologically from adjacent ones, and 2) new ones were formed at the contact with the rostrum and carina, exactly where peduncular scales form in scalpellomorphs (Young 2001; see below). We are therefore unable to support their interpretation as lateral plates. The possibility has to be raised that the fundamental homologies of lateral plates in balanomorphs are incorrect, and that the balanomorph primary wall evolved as a de novo structure, probably by modifcation of peduncular scales.

The possibility that lateral plates were somehow "re-evolved" from the modified peduncular scales in Brachylepas would have to be based on the identification of homologies of peduncular plate columns present in scalpellomorphs with those in Brachylepas. The plesiomorphic condition in thoracican peduncular scales comprises 8 columns, introduced as two, alternating, sets - rl-cl, and sr - l-sc, seen in some scalpellids and all stramentids (Newman \& Ross 1998; Young 2001). However, all thoracican taxa crownward of the scalpellids have numerous columns of peduncular scales (Pollicipeidae, Brachylepadidae) which are not homologous with those of the plesiomorphic pattern (Young 2001). To simply presume that the three adjacent lateral columns set between the rostrum and carina represent $\mathrm{rl}, \mathrm{l}$ and $\mathrm{cl}$ is not justified in our view.

The new genera Epibrachylepas and Parabrachylepas both possess two symmetrical, slightly concavo-convex, oval-triangular plates, much larger than the adjacent peduncular scales, positioned between the rostrum and carina on each side (Fig. 2E,F; Fig. 4A). These had no specialised articulation with the carina and rostrum, but clearly formed part of the primary wall and orifice in these genera, as the raised portion of the interior matches up with equivalent regions on the rostrum and carina. These plates, here designated M (marginal) 
have implications for the homology of plates in the balanomorph wall. In postmetamorphosis balanomorphs, the primary wall is made up of rostrum, carina and two "lateral" plates (traditionally laterals, following Darwin, but CL1 of Yamaguchi \& Newman 1990) (see Runnström 1925; Glenner \& Høeg 1993). Thus, the post-settlement juvenile balanomorph has the same 4 plated arrangement as found in derived brachylepadids, and homology seems difficult to avoid.

Continuing crownwards, the large Pachydiadema (Fig. 2C, Fig. 4C) has an eight plated wall formed by the addition of plates between the M plates and the rostrum and carina. These are traditionally called RL and CL, but are RL and CL2 sensu Yamaguchi \& Newman (1990). Following the logic of the M plate designation, these plates are herein designated RM (rostromarginal) and CM (carinomarginal).

The balanomorph primary wall is reinterpreted to be non-homologous with that of the distantly ancestral scalpellomorphs. Rather, it evolved by the sequential addition of newly formed primary wall plates (M, RM, CM) presumably by modification of peduncular scales. The pattern of basal balanomorph evolution thus lead from a 4 plated form (like the "urbalanomorph" of Ross and Newman 1976; Jones 2000), comprised of R-M-C, to an eight plated one, R-RM-M-CM-C, and thence to the crown group, at the base of which the distinctive overlap pattern was evolved. The secondary reductions in plate numbers, and fusion of plates found in the main balanomorph radiation have been well documented (e.g. Newman \& Ross 1976).

\section{The orifice and the operculum}

The orifice is only found in sessile barnacles which possess an operculum; for Newman et al. (1969, R226), the presence of true opercula, moving separately from the fixed wall, was restricted to verrucomorphs and balanomorphs. 
However, in the systematic section of the Treatise (p. R283) they subsequently refer to brachylepadomorphs as having an operculum. In Pycnolepas and Brachylepas, there is close articulation between the terga, scuta and the upper latus, forming a separate unit which articulated with the carina and rostrum (Fig. 2C,D); all other lateral plates were lost (Withers 1935). The concept of an operculum also carries with it reference to a moderately depressed, lid-like structure. The "operculum" in verrucomorphs is formed from only one pair of scuta and terga, articulates on only one side, and is not therefore strictly homologous with that of balanomorphs. The question remains as to what defines an operculum and consequently an orifice.

The concept of an opercular sheath is closely associated with that of an orifice and goes back to Darwin's original description and discussion (1854). The term has been used very broadly, applying effectively to the inner surface of the primary wall which contacts the opercular plates in all operculate cirripedes (Newman et al. 1969), including Brachylepas and Pachydiadema (Buckeridge 1996). However, little attention has been given to the nature of the transition to the operculate condition and specifically how the orifice and sheath originated. The material described here records the important transition between the condition seen in Brachylepas and its allies, through Pachydiadema, to the balanomorphs Catomerus and Eochionelasmus (Ross \& Newman 2001) which certainly possess a sheath.

\section{Articulation of wall plates; radii, alae and the opercular sheath}

Many balanomorphs possess wing-like processes on the upper part of the primary wall plates, which are thinner than the main wall (parietes), and mark a sharp upward turn in the orientation of growth lines (Newman et al. 1969). These are called radii (single, radius) where they overlap an adjacent structure, and alae (single, ala) where they are overlapped (Figs. 5,6; Newman et al 1969). These have traditionally been used as a good synapomorphy of Balanomorpha; however, Buckeridge (1996) identified alae in the carina of Brachylepas, These 
structures are actually specialised for tergal articulation and are therefore not homologous with balanomorph alae (see Systematic Palaeontology, description of Brachylepas guascoi). Likewise, structures called alae and radii in verrucomorphs are certainly not homologous with those found in balanomorphs.

Anderson (1994) explained the development of radii as a functional consequence of the necessity to expand the circumference of the orifice with growth. This is brought about either by the erosion of the apical portion of the plate (monometric growth), or diametric growth, by the formation of outgrowths from the apicobasal margins, which expand the circumference of the wall apically as well as basally (Anderson 1994, p. 281). Alae and radii developed from interlocking imbrications between wall plates, which carry specialized articular surfaces in basal balanomorphs (e.g. C. polymerus, Fig. 5,6B) and presumably developed opercular expansion as a secondary function. Pachydiadema lacked radii and alae and dealt with the problem of increasing opercular expansion differently, by a combination of allometric change in shape of the wall plates, and apical spalling of the early growth stages (see Systematic Palaeontology). The M plate progressed from a triangular outline in juveniles to a trapezoid-rectangular shape in fully grown individuals.

In Pachydiadema the primary wall was rather weakly articulated, with the overlap of narrow flanges on plate margins by rounded surfaces on adjacent articulating plates (Figs. 2,4,5-7). This overlap is significantly greater on the lateral surfaces of the rostrum. The exterior surfaces of all the wall plates posses a central or subcentrally placed, raised vertical ridge, and lateral depressed surfaces (Figs 5-7). The growth increments and sculpture are continuous across the exterior surfaces indicating that both the central region and lateral surfaces were truly external. The upper interior surfaces each carry a narrow vertical ridge marking the positions of contacts and angled margins of the opercular plates - no sheath was present.

The overlaps between wall plates in Pachydiadema are notably different to those of crown group balanomorphs; the carina overlaps the rostromarginals, and the 
marginals are overlapped by both rostro- and carinomarginals (Fig. 4). The transition from Pachydiadema to the condition seen in the eight plated Catomerus, and more derived six plated balanomorphs, which have a consistent and quite different overlap pattern, a sheath, and discrete parietes/alae - radii can be achieved simply by extended plate imbrication (Figs 4-6). The raised central regions in Pachydiadema became the parietes, and the depressed lateral regions imbricated and developed specialized articulation facets which eventually became the alae and radii (Figs 4-6). As a consequence of this, the non-articular, interior portion of each $\mathrm{M}, \mathrm{CM}$ and RM plate each now possessed a free inner surface, which, together with those on the $C$ and $R$, became closely articulated and formed the sheath. The change of overlap pattern was a further consequence of this modification (Figs 4-6). The lateral surfaces of the carina formed alae, and were imbricated by the radii on the interiors of the RM plates. The overlap of the CM over the $\mathrm{M}$, present in all crown group balanomorphs, was an extension of the condition present in Pachydiadema. A change in the overlap relationship between the $\mathrm{M}$ and the RM plates occurred, such that the $\mathrm{M}$ imbricated the RM. This was probably a structural necessity of extended imbrication, and also permitted the interior, carinal portion of the $\mathrm{M}$ plate to form part of the sheath. The overlap relationships of the RM and R were simply extended. Many balanomorphs possess discrete articular facets on the alae and radii, which in Catomerus are tear-drop shaped; these were figured in $C$. polymerus by Anderson (1994, fig. 9.23 a,b) on the interior of plates as "sockets for ala". These developed into the more expanded radii and alae of forms such as Chirona (Figs 5,6).

Thus, complex changes in the wall plates of balanomorphs in order to maintain consistent overlap relationships with distantly ancestral scalpellomorphs (e.g. the replication of a CL plate - Yamaguchi \& Newman 1990) are not needed. Rather, the new wall plates (M, RM and CM) which evolved initially in Epibrachylepas (M) and developed further in Pachydiadema (RM,CM) were modified by extended imbrication to increase the strength of the wall, resulting in the overlap pattern characteristic of balanomorphs (Yamaguchi \& Newman 1990). The free, contiguous inner surfaces of the modified wall plates were then 
able to form a smooth subcircular sheath, permitting a tight and precise fit of the operculum (Fig.4).

\section{Peduncular scales, imbricating plates and latera}

There has not always been clear distinction between the terms lateral plates (or latera), sublaterals, imbricating plates and peduncular scales, and considerable unresolved discussion has attended the identification of homologies between these structures. The significance of this discussion is considerable, ever since Darwin (1854) remarked on the homology of the imbricating plates of Catomerus with the peduncular scales of scalpellomorphs, and thus identified its basal position amongst balanomorphs and intermediate morphology between lepadids and balanids (pedunculate and balanomorph thoracicans).

Lateral plates and peduncular scales, as seen for example in Capitulum, appear to be introduced at different positions, separated by a peduncular-lateral (P-L) line (Young 2001). New lateral plates are formed alternately on the outside of previously formed plates (Broch 1922), above this line, whereas peduncular scales appear above previously formed ones beneath this line. This forms a working definition which can be used consistently to discriminate between lateral plates and peduncular scales, which can probably be applied to all scalpellomorphs, with the possible exception of some Zeugmatolepadidae.

In Brachylepas naissanti, smaller new plates can be seen to be forming on the interior of the skirt of smaller surrounding plates, adjacent to the rostrum and carina. Therefore, applying the same criterion, the smaller plates in B. naissanti (Fig. 3) are peduncular scales, and thus cannot be homologous with laterals, as hypothesized by Newman (1987 - see above). The same situation probably obtains in Epibrachylepas and Parabrachylepas described below, although articulated material of these is not known. In most brachylepadids the lower peduncular scales have a highly specialized articulation of interpenetrant knobs and grooves (Withers 1935; Zullo et al. 1987). 
The whorls of imbricating plates which surround the capitulum in Pachydiadema and some extant balanomorphs (Catomerus, Catophragmus, Catolasmus, Eochionelasmus, Chionelasmus, Waikelasma) are, however, significantly different to those in Brachylepas, because these are added peripherally. This is evident because the plates become progressively smaller towards the margin, and there are no smaller plates intercalated with the larger, more proximal ones (Fig. 15). In Pachydiadema the plates are solid calcite structures, whereas in Catomerus and Catolasmus, these are alternating, concavo-convex, relatively thin structures with large spaces between the plates.

\section{Opercular plates}

The opercular plates (scuta, terga, upper latus) have not been widely used in the study of deeper relationships in cirripedes, although scuta and terga are extensively used in balanomorph taxonomy (e.g. Pilsbry 1916; Jones 2000). Withers (1935) showed how the morphology of scuta of successive species of Pycnolepas and Brachylepas approached the condition present in balanomorphs, with progressive movement of the apicobasal ridge towards the tergal margin, and concomitant reduction in the tergal surface of the scutum, until the condition in B. guascoi is reached, where the tergal surface is reduced to a small vertical region ("tergal slip") and the apicobasal ridge forms the tergal margin. Zullo et al. (1987) briefly discussed Wither's ideas from a functional viewpoint, but the lion's share of attention in balanomorph origins has been devoted to homologies of wall plates (see above).

The use of terga and scuta in a phylogenetic context has been hampered by the limited terminology applied to plate morphology, and poorly constrained homologies. These remain unchanged since Darwin's original work (1854); the problem is that Darwin constructed the nomenclature for derived balanomorphs, and no-one has subsequently followed the evolutionary origins of the structures back into the stem group. Indeed, the standard illustration of tergal and scutal 
terminology, used by Withers $(1935,1953)$, Newman et al $(1969)$ and Southward (2006) has not changed for over 160 years. This is a particularly acute problem in the case of the articulation between the scutum and tergum, which shows significant morphological change in the transition between the scalpellomorphs and balanomorphs (Withers 1935; Zullo et al. 1987) and, indeed, within balanomorphs. The structural modifications and homologies of scutal and tergal stuctures are more complex than has hitherto been realised. A new, modified terminology is proposed in this paper (Figs. 8,9).

In scalpellomorphs such as Calantica (Fig. 8A) the scutum merely rests on the tergum, and an unmodified surface on the inner, apical, part of the tergal margin of the scutum contacts the tergum close to the border between the occludent and scutal margins. In more derived taxa (e.g. Capitulum, Lithotrya, Brachylepas), the tergum develops a raised surface, subparallel with the occludent margin, which is here called the scutal auricle (sa) and is separated from the rest of the plate by a shallow scutal groove (Fig. 8B-D). The convex surface of the auricle articulates with a concave tergal notch (tn) on the scutum, adjacent to the apex, as well shown by Capitulum and Pycnolepas (Figs 8,9; articulation represented by green coloration). The articulation of the scutum and tergum in Capitulum and brachylepadids is complicated by the presence of the upper latus which rests on the scutal-tergal contact, and articulates on one side with the tergal slip of the scutum, and on the other with the tergum (Figs 8B-D; 9E,F).

Reduction in size and eventual inflexion of the tergal region of the scutum (i.e. the tergal slip - the portion of the exterior surface which falls on the tergal side of the apicobasal ridge) results in the apicobasal ridge forming the tergal margin of the plate (Withers, 1935). Thus, in species such as Brachylepas guascoi (Fig. 9A) and B. americana (Zullo et al. 1987) the inflexed, flat tergal slip (ts; all that remains of the tergal portion of the scutum) forms a gently concave contact with the upper latus, indicated in Figs 8,9 by y-y brown coloration. The other side of the upper latus articulates with the scutal wall (sw) of the tergum, shown as the $\mathrm{x}-\mathrm{x}$ brown articulation (Figs. 8,9). 
The next stage of evolutionary transition (Fig. 9F, Epibrachylepas newmani) in which the tergal slip develops into a concave depression on the scutum, homologous with the articular furrow of Darwin (1854); this contacts the upper latus (articulation y-y), the other side of which contacts the scutal wall of the tergum $(\mathrm{x}-\mathrm{x})$. The oblique ridge separating the furrow and the tergal notch forms the articular ridge, still only very weakly developed in Epibrachylepas. Previous studies (e.g. Zullo et al. 1987) have presumed that the articular furrow, sensu Darwin, is homologous with the tergal notch, which is not the case. Modifications of the tergum accompanying this transition in scutal morphology involve enlargement and steepening of the scutal auricle, groove and wall.

The transition in tergal structure between Epibrachylepas and crown group balanomorphs exemplified by Octomeris and Solidobalanus (Fig.9G,H) are finally comprehensible. Firstly, the upper latus is lost. On the tergum, the scutal auricle is still developed as a prominent process, which articulates with a shallow tergal notch on the scutum (Fig. 9G,H, green). The tergal slip of the scutum has changed from being a shallow depression to become the deeply inset articular furrow (Fig. $9 \mathrm{G}, \mathrm{H}$, brown). A tergal wall ( $\mathrm{tw}$ ) forms the roof of this groove, but has changed orientation from a vertical surface to an internally directed, concave surface set in the plane of the valve. The boundary between the scutal wall and the remainder of the external surface of the valve is a sharp surface which defines the scutal margin of the tergum. The scutal groove enlarges and deepens to form the articular furrow of the tergum of Darwin (1854) and subsequent workers. The scutal wall in balanomorphs usually comprises two more or less discrete surfaces (e.g. Fig. 9 G,H, brown).

The balanomorph opercular valves are now deeply interlocked with what is essentially a triple articulation, comprising (Figs 8,9) 1) a (green colorised) tergal notch-scutal auricle contact, retained from Calantica and Pycnolepas; 2) a (red colorised) scutal articular ridge-tergal articular furrow inherited by modification from the shallow scutal groove of Brachylepas; 3) a (brown colorised) scutal wall-tergal wall articulation, inherited from the original articulation site of the upper latus against the scutum ( $\mathrm{y}-\mathrm{y})$ and tergum (x-x). 


\section{Cladistic analysis}

Unconstrained heuristic analysis using PAUP 4.1, optimised to deltran, was performed on a set of 40 unweighted characters, using 12 cirripede taxa (Table 2,3) with Calantica sp. as a designated outgroup. This yielded 2 equally parsimonious trees, and a single consensus tree is provided here, which shows Pachydiadema cretacea as sister taxon to the two extant balanomorphs, Echinolasmus ohtai and Catomerus polymerus, nested within a succession of taxa (Fig. 10). These are, in successively more basal order, Epibrachylepas newmani, Parabrachylepas ifoensis, Brachylepas naissanti, B. guascoi, B. fallax and Pycnolepas bruennichi. The Eochionelasmus-Catophragmus clade is very well supported (Bremer $>6$ ), as is that including these two taxa and Pachydiadema (Bremer 6). Likewise, there is strong support for a clade including Epibrachylepas + Pachydiadema + the two balanomorphs (Bremer 5). The other nodes are supported by variable Bremer values (1-3).

The cladistic analysis performed here provides a basis with which to discuss the origin of balanomorph cirripedes from a pedunculate ancestor, and the classification of basal forms. Part of the pattern of evolution outlined in the cladogram is not novel, as Withers (1935) and Zullo et al. (1987) discussed the phylogeny of "brachylepadids" in some detail, and proposed both the evolution of Pycnolepas from a pollicipedid ancestor, and the relationships of successive Brachylepas species, B. fallax -B. naissanti-B. guascoi. This represents what would currently be described as a morphocline, showing a progressive decrease in the height and increase in the breadth of the carina and rostrum, and change in the shell form from laterally compressed to a more circular outline. Withers (1935) had noted how the terga and scuta of Brachylepas guascoi approached the balanomorph morphology, but attributed this to convergence.

The relationships identified here and the consequences for classification are summarized in Fig. 11. 


\section{Superorder Sessilia Lamarck, 1818}

- Peduncle lacking, low skirt of imbricating plates present in basal forms (character $1,0->1$ )

- Moveable operculum present (character 10, 0->1)

Strong molecular evidence for the monophyly of sessile thoracicans (Balanomorpha and Verrucomorpha) was presented by Pérez-Losada et al. (2008) using a large suite of living taxa. This is supported here by morphological evidence derived from living and fossil forms. The base of the Sessilia falls within the genus Pycnolepas; complete specimens of Pycnolepas articulata Collins, 1980 (Fig. 3) from the Aptian of Antarctica clearly possessed a peduncle, as the three individuals form a bouquet-like cluster, and peduncular plates are arranged in an elongated structure (Fig. 2B). In contrast, the later P. rigida (J. de C. Sowerby, 1836)(Albian) and P. bruennichi Withers, 1914a (Danian, Palaeocene) evidently lacked a peduncle, as there are only a small number of types of imbricating plate in these species, indicative of the presence of 3-5 rows of plates (Withers 1935, confirmed here).

The Verrucomorpha Pilsbry, 1916 evolved from a species of Pycnolepas (Withers 1935), with one scutum-tergum pair becoming fixed and incorporated with the carina and rostrum into a wall, and the other forming a moveable opercular lid (Darwin 1854). The basal verrucomorph, Eoverruca hewitti Withers, 1935 is shortly to be redescribed on the basis of abundant new material (Gale, in press b.); it possessed a skirt made up of several rows of small imbricating plates and a calcified basis. Neoverruca, a putative ancestral verrucomorph (Newman \& Hessler 1989), was shown by molecular data to be a derived scalpellomorph (Pérez Losada et al. 2008). Both Neoverruca and Proverruca Withers, $1914 \mathrm{~b}$ are therefore convergent with true verrucomorphs. 
The genera Pycnolepas and Brachylepas are identified as comprising a paraphyletic assemblage of taxa including basal sessilians, forms close to the base of the verrucomorphs, and basal balanomorphs. Both the Brachylepadomorpha Withers,1923 and Brachylepadidae Woodward, 1901 are also paraphyletic, and their usage is not recommended.

\section{Order Balanomorpha Pilsbry, 1916}

- M plate present in primary wall (character 5, 0->1)

- Scutal outline approximates to a right triangle, in which the hypotenuse is formed by the occludent margin (character 21, 0->1)

- Angle between basal and occludent margin of scutum is acute, 40-60 (character 22, 0->1).

Included taxa are Epibrachylepas, Parabrachylepas, Pachydiadema and all Palaeocene-Recent balanomorphs.

\section{Suborder Neobalanomorpha nov.}

- $\quad$ specialized articulation structures present between plates of primary wall (character 6, 0->1)

- $\quad$ extensive imbrication between plates of primary wall (character 7, 0->1)

- M overlaps CM (character 8, 0->1)

- CM overlaps C (character 9, 0->1)

- $\quad$ Opercular sheath present (character 12, 0->1)

- Upper latus absent (character 14, 2->3)

Palaeocene-present day, including all taxa generally included in Balanomorpha, with the exception of the Cretaceous Pachydiadema, included by Withers (1935; Newman et al. 1969; Foster \& Buckeridge 1987). There is a clear morphological and stratigraphical hiatus between the Cretaceous taxa which represent stem group balanomorphs, and the Palaeocene-present day taxa which are identified here as the crown group (Neobalanomorpha). 
The new account of the fossil record presented here partly compliments the molecular phylogeny of Pérez-Losada (2008), who identified the Sessilia as a monophyletic group comprising verrucomorph and balanomorph sister groups, with pollicipedids and lithotryids positioned on the crownward part of the stem group. The Late Jurassic (Tithonian) Etcheslepas (Gale in press a) is morphologically intermediate between Capitulum and Pycnolepas, and thus supports the correctness of the molecular placement of pollicipedids by PérezLosada et al. (2008). The fossil evidence for the basal sessilian radiation is now quite detailed (Fig. 11), and further fossil evidence for the origin of verrucomorphs within the genus Pycnolepas will be presented elsewhere (Gale, submitted).

\section{Functional morphology and evolution}

A detailed functional analysis of the origin of balanomorph barnacles was provided by Anderson (1983), which was based on a comparision of morphology and life habits of the extant, pedunculate calanticid Calantica villosa and the basal balanomorph Catomerus polymerus. He concluded that the morphology of balanomorphs was an adaptation to life in an intertidal habitat, and that the changes which took place in this transition were driven by the selective processes of resisting dessication, predation and physical abrasion by waves and sediment. Thus, the tall conical capitulum of Calantica, with a flexible peduncle, was unsuited to the rough habitat of the intertidal, and was replaced by the low, squat form of Catomerus, with a broad basis, a wall of closely articulating plates, and a rather flat, tightly closing operculum. The low profile and solid exoskeleton provide defence against abrasion and predation, and tightly articulated primary wall plates and operculum reduce evaporative loss by minimising the area of soft tissue on the exterior of the animal which is exposed to the air. The tough, highly resistant arthrodial membrane of crown group balanomorphs is probably a further adaptation against dessication, as yet not investigated. 
There is now fossil evidence, presented here, and supported by cladistic analysis, for many of the morphological stages in the transition from a pedunculate ancestor to a sessile descendant. The well supported brachylepadid lineage (Fig. 10) Pycnolepas - Brachylepas fallax - B. naissanti - B. guascoi - Epibrachylepas newmani serves to illustrate many of these these changes Pycnolepas has a tall carina, rostrum and scutum and tergum, and was laterally compressed in form, thus differing only in detail from Anderson's species Calantica villosa.

Brachylepas fallax, although not known from articulated material, is very similar to Pycnolepas in terms of overall form and plate development, retaining a tall rostrum, carina and opercular plates. A dramatic transition in the morphology of the brachylepadids took place between B. fallax and B. naissanti (known from an articulated specimen, Fig. 3), and involved changes in the form of the orifice, carina, rostrum and opercular plates. The rostrum and carinae became low semiconical plates, and the orifice in B. naissanti and B. guascoi developed a rhombic, rather than oval, outline. The scuta and rostra became more closely articulated (Figs. 8,9), and as consequence, the scutal surface of the tergum and the tergal surface of the rostrum were foreshortened. However, the scuta and rostra still formed a tall structure, protruding from the orifice (Figs. 2, 13).

The next major transition was to the condition seen in Epibrachylepas and Parabrachylepas. This involved shape change of the scutum and tergum, such that they had lower profiles, and closer, more specialised articulation between the tergum and rostrum. single enlarged symmetrical lateral plate (M) developed between the rostrum and carina. The overall effect was to significantly lower the profile of the cirripede wall, and decrease the height of the operculum, such that it no longer stood proud from the orifice (Fig. 2). Finally, in Pachydiadema, an 8 plated wall, composed of robust plates including CM, M and RM developed.

General features of this evolutionary succession involved:

- more specialised articulation between the tergum and scutum, with the development of more articular surfaces (see Figs 8,9). 
- decrease in height and change in shape of the scutum, from a relatively tall triangular plate with an upwardly pointed apex, to a lower, broader morphology, with a shorter, tergally directed apex (Figs 8,9).

- an increase in the angle between scutal and tergal pairs, such that the valves lay in a flatter orientation in the orifice.

- change in the lateral profiles of the carina and rostrum, such that they slant towards the terga and scuta at a much lower angle.

- development of a strongly imbricated, firmly articulated, primary wall constructed of large, robust plates (Fig. 2).

The consequences of these changes was to lower the profile of the entire cirripede, such that the wall presented the form of a low, oval cone, much less vunerable to predation and the abrasive action of waves. The changes to the opercular plates were necessitated by the development of a lower profile, and the need to strengthen potentially weak structural lines, specifically, the tergalscutal articulation. The development of a well developed wall made up of firmly articulated, larger plates would have provided vital structural strength, and also reduced evaporative loss, because fewer, larger plates provide fewer surfaces bounded by soft tissues.

The musculature which operates to depress and abduct the opercular valves in calanticids and basal balanomorphs has been discussed in detail by Anderson (1983), who drew detailed comparisons between the extant scalpellomorph Callantica villosa and the basal balanomorph Catomerus polymerus, based upon dissection and histological study. In calanticids (and scalpellomorphs in general) the scuta and terga are depressed by numerous longitudinal peduncular muscles, which extend up from the base of the peduncle and insert onto the basal, interior margins of the scuta and terga (Fig. 12a). In contrast, in the basal balanomorph Catomerus, three discrete muscle blocks extend from the base to insert on the terga and scuta on each side (Fig. 12b). The tergal depressor is a large muscle which inserts onto well-demarcated grooves and ridges on the carinal interior of the terga (Fig. 12b,f-i). The scuta are depressed by two smaller muscles, the lateral scutal depressors, which insert onto the interior margin of the scuta 
adjacent to the tergal contact (Fig.12b, f-i), and the rostroscutal depressors, which insert onto the basal rostral margin of the scuta. The scuta are adducted by the large scutal adductor muscle, well known from fossil material. Because the well preserved fossil material described here bears scars of muscle insertion sites, it has been possible to reconstruct the musculature of basal balanomorphs, as a basis for functional comparisons.

Of the species investigated, Parabrachylepas has opercular musculature which is closest to that of pedunculate cirripedes, with an array of small muscle insertion sites running along the basal interior margin of the scutum and the basal and lower scutal margins of the tergum (Fig. 12c). Approximately 12 small insertion sites are present on the tergum, and the same number on the scutum. Additionally, a larger site for the rostroscutal depressor is present at the basalscutal angle of the scutum. In Epibrachylepas newmani, relatively large sites are present for the rostroscutal and lateral scutal depressors, and between these, six small sites for scutal depressor muscles are seen (Fig.12d). The tergum has between 5 and 7 oblique, elongated pits for insertion of the tergal depressors. Similar sites for tergal depressors are present in Pachydiadema cretacea, and the scutum of this species shows clear rostroscutal and lateral scutal depressor sites at the angles of the valve (Fig. 12e). Smaller, inconspicuous insertion sites appear to be present between the two larger ones.

In comparison with the two crown group balanomorph species, which both have large rostro-scutal and lateral scutal depressors, the scutal depressor muscles in brachylepadids and Pachydiadema cretacea are rather variable in number and size. Both crown group balanomorphs examined have very large, but differently shaped, tergal depressor sites; in Eochionelasmus,ohati, a v-shaped, depressed area, shallowly grooved overlain by a flange (Fig. 12f,h), is present, but in Catomerus polymerus a row of five tooth-like ridges and intervening grooves acts as the insertion site (Fig. 12g; see also Ross \& Newman, 2001). This arrangement is broadly similar to that seen in Epibrachylepas and Pachydiadema, in the oblique, carinally directed orientation of a small cluster of insertions. It is interesting that the depressor muscle arrangement in Epibrachylepas and 
Pachydiadema is very similar to that of basal balanomorphs, but that the Cretaceous taxa possessed less powerful tergal depressors, as the insertion sites are not so well marked. The conclusion is that the changes in opercular valve orientation documented above were accompanied by concomitant changes in muscle orientation and development, as suggested by Anderson (1983).

\section{Discussion}

The phylogeny of Pérez-Lodosa et al. (2008), calibrated to a molecular clock, suggests that the balanomorphs and verrucomorphs had diverged by $147 \mathrm{Ma}$ (Tithonian, Late Jurassic), and that the crown group balanomorph radiation (Neobalanomorpha herein) took place during the late Cretaceous (approximately Cenomanian, circa 95-100 Ma). However, the oldest neobalanomorphs are of Late Palaeocene age (Buckeridge 1983; Pachylasma, Bathylasma, Eolasma from New Zealand). It is interesting, therefore, that in a rocky shoreline habitat (an optimal situation for the group) of Late Cretaceous age (Campanian age, $80 \mathrm{Ma}$ ) neobalanomorphs are absent, and only stem group balanomorphs are present. The coast at Ivõ Klack was open to oceanic currents, and the presence of diverse Tethyan invertebrate groups (rudist bivalves, scleractinian corals etc.) testifies to the cosmopolitan nature of the fauna. Indeed, most discussions of balanomorph origins point to an intertidal rocky environment as that most likely place of origin for the group (Anderson 1983). It is, of course, possible that balanomorphs had evolved in a separate faunal province, but the cosmopolitan nature of many Late Cretaceous faunas (e.g. inoceramid bivalves, the crinoids Uintacrinus and Marsupites) is suggestive of very wide dispersal. Buckeridge (1996) outlined the possibility that balanomorph radiation had occurred in the Australasian region, but even there, no records of the crown group occur before the late Palaeocene. The extinctions of the K-Pg boundary offer a possible explanation. Over $50 \%$ of cirripede genera apparently became extinct at approximately this event (data from Newman et al, 1969; Foster \& Buckeridge 1987), including all stem group balanomorphs. Of the thirteen genera of cirripedes found at Ivö Klack, ten have no post-Cretaceous record. Of the three survivors, two, Pollicipes and Capitulum, still live very 
successfully in intertidal habitats (Barnes 1996; Van Syoc et al. 2010), whereas Arcoscalpellum is probably paraphyletic (Linse et al. 2013) and found at present only in the deep sea. It is possible that the K-Pg extinction strongly affected many cirripedes successful in Cretaceous coastal habitats, and thus created empty ecological niches, subsequently filled by the radiating neobalanomorphs . A similar scenario has been proposed for the radiation of the mammals into ecological space made vacant by dinosaur extinction (Archibald 2011). In view of this, it is likely that the hypothesised Cretaceous date of neobalanomorph radiation is rather too early (Pérez-Lodosa et al. 2008). The intriguing possibility exits that a single stem group form, probably close to Pachydiadema, survived the K-Pg extinction, and subsequently gave rise to the crown group radiation in the Palaeocene. This can only be tested by the discovery of new fossil material.

\section{Systematic Palaeontology (ASG)}

\section{Superorder Sessilia Lamarck, 1818}

\section{Genus Brachylepas Woodward, 1901}

Diagnosis. Rostrum and carina low and semiconical; imbricating plates united by mortis- and tenon like pegs and corresponding holes; m plates absent.

Type species. B. naissanti (Hébert, 1855).

Included species. B. fallax (Darwin, 1851); Turonian-Maastrichtian chalk, northwest Europe, B. naissanti (Hébert); Late Campanian-Maastrichtian chalk, northwest Europe, B. guascoi (Bosquet, 1857); Campanian-Maastrichtian, Sweden and Netherlands, B. americana Zullo, Russell \& Mellen 1987; Campanian, Brownstown Formation, Arkansas, B. angulosa Collins 1973; Ripley Formation, Maastrichtian, of Mississippi; B. nervosa Alekseev, 2009 from the Maastrichtian of Mangyschlak, Kazakhstan. B. solida Zullo, 1987 from the Maastrichtian Mount 
Laurel Sand of Delaware is unrelated to Brachylepas, and belongs to a new genus also found at Ivõ Klack (Gale \& Sørensen submitted).

Brachylepas is here considered to represent a paraphyletic basal sessilian group.

\section{Brachylepas guascoi (Bosquet, 1857)}

(Fig. 13b; Fig. 14A-P; Fig. 15A-R)

p1857 Mitella guascoi Bosquet, p. 11, pl 1, figs 8,9 only.

1935 Brachylepas guascoi (Bosquet), Withers, p.383-7, pl.49, figs. 3-14.

1953 Brachylepas guascoi (Bosquet), Carlsson, p.26-7, pl. 6 figs. 8-10.

Diagnosis. A large, thick plated Brachylepas, with a distinctive external sculpture of laterally imbricating, evenly spaced growth increments. Upper latus very deeply inserted between tergum and scutum.

Types. The carina figured by Steenstrup (1839, figs 20,20*) as Pollicipes nilssoni, from the upper Lower Campanian of Ignaberga, southern Sweden, was selected by Withers (1935, p. 111) as lectotype. Whereabouts unknown. See Withers (1935) for a detailed account of the rather complex synonomy and history of this species.

Material. Over 250 valves, including rostra, carinae, terga, scuta, upper laterals, and scale-like imbricating plates. All from the upper lower Campanian of Ivö Klack. NHM IC 823-54. There is also material from Iv Klack in the NHM, London, and Copenhagen MMH . Material from the Bosquet collection, Maastrichtian of the Netherlands and Belgium was figured by Withers (1935), and is in the Brussels NHM. There is extensive material from many localities in the Kristianstad Basin in Swedish collections (see Carlsson 1953).

Description. The external surfaces of all larger plates (carinae, rostra, sctua, terga) bear a similar sculpture, comprising of apically imbricating, evenly spaced, low ridges, which have a width of approximately $0.5 \mathrm{~mm}$ in the fully grown plates 
(Figs 14,15). In many examples, the outer layer has flaked away, taking the sculpture with it (e.g. Fig. 14D,G) This is particularly true of the terga, which are mostly devoid of their outer surface. The valves are all thick and robust.

The carina (Fig. 14A-C) is semiconical, and truncated on the inner margin by vertical or slightly curved surfaces, which bow at a variable angle to the interior. The carinae are somewhat taller than broad, and many are asymmetric, and display a variable lateral curvature, to either right or left sides, such that the valves appear to be leaning over. The interior is strongly concave, and divided into a central-basal smooth region, and an articular surface for the carinal margin of the tergum, which forms a v-shaped region extending from the base of the inner margins to the apex. The articular surface bears fine growth lines, which are parallel with margin of the inner surface, and subparallel with the external surface. The rostrum (Figs 14N-P; 15D-H) is also semiconical, but lower than the carina, and the inner margins converge at a somewhat lower angle $\left(110-140^{\circ}\right)$. The interior is also concave, and divided into a lower smooth zone and an upper articular surface for the scuta which are of equal height. The base of the scutal articulation is slightly sigmoidal, and accommodates perfectly the base of the scutum. The basal margin of the rostrum is variable, and is either sharp, or on a few valves has a flat rim which bears the marks of articulation, presumably with the inflected bases of the small lateral plates (see Withers 1935 pl.49 fig.11) . Both carinae and rostra have irregularly scalloped external basal regions, marking the sites of articulation of lateral plates. The interior surface of some rostra show rows of tiny slit-like pores oriented apicobasally (Fig. 14M). The apices of fully grown carinae and rostra are commonly truncated, and show signs of bioerosion (algal or fungal borings; Fig. 15F,H) and physical abrasion. The apices of small individuals are complete (Fig. 14N-P).

The scutum has the form of a slightly irregular isoceles triangle, and the external surface is nearly flat, curving only towards the occludent margin (Fig. 14A,B). The occludent margin is slightly convex, the tergal margin straight, the basal margin weakly sinuous. The apicobasal line forms the tergal margin, and the tergal slip is positioned vertically, or even a little overhung by the apicobasal line 
(Fig. 14B,E). This surface contacted the inner, scutal side of the upper latus (Fig. 9E). On the interior of the scutum, the apical portion of the occlusal surface is very broad and flat, and marked by numerous growth lines (Fig. 14A). The tergal notch is well developed (Fig. 9E; Fig. 14B,E). Smaller scuta are more nearly equilateral in outline (Fig. 14F), and become proportionately elongated along the apicobasal line with increased size.

The tergum is subrhomboidal in outline and has a prominent apicobasal line, which separates a smaller scutal portion from a larger carinal one (Fig. 9E; Fig. $14 \mathrm{C}, \mathrm{D}, \mathrm{G}, \mathrm{H})$. The plate is angled along the axis of the apicobasal line, which develops a ridge towards the basal angle for contact with the interior of the upper lateral plate (Fig. 9E). A low scutal auricle is developed, and separated from the rest of the scutal margin by two shallow grooves. The angle between the basal and occludent margins is $110-120^{\circ}$. The interior of the tergum displays a deep groove running from the centre of the plate to the basal angle (Fig. 14H). Terga change in outline with increased size (Fig. 14C,D,G), with progressive reduction in size of the scutal area of the plate, and apicobasal elongation.

The upper lata are fairly common in the new material (14 identified), and can be confidently assigned to this taxon from the highly distinctive surface sculpture. The suspected absence of an upper latus in B. guascoi, by Withers (1935) and subsequently Zullo et al. (1987) can now shown to be untrue. The upper latus (Fig. 14I-L) is triangular and four times taller than broad; the outer surface is flat, and traversed by coarse, prominent ridges and grooves, parallel with growth. The interior has a deep median flange (Fig. 9E; Fig. 14I), present on the upper two thirds of the plate, which articulates with the scutum and tergum (Fig. 9E).

The scale-like imbricating plates bear widely spaced growth lines, paralleling the sculpture of the capitular plates (Fig. 15I-R), and a fine, radial sculpture of ridges, which is only rarely visible on the capitular plates (e.g. Fig. 14F). By reference to the articulated specimen of B. naissanti (Fig. 4), the most basally positioned plates are triangular in lateral outline (Fig. 15I,J,L) and carry a large inwardly directed basal flange (fig. 15L). A internally directed peg fits into a median socket 
on the underlying plate (Fig. $15 \mathrm{~N}, \mathrm{Q}$ ), as shown in naturally articulated material figured by Zullo et al. (1987 fig. 7,1 ). More apically positioned plates are oval in outline and have weakly developed articulation structures (Fig. 15M,N,O,P,R). The basal margin of all plates is variably crimped in the centre.

Reconstruction and mode of life. The reconstruction of B. guascoi provided here (Fig. 13b) is based on careful placement of the carinal, rostral and opercular plates of matching size. The whorls of imbricating plates are reconstructed following the arrangement in B. naissanti (Fig. 4; Withers 1935; Newman 1987). The overall construction is evidently similar to that in B. naissanti, but the terga and rostra protrude somewhat further from the operculum. This is not an error of reconstruction, because the drawing was based on similarly sized tergal:carinal and rostral:scutal pairs, which fitted perfectly together.

Withers (1935) described and figured a partial calcareous basis in a specimen of B. guascoi (pl. 49, fig. 12), and for this reason we searched the surfaces of boulders at Ivõ Klack for evidence of cirripede attachment sites. Although the boulders are extensively encrusted with serpulids, oysters, other bivalves and brachiopods (Christensen \& Surlyk 1974; Surlyk \& Sørensen 2010), no evidence of any cirripede basis was forthcoming. If B. guascoi did live on the boulders at Ivõ Klack, it has not left any trace of its attachment sites. It possibly lived in semisheltered subtidal habitats between the boulders, attached to small clasts and shells.

Comparison with other species. B. guascoi falls closest to B. americana Zullo, Russell and Mellen, 1987, as recognised and discussed by Zullo et al. (1987). Differences are;

- in B. americana, a fine median ridge is present on the carinae and rostra, absent in B. guascoi.

- Minor differences in the shape of the terga and scuta, such as the more consistently downturned occlusobasal corner in B. guascoi.

- Absence of sculpture of fine radial ridges on B. americana, always present on B. guascoi. 
The species are clearly very closely related, and both are very abundant where they occur; thousands of valves of B. americana were collected from the type locality in the marginal marine sediments of Late Campanian or Early Maastrichtian of Arkansas (Zullo et al. 1987), and B. guascoi is very common in the marginal marine sediments of many localities in southern Sweden (Carlsson 1953). Both localities represent rocky shoreline environments, which were evidently exploited successfully and widely by the B. americana-B. guascoi clade during the latest Cretaceous (Campanian-Maastrictian). B. guascoi differs from $B$. fallax (Fig. 13a) in the shape and sculpture of the capitular valves, and the lower, truncated form of the carina and rostrum. The imbricating plates are similar in shape in both species (Fig. 15S,T) but differ in details of sculpture. B. nervosa Alekseev, 2009 is closest to B. fallax, but differs from that species most importantly in the more elongated tergum with an acute basal angle.

\section{Brachylepas naissanti (Hébert, 1855)}

(Fig. 2F1-3; Fig. 17M-0; Fig. 19S-T)

A full taxonomic treatment of this species is not included here, because of the very limited nature of the new material, which adds little to Wither's (1912a, b; 1935) account, and his complete synonomy. Newman (1987) refigured the only entire specimen of B. naissanti under the name B. cretacea Woodward; this specimen (In. 27160) is illustrated photographically here (Fig. 3).

TYPES. A carina from the Upper Campanian of Meudon, France, figured by Hébert (1855, pl. 29, fig 10 under the name of Emarginula (?) naissanti was selected as lectotype (Withers, 1935).

MATERIAL. Two rostra from Ivö Klack. NHM IC 880.

DESCRIPTION. The better preserved of the two rostra (fig. 17M-0) has a low, semiconical form, and the exterior surface bears rather coarse, smooth, radiating ridges and intervening grooves. Regularly spaced, co-marginal growth lines are 
present, and where these intersect with the grooves, shallow depressions are present. There is additionally a very fine radial sculpture, which is more clearly developed in the grooves. The specimens closely match those illustrated by Withers (p. 380, figs 45, 59-62). ). The imbricating plates of this species are very distinctive, as they possess a central ridge lacking in other Brachylepas species (Fig. 19 S,T; compare also with B. fallax, Fig. 15S,T).

\section{Order Balanomorpha Pilsbry, 1916}

\section{Genus Epibrachylepas nov.}

Diagnosis. Scuta with a discrete occlusal surface, marked by flanges parallel with growth increments, and a short rostrobasal margin; tergum subtriangular, with prominent scutal auricle and broad apicobasal ridge; capitular plates robust, with low lateral profile; four plated primary wall; M plate pentagonal; imbricating plates with prominent median ridge or flange; conspicuous reticulate sculpture present on capitular plates.

Type species. Epibrachylepas newmani sp nov.

Referred species. E. newmani,sp nov. ; Proverruca(?) smeetsi (Bosquet, 1857) represented by two scuta (Withers, 1935, pl 40 fig. 6) from the Maastrichtian of Limbourg, Netherlands, can be referred to this genus on the basis of a close similarity of shape with E. newmani, but has a different sculpture.

\section{Epibrachylepas newmani sp nov.}

(Fig. 9F; Fig. 16A-R; Fig. 17A-L)

Derivation of name. In honour of the extensive contributions to cirripede research made by William Newman, whose generous help with Recent specimens and advice has made this present study possible. 
Diagnosis. As for genus.

Types. The holotype is the well preserved tergum (Fig. 16 E, NHM IC 858). The other figured specimens are paratypes (IC 825, 830-1, 855-868).

Material. Approximately 450 isolated valves from the lower Upper Campanian of Ivö Klack, including carinae, rostra, scuta, terga, upper lata, marginal plates and imbricating plates.

Description. Although all valves are isolated, the highly distinctive external sculpture of the capitular plates makes referral to this species straightforward. The imbricating plates are less obviously associated because they have a different sculpture to the capitular valves. However, having positively identified imbricating plates of B. guascoi and P. ifoensis from both sculpture and microstructure, the remaining group must belong to E. newmani.

The carinae and rostra (Fig. 16L-R) are semi-conical and are slightly broader than tall, and the apices are commonly truncated. The external sculpture consists of fine ridges radiating from the apical margin, and co-marginal flanges which are more prominent towards the base (Fig. 16N,P,Q). The apices have often been worn away by in-life abrasion. A series of shallow scalloped embayments are variably present on the basal, outer part of the carinae and rostra (Fig. 14L), which are attachment sites for imbricating outer plates, as in B. naissanti (Fig. 4). The carinae and rostra can be only be distinguished on the morphology of the interior surface; in, the lower concave embayment is deeper in the carina (fig. 160) than that in the rostrum (fig. 16M). The upper interior portion of both rostra and carina is traversed by sinuous growth lines (Fig. 16M,N); the scuta and terga in retracted position articulated firmly against the lower boundary of this region.

Scuta are represented by over 100 valves (Fig. 16A-H; fig. 17E,F,I). They are triangular in lateral outline, with slightly concave tergal margins, flat to convex basal margins, and convex occlusal margins. There is a short, discrete, short 
rostrobasal margin. The height: breadth ratio is variable (compare Fig. 16C and Fig. 17E). The external surface is divided into two regions, a slightly convex lateral surface, and a variably well defined area adjacent to the occlusal margin, which is set at an angle to the lateral surface. The two regions are sometimes separated by a coarse rib (e.g. Fig. 16B). The basal margin, and growth lines inflect up towards the occludent margin at the boundary between the two regions. The external sculpture is comprised of narrow, curved radial ridges and intervening grooves, which run from the apex to the basal margin, but are weakly developed on the occludent surface (Fig. 16A-C). These are highly variable in number and development. In the majority of individuals, there are about 15 ridges on the lateral surface, and 5 on the area adjacent to the occlusal margin, but more rarely there may be up to 40 in total. Narrower, minor ridges are sometimes present between the coarse ones. Additionally, protruding comarginal flanges are developed, which increase in prominence towards the occludent margin Fig. 16A-C). These form ledges which protrude distinctly at the occludent margin itself. The flanges are better developed close to the basal margin, and typically 3-5 are conspicuous. There is considerable variation in the relative development of the radial and co-marginal components of the sculpture. In some individuals, the radial ridges are prominent (Fig. 16C), in others the comarginal flanges dominate (Fig. 17E). The interiors of the scuta are concave (Fig. 16D, Fig. 17I), and variably separated into a more apical cavity, which houses a large, oval scutal adductor scar, and a more basal, shallower region running along the basal margin. A prominent and fairly deep tergal notch is present, which is separated from the tergal slip by a low ridge, the crest of which is subparallel to the tergal margin (Fig. 16D; Fig. 17I). In some large individuals, notches for the scutal depressor muscles are present adjacent to the basal margin; large scars close to the tergo-basal and carino-basal corners were sites for insertion of respectively, the larger lateral scutal and carinoscutal depressor muscles (Fig. 12D). Approximately five smaller muscle scars are present between the larger ones.

Over 100 terga are present in the collection (Fig. 16E-H). These are rhomboidal in outline, with the occludent and upper scutal margins being roughly half the 
length of the lower scutal and carinal margins. A prominent gently curved apicobasal ridge is present. A strong, convex scutal auricle is present, separated from the more basal portion of the scutal surface by a deep and well defined groove. A sculpture of coarse, co-marginal flanges and intervening grooves is present, which number between 15 and 20. On the lower scutal surface are a number of radial ridges and grooves which either originate at the apex or splay from the apicobasal ridge. The occludent margin is gently curved. The interiors of the terga have a central, slighly depressed region which follows the line of the apicobasal ridge, and short tooth-like protrusions from the flanges on the exterior surface are visible on the margin which probably interlocked with corresponding structures on the opposing tergum (Fig. 16H). A series of 5-7 oblique shallow scars for insertion of tergal depressor muscles are present close to the carinal margin (Fig. 16H).

The terga are quite variable in form, specifically, in their relative elongation and the prominence of the scutal auricle. A number are exceptionally thick, and some have extensive in-life bioersion of the apical region by microboring organisms (Fig. 16G) and also mechanical abrasion (Fig. 16F).

Five upper lata are present in the collection. These (Fig. 16I-K) are triangular, with flat external surfaces, and are three times as tall as broad. The scutal margin is slightly convex, the tergal margin straight. The lower part of the external surface bears transverse flanges, which increase in prominence towards the base, and the lowermost five are best developed. The interior of the upper laterals has two concave surfaces on the lateral margins, which contacted the scutum and tergum respectively (Fig. 9), and which bear growth lines. The upper parts of the concave surfaces are separated by a median ridge. These v- towards the apex, and a smooth, lower, centrally placed triangular zone is present.

30 marginal (M) plates are present; these are pentagonal with a symmetrically oval-triangular outline, slightly taller than broad and gently concavo-convex (Fig. 17A,B). The external surfaces bear a reticulate sculpture made up of radiating narrow ridges, and co-marginal flanges, exactly as developed on the scuta. The 
interior surfaces of these plates have a smoothly concave lower region, and the upper raised portion is traversed by horizontal growth lines. There is no evidence of structures suggesting overlap with the carina or rostrum.

The imbricating plates (Fig. 17C,D,G,H,J-L) are rhomboidal in outline, and the outer surfaces are marked by 3-5 chevron - like ridges which V-downwards and a fine radial sculpture. The plates of the upper whorls are flat and relatively thin (Fig. H,K,L); those of the lower whorls bear a raised median ridge which forms a buttress - like spur at the base of the plates (Fig. 17C,D,G).

Reconstruction. The arrangement of the opercular plates, carinae and rostra can be reconstructed with certainty, as the terga and scuta fit together, and the upper latus fits precisely into the gap left between these (Fig. 2, F1). The operculum then articulates with the interior of the conical carina and rostrum, in a similar fashion to that in Brachylepas naissanti (Withers, 1935; Newman, 1987). A single, relatively large marginal plate is present, fitting into the gap between the rostrum and carina (Fig. 2 F2). The form of the skirt of imbricating plates can be reconstructed with some assurance using two pieces of information; 1) the range of morphology of the plates gives some idea of the number of rows present, and 2) the width of plates, in comparison with the dimensions of the carinae, rostra and marginal plates permits an estimation of the number of columns. It is likely that 3-4 alternating rows of imbricating plates were present (Fig. 2 F3), set in 20-25 columns. The buttress-like flanges on the lower tiers of imbricating plates are conspicuous (Fig. 2 F3).

Palaeoecology and mode of life. E. newmani was of consistently small size of with an estimated rostral-carinal maximum dimension of less than $10 \mathrm{~mm}$. There is some evidence of physical abrasion of the apices of the carinae and rostra (e.g. Pl. fig., and the apical portions of both terga and scuta show evidence of microboring by fungi or algae, and gastropod predation (Fig. 17F). The taxon possibly lived attached to pebbles and shells in the sediment between boulders in the shallow subtidal zone. 


\section{Genus Parabrachylepas nov.}

Diagnosis. The tergum is subrectangular, and only a single, convex, carinal margin is present. A large, well demarcated scutal auricle is present. The upper latus is low and broad. A juvenile sculpture of widely and evenly spaced, narrow co-marginal ridges is replaced in the adult by an indistinct reticulate sculpture. Primary wall comrpised of four plates.

Type species. Parabrachylepas ifoensis (Withers, 1935)

Referred species. P. ifoensis (Withers, 1935)

\section{Parabrachylepas ifoensis (Withers, 1935)}

(Fig. 2 E1-3; Fig. 18A-0; Fig.19A-R)

1935. Calantica (Scillaelepas) ifoensis Withers, p.128, pl. 10 figs 1-6.

p. 1935. Pachydiadema cretacea Withers, pl 50 figs 4,5 only.

1953 Calantica (Scillaelepas) ifoensis Withers, Carlsson p. 12, pl.2, figs. 3, 10-12

Diagnosis. As for genus.

Types. A tergum from Ivö Klack (NHM In. 29410) is holotype. The remaining specimens cited by Withers (1935, p. 128) are designated paratypes.

Material. The new material includes abundant material of this species, including a large number of immature valves, and scale-like plates of the outer imbricating whorls, numbering about 450 in total. NHM IC 881-907.

Description. There are a number of aspects of the external sculpture which are consistent between different valve types, and which change significantly with ontogeny. The fully grown scuta and terga have a sculpture of rather coarse, low radial ribs which intersect with similarly poorly defined and irregular comarginal ribs to produce a weak reticular effect (Fig.18D,H). The valves of small 
individuals, in contrast, have a very different surface, with very evenly spaced, regular, low co-marginal ridges present on scuta, terga, carinae, rostra and marginal (Fig. 18A,E,M).

When small, both the carina and rostrum are semiconical, and taller than broad, and carry an external sculpture of low ridges parallel with the base (Fig. 19A-H). Rostra and carinae can be distinguished by the form of the interior; the carinae have a smooth lower concave surface which represents about $50 \%$ of the total height of the plate (Fig. 19H), whereas in the rostra this surface is much lower, representing perhaps $20 \%$ of the total height (Fig. 19C,F). The fully grown carinae and rostra (Fig. 19I-K) are proportionately tall with angled sides, and weak, growth parallel ridges.

The scuta (Fig. 18A-E) are sub-triangular, taller than broad, and the occlusal margin is quite strongly convex; the tergal margin is gently concave to straight. The region adjacent to the tergal margin is sharply downturned, and the apicobasal ridge runs close to the scutal margin of the valve. A tergal slip is present, and is more conspicuous in large plates (Fig. 19D). The rather irregular, flange-like co-marginal ridges (Fig. 18M) are protuberant along the lower occlusal margin (Fig. 18A,E). The interior of the scutum has a thickened apical region, with a strongly developed occlusal surface, and a broad tergal notch. The site of insertion of the scutal adductor is rather deeply embayed. On a few valves, the sites of the scutal depressor muscles can be seen as small apicobasal notches, running just above the interior basal margin (Fig. 18C) - 10 to 15 discrete sites are present. The smaller scuta are proportionately lower, and have a longer, more convex basal margin, which is inflected upwards close to the occludent margin (Fig. 18A,E). The largest scuta (Fig. 18C,D) are proportionately tall, with a strongly convex rostral margin and a short, straight basal margin.

The fully grown terga (Fig. 18H) are sub-rhomboidal, and a sharply marked apicobasal crest separates a flat region next to the occludent margin from that adjacent to the scutal margin. The valve is of a very unusual shape, as mentioned by Withers (1935, p. 129), because there is no distinction between the upper and 
lower carinal margins; the single margin is markedly convex. The smaller terga (Fig. 18F,G,L) have a large scutal auricle, and a weak apicobasal ridge. The interior of the tergum (Fig. 18G) is gently concave, and the area adjacent to the basal and lower scutal margins carries 10 shallow grooves for the tergal depressor muscles (Fig. 12C).

The upper latus (Fig. 18N,0) is flat and triangular, and slightly higher than broad. On the interior surface, two flat surfaces articulate with the tergum and scutum respectively, separated basally by a flat, smooth triangular area. The marginal plates (Fig. 18I-K) are trapezoidal to triangular in outline, symmetrical,and gently convex externally. Internally (Fig. 18J), they are concave, with a low depressed region adjacent to the basal margin, and a tall upper region marked by transverse growth lines. The delicate plates of the imbricating outer whorls are common in residues from Ivõ Klack (Fig. 19M-R). They are oval to trapezoidal in outline, very flat, and the exterior surface is smooth or rarely marked by weak co-marginal growth lines. Many plates have a notch (e.g. Fig. 190,Q,R) on the basal margin, and a short corresponding prong in the interior surface for articulation (Fig. 19Q,P), as shown by Zullo et al. (1987, fig. 7,1-4), such that they fitted together with a mortis and tenon articulation. The plates of the basal whorl have a broadly triangular form, and more strongly developed articular processes (Fig. 19Q,R), whereas the more apical plates are oval to rhomboidal with weak articular structures (Fig. 19M,N,O).

Reconstruction. As in the case of Epibrachylepas newmani sp nov., the plates of the operculum, the carina and rostrum fit together well, to show a cirripede with a low operculum, bearing a low upper latus (Fig. 2 E1). A single marginal plate was present on each side, set between the carina and rostrum (Fig. 2E2). The plates of the imbricating whorls were thin and delicate and probably arranged in 3-5 alternating rows (Fig. 2 E3), and the overall appearance of the cirripede has a low profile.

Palaeoecology. P. ifoensis is unusual amongst Ivõ Klack cirripedes in that, whilst the smaller valves of immature individuals are abundant, valves of fully grown 
specimens are rare. It is uncertain whether this represents a sorting process, or that few individuals achieved large dimensions. The species probably attached to pebbles and shells in the shallow subtidal zone.

\section{Genus Pachydiadema Withers, 1935}

Diagnosis. Large, oval, cirripedes with a low profile, in which the weakly articulating primary wall is constructed of 8 plates, surrounded by imbricating whorls of solid smaller plates. All external surfaces of adult lateral plates, and the terga, display flat apical surfaces, where the young stages of the plates have spalled off. The operculum is of low profile and a small upper latus is present between the scutum and tergum.

Type species. Catophragmus (P.) cretaceum Withers, 1935.

Pachydiadema cretacea Withers, 1935

(Fig. 2G1-3; Fig.3b;Figs 5,6A;Fig. 7;Fig. 12e; Figs 20-22)

p. 1935 Catophragmus (Pachydiadema) cretaceum, Withers 1935, p. 390, pl. 50 figs 1, 6-12 only.

1953 C. (P.) cretaceum Withers, Carlsson, p.28, pl 6 figs 11-13.

Diagnosis. As for genus.

Type material. The original material of Withers (1935) only partly belongs to this taxon, as is made clear by new, more extensive collections. The holotype, a scutum (NHM In. 29260) is conspecific with material described here, but the two figured terga (pl. 50, figs 2,3; In. 29261, In. 29262) are correctly referred to an effaced, bioeroded form of the cirripede Calantica (Scillaelepas) caelata Withers, 1935 which is common at Ivö. The two carinal plates figured by Withers (pl.50 figs 4, 5; In. 29264, In. 29265) are damaged rostra or carinae of Parabrachylepas ifoensis. 
New material. The new collection includes approximately 350 plates referrable to this species, including 14 scuta, 18 terga, 1 upper latus, 6 rostra, 17 carinae, numerous other lateral plates, and many plates of the outer imbricating whorls. Some plates are represented by a large range of sizes; the distinctive carinae range from maximum dimension 4-20 mm. NHM IC 792-822.

Description. The plates of the primary wall and outer imbricating series are distinctive fossils, commonly of a maximum dimension of 7-15 mm, subrhomboidal to sub-trapezoidal in outline, and very robust (1-3 mm thickness). Although most are abraded, and lack complete margins, a small number are very well preserved, and retain delicate flanges for overlap by adjacent plates. All wall plates share a distinctive external colour banding, representing growth zones parallel with the basal margin, and comprise alternate pink-brown and paler zones, of approximately Imm width (Fig. 21M). The apical terminations of all larger plates are essentially planar fractures along growth surfaces, where the younger, more apical, portions of the plates have spalled off (e.g. Fig. 20AD,I,JQ,S). A narrow median vertical ridge is present on the upper internal surface of all plates except the carinae (Fig. 20E-H,K,W). The external sculpture is variable, from almost smooth with evenly and widely spaced growth lines (Fig. 20A-D; Fig. 21A,L,R,S) to closely spaced ridges (Fig. 21T,U).

Detailed examination of plate outlines, curvature, symmetry, position of overlap surfaces and the form of external ridges was used to identify the positions of wall plates. There are three types of symmetrical plates, and two asymmetrical ones; the former are carinae, marginals and rostra, the latter rostromarginals and carinomarginals.

The plates identified as carinae are oval in outline in young specimens (Fig. 21AC), but spalling of earlier growth stages in larger individuals has resulted in transverse truncation of the plates, and the portion remaining has a trapezoidal outline (Fig. 20D; Fig. 21R). The carinae are slightly concavo-convex and the outer surface bears up to three, variably developed, outwardly diverging radial ridges, which form a low crest on the plate. These are irregularly asymmetrical in 
development. The lower third of the interior of the plates is smooth and slightly concave, the upper two thirds marked by dense transverse growth lines, and lacks any median ridge (Fig. 20H; Fig. 21B,G). The margins which contact the carinomarginal plates are rounded, and slightly overlap these plates (Fig. 7E). Small plates (height $4 \mathrm{~mm}$ ) taper apically, and show significant bioerosion of the apex (Fig 21F,G).

The carinomarginals are asymmetrically trapezoidal in lateral aspect, and in apical/basal view are concavo-convex (Fig. 20A,E). The exterior of the plate is formed of three discrete regions, divided vertically by inflections of the growth lines. The carinal portion is strongly inflected towards the contact with the carina, and bears a narrow flange which is overlapped by the rounded margin of the carina (Fig. 7C; Fig. 20I). The central region is raised, and forms an oblique ridge. The lateral portion makes up half the length of the plate, is gently convex, and overlaps the marginal plate. The interior of the plate is divided into a lower, concave, smooth portion, and an upper region traversed by growth lines, which is separated into a larger carinal and a smaller lateral region by an oblique ridge. The fully grown marginal plates (Fig. 7 A, G; Fig. 20B,F) are trapezoidal in lateral aspect, as tall as broad, and taper slightly apically. They are flat, and each lateral margin bears a narrow inset flange for overlap by the carinomarginal and rostromarginal respectively. A raised ridge runs centrally from the basal to the apical margins. The smooth portion of the interior surface occupies the lower third of the plate, and the upper region is divided into two equal portions by a narrow vertical ridge. The immature marginals (Fig. 22N,P; Fig. 22A-D) are low and triangular in outline, and become progressively more trapezoidal by reduction of the apical angle, and spalling of the apical portion.

The rostromarginals (Fig. 20C,G) are weakly concavo-convex, asymmetrically trapezoidal in lateral view, and the basal margin inflects towards the lateral and rostral margins. The margins overlap the adjacent marginal and rostral plates; the rostral margin is nearly twice as high as the marginal one. The interior of the plate is gently concave, and the smooth basal region occupies half the height of the plate. The apical region is divided into two subequal portions by an oblique 
ridge, slanted towards the contact with the marginal plate. The fully grown rostrum is rectangular, flat, twice as high as broad, and approximately symmetrical about the mid-line (Fig. 20J-L). A central raised ridge runs from the basal to the apical margins, and is flanked on either side by depressed flanges of unequal width, which were overlapped by the adjacent rostromarginal plates. The interior of the rostrum is concave, and the smooth basal portion occupies the lower quarter of the plate. The upper three quarters of the plate are traversed by dense curved growth lines, and divided into two subequal regions by a narrow vertical ridge. The rostra display slight but highly variable asymmetry. Rostra of smaller individuals are trapezoidal in outline with a weakly defined apicobasal ridge (Fig. 21D,E).

The plates of the imbricating whorls are highly variable in form, but can be separated from the broadly similar plates of the primary wall by the fact that most are proportionately broader and lower (Fig. 20M,N,S,W). The detailed morphology of a few types permits precise location on the lateral surface of the primary wall. For example, broad plates which are slightly convex on the interior surface fit neatly into the depression between the rostromarginals and marginals (Fig. 7H, I). The presence of vertical median ridges on the interiors of many imbricating plates indicates that most overlapped two plates of the preceding whorl. The height of the lateral surface varies considerably, and extreme forms, which are flattened, with very low lateral walls occupied positions in the outer whorls (Fig. 20M,N).

12 scuta, 18 terga and a single upper lateral have been collected. The scuta (Fig. $20 \mathrm{P}, \mathrm{T}$ ) have the form of isoceles triangles, in which the occludent margin is slightly longer than the basal and tergal surfaces. The tergal and basal margins are very slightly convex, and the plates are gently concavo-convex. The apical portions of the scuta are invariably worn smooth, such that growth laminae are irregularly shown. A small number (3-4) of ridged growth lines, parallel to the basal margin, are preserved on most specimens, adjacent to the basal margin. On the exterior of the basal part of the scutum, deflection of the growth lines indicates the site of articulation with the upper latus (Fig. 2 G1; Fig. 20P,T). The 
interior of the scuta displays a large, oval scutal adductor scar, and sites for insertion of the lateral and rostro-scutal depressors, and smaller depressor muscles are visible in between (Fig. 12E). The interior tergal margin shows a shallow tergal notch and a tergal slip.

The terga (Fig. 20Q,U; Fig. 21H-J) are very robust and rather variable in outline; most are subrectangular, but others are nearly triangular. All are strongly modified by spalling of the younger growth stages to leave a flat to undulose upper surface, surrounded by a low, ridged margin. The margin is divided into 1) a nearly straight occludent surface, 2) a curved surface for contact with the carina and carinomarginals, 3 ), a surface for contact with the carinomarginals and marginals, 4 , a surface in contact with the upper latus, and 5) the scutal margin. A scutal auricle is weakly but variably developed. The interior of the tergum is concave, and growth lines are visible along the occludent and carinal margins. Sites for insertion of tergal depressors are visible along the lateral part of the tergum; these comprise 5 to 7 weakly defined pits and ridges, set in an arc parallel to the lateral margin (Fig. 12E; Fig. 20U).

The single upper latus (Fig. 20R,V) is a small oval plate, with a flat, spalled upper surface, and vertical surfaces, set at an angle, for contact with the scutum and tergum. The lateral margin shows prominent growth lines, matching those on the adjacent portions of the scutum and tergum. The base has a small flange which fits beneath the scutum.

Ontogeny. The smallest plates in the material have a maximum dimension of approximately $2 \mathrm{~mm}$. The immature plates retain the early growth stages (Fig. 21F,G,N-Q), and the marginals are triangular in outline (Fig. 20N,P; Fig. 22A-C). These change shape as they grow (Fig. 22) by decrease in apical angle - they become trapezoidal in outline (Fig. 22E,F), and depressed margins for overlap by adjacent plates appear. At the stage represented by Fig. 22C, the apical portion of the plate spalls off, leaving a flat surface seen in all fully grown plates. It appears that the position at which spalling occurs is predetermined by a line of weakness (Fig. 21A - note prominent growth line). The apical parts of the immature plates 
are invariably riddled with microborings (Fig. 21F), and it appears that shedding this portion provided a temporary relief from the activity of borers. However, their actions continued, as shown by the acrothoracican borings on a tergum which has already shed the early growth stages (Fig. 21H).

Reconstruction. The abundant plates available have permitted reconstruction of the form of the entire cirripede, although the exact configuration of the imbricating lateral whorls has to be partly inferred (Fig. 22G). The distinct articular surfaces on the exterior of the wall plates does, however, provide evidence of the configuration of the first whorl of plates. An 8 plated form is a structural necessity, because the marginal plates and rostrum possess facets which are overlapped on both sides. A selection of wall and imbricating plates of approximately similar sizes was placed on a plasticene base in natural configuration, and show the outline to be oval, with a slightly narrower rostral end. In lateral profile, the form is of a low dome, somewhat higher at the rostral end (Fig. 22G). The opercular plates are only slightly elevated above the wall, and the rostral:scutal pairs articulated across the median line at a low angle (about 100 degrees). The external surface of all plates, except the abraded scuta, is formed by truncated, spalled growth surfaces, which have a narrow raised rim, and a flat to undulose central region. The species attained large dimensions, estimated at a maximum rostral-carinal dimension of $8 \mathrm{~cm}$. It had a remarkably solid, massive construction, and although extensively bored in life by algae/fungi and acrothoracicans, not a single plate found has a predatory boring in it, although gastropod borings these are present in other species of cirripede at Ivõ Klack.

Palaeoecology. It is probable, by analogy with extant balanomorph cirripedes, that $P$. cretacea lived attached to the gneiss boulders, in the intertidal or high subtidal zone, at Ivö Klack. The complete absence of calcified cirripede bases on these boulders provides evidence that it possessed only a membranous basis. of extant species, P. cretacea is most closely comparable in general morphology and habitat with Catelasmus pilsbryi Broch, 1922 (Fig. 23), with which it shares a low lateral profile and numerous rows of imbricating plates. Both show extensive 
superficial bioerosion, and have spalled off the outer portions of plates. However, the imbricating plates of $C$. pilsbryi are concavo-convex, with a significant crescent-shaped space between alternating plates (Fig. 23D,E); in contrast, the wall of $P$. cretacea was massive, with no spaces between the plates.

\section{Acknowledgements}

Work in Sweden was made possible by a VILLUM Foundation grant to ASG, which supported a 4 month sabbatical stay in the University of Copenhagen, 2011-2012, and a Carlsberg fellowship to AMS, both of which are gratefully acknowledged. Bill Newman (San Diego) kindly provided specimens of extant cirripedes and most useful advice; Jens Høeg (University of Copenhagen) is thanked for a helpful review of the homology section, and his support for the research. The authors were told of the site yielding well preserved material at Ivõ Klack by Manfred Kutscher of Rugen, and we are most grateful to him. Further visits to the Zoology Museum in Copenhagen were made possible by a SYNTHESIS grant to ASG in 2013, which is gratefully acknowledged. John Buckeridge and Benny Chan provided thoughtful reviews.

\section{References}

Alekseev, A.S., 2009. Usonogie raki (Cirripedia, Thoracica) verkhnego mela Mangyshlaka. Byulleten' Moskovskogo Obshchestva Ispytatelej Prirody, Otdel Geologicheskij 84, 23-38.

Anderson, D.T. 1983. Catomerus polymerus and the evolution of the balanomorph form in barnacles (Cirripedia). Papers from the Conference on the Biology and Evolution of Crustacea, held at the Australian Museum, Sydney, 1980. Australian Museum Memoir 18, 7-20. 
Anderson, D.T. 1994. Barnacles: structure, function, development and evolution. Chapman \& Hall, London, Glasgow, New York, Tokyo, Melbourne, Madras. 357pp.

Archibald, J.D. 2012. Extinction and radiation: how the fall of the dinosaurs led to the rise of mammals. John Hopkins Press.

Ascanius, P. 1767. Icones rerum naturalium, ou figures enluminées d'Histoire Naturelle du Nord. Copenhagen. 22pp, 10pls.

Barnes, M. 1996. Pedunculate cirripedes of the genus Pollicipes. Oceanography and Marine Biology: an Annual Review. 34, 303-394.

Bosquet, J. 1857. Notice sur quelques cirripedes recemment découvert dans le Terrain Crétacé du Duche de Limbourg. Natuurkundige Verhandelingen uitgegeven door de Hollandsche Maatschappij vor Wetenschappen te Haarlem (2) 13, ii+1-36, pls 1-3.

Broch, H. 1922. Papers from Dr. Th. Mortensen's Pacific Expedition. 1914-16. No. 10. Studies on Pacific Cirripeds. Videnskabelige Meddelelser Dansk Naturalhistorisk Forening 73, 215 -358.

Buckeridge, J. S. 1983. Fossil barnacles (Cirripedia: Thoracica) of New Zealand and Australia. New Zealand Geological Survey Palaeontological Bulletin 50, 151pp, 13pls.

Buckeridge, J.S. 1996. Phylogeny and biogeography of the primitive Sessilia and consideration of a Tethyan origin for the group. In: Schram, F.R. \& Hoeg, J.T. (eds): New frontiers in barnacle evolution. Crustacean Issues, 10, 255-267. A.A. Balkema Rotterdam, Brookfield.

Buckeridge, J.S. \& Newman, W.A. 2006. A revision of the Iblidae and the stalked barnacles (Crustacea: Cirripedia: Thoracica), including new ordinal, 
familial and generic taxa, and two new species from New Zealand and Tasmanian waters. Zootaxa 1136, 1-38.

Carlsson, J.G. 1953. The Cretaceous cirripedes of Sweden. Lunds Universitets Arsskrift 49, 32pp.

Collins, J.S.H. 1973. Cirripedes from the Upper Cretaceous of Alabama and Mississippi, Eastern Gulf Region, USA. 1. Palaeontology, pp. 349-80. Bulletin of the British Museum (Natural History), Geology, 23, 6.

Collins, J.S.H. 1980. A new Pycnolepas (Cirripedia) from the (?) Lower Aptian of Alexander Island. Bulletin of the Antarctic Survey, 50: 21-6.

Darwin, C.R. 1851. A monograph on the fossil Lepadidae, or pedunculated cirripedes of Great Britain. Monograph of the Palaeontographical Society London 1851, vi + 88 pp.

Darwin, C.R. 1854. A monograph on the sub-class Cirripedia, with figures of all the species; The Balanidae (or sessile Cirripedia), the Verrucidae, etc. The Ray Society, London. viii + 648 pp., 30 pls.

Foster, B.A. \& Buckeridge, J.S. 1987. Barnacle Palaeontology. In: Southward, A.J. (ed.), Barnacle Biology. Crustacean Issues 5, 43-61.

Gale, A.S. 1997. Goniasteridae (Asteroidea, Echinodermata) from the Late Cretaceous of North-West Europe. 1. Introduction. The Genera Metopaster and Recurvaster. Mesozoic Research 1, 1-69.

Gale, A.S. In press a. New thoracican cirripedes (Crustacea) from the Jurassic and Cretaceous of the UK. Proceedings of the Geologists' Association.

Gale, A.S. In press b. Origin and evolution of the verrucomorph thoracicans (Crustacea, Cirripedia). Systematic Palaeontology. 
Gale, A.S. \& Sørensen, A.M. submitted. Cirripedes from a Cretaceous rocky shoreline at Ivö Klack, southern Sweden. Cretaceous Research.

Glenner, H. \& Høeg, J.T. 1993. Scanning electron microscopy of metamorphosis in four species of barnacles (Cirripedia Thoracica Balanomorpha). Marine Biology 117, 431-8.

Hébert, E. 1855. Tableau des Fossiles de la Craie de Meudon, et description de quelques especes nouvelles. Mémoire de la Societe géologique de France (2), 5, 345-74.

Jagt, J.W.M., Zonova, T.D. \& Jagt-Yazkova, E.A. 2007. Review of the brachylepadomorph cirripede genus Pycnolepas, including an Early Cretaceous species from the Russian Far East. Zootaxa 1545, 33-47.

Jones, D.S. 2000. Crustacea Cirripedia Thoracica: Chionelasmatoidea and Pachylasmatoidea (Balanomorpha) of New Caledonia, Vanuata and Wallis and Futuna Islands, with a review of all currently assigned taxa. In Crosnier, A. (ed), Résultats des Campagnes MUSORSTORM, volume 21. Mémoires du Muséum national d'Histoire naturelle 184, 141-283.

Lamarck, J.B. de 1818. Histoire naturelles des animaux sans vértébres 5. 382-3, cirrhipèdes sessiles; 401, cirrhipèdes pédoncules. Paris.

Linse, K., Jackson, J.A., Fitzcharles, E., Sands, C.J. \& Buckeridge, J.S. 2013. The phylogenetic position of Antarctic Scalpelliformes. (Crustacea: Cirripedia: Thoracica). Deep Sea Research 173, 99-116.

Newman, W.A. 1987. Evolution of cirripedes and their major groups. In: Southward, A.J. (ed.), Barnacle Biology. Crustacean Issues 5, 3-43. A.A. Balkema, Rotterdam. 
Newman, W.A. 1996. Cirripedia; Suborders Thoracica and Acrothoracica In:

Forest, J. (ed), Traité de Zoologie, Anatomie, Systématique, Biologie, 7(2), 453-540, Masson, Paris.

Newman, W.A. \& Hessler, R.R. 1989. A new abyssal hydrothermal verrucomorphan (Cirripedia, Sessilia): The most primitive living sessile barnacle. Transactions of the San Diego Society of Natural History. 21, 259-273.

Newman, W.A. \& Buckeridge, J.S. 1992 A reexamination of Waikalasma (Cirripedia, Thoracica) and its significance in balanomorph phylogeny. Journal of Paleontology: 66, 341-5.

Newman, W.A. \& Ross, A. 1976. Revision of the balanomorph barnacles; including a catalog of the species. San Diego Society of Natural History Memoir $\mathbf{9}$, 108pp.

Newman, W.A. \& Ross, A. 1998. Peduncular armament in the Scalpellomorpha (Cirripedia) and a new abyssal species from the East Pacific Rise. Journal of Crustacean Biology 18, 572-80.

Newman, W.A., Zullo, V.A. \& Withers, T.H. 1969. Cirripedia. In: Moore, R.C. (ed.) Treatise on Invertebrate Paleontology, Part R, Arthropoda 4,1: R206-295.

Newman, W.N. \& Yamaguchi, T. 1995. A new sessile barnacle (Cirripedia, Brachylepadomorpha) from the Lau Back-Arc Basin, Tonga; first record of a living representative since the Miocene. Bulletin du Muséum national d'Histoire naturelle Paris, $4^{\text {th }}$ series, 17, section A, pp. 221-243.

Pérez-Losada, M., Harp, M., Høeg, J.T., Actituv, Y., Jones, D., Watanabe, H. \& Crandall, K.A. 2008. The tempo and mode of barnacle evolution. Molecular Phylogenetics and Evolution 46, 328-346. 
Pilsbry, H.A. 1916. The sessile barnacles (Cirripedia) contained in the collections of the US National Museum, including a monograph of the American species. Bulletin of the United States National Museum 93, 366pp.

Ross, A. \& Newman, W.A. 2001. The Catophragmidae: members of the basal balanomorph radiation. Sessile Organisms 18, 77-91.

Runnström, S. 1925. Zur Biologie und Entwicklung von Balanus balanoides (Linné). Bergens Museum Arbok 5, 46pp.

Sørensen, A.H. \& Surlyk, F. 2010. Palaeocology of tube-dwelling polychaetes on a Late Cretaceous rocky shore, Ivö Klack, southern Sweden, including some of the northernmost zooxanthellate corals. Cretaceous Research 31, 259-63.

Sørensen, A.M. \& Surlyk, F. 2011a. Late Cretaceous scleractinian corals from the rocky shore of Ivö Klack (Skane, southern Sweden). Cretaceous Research 31 , 553-66.

Sørensen, A. M. \& Surlyk, F. 2011b. Taphonomy and palaeoecology of the gastropod fauna from a Late Cretaceous rocky shore, Sweden. Cretaceous Research 32 472-479.

Sørensen, A. M., Surlyk, F. \& Jagt, J.W.M. 2012. Adaptive morphologies and guild structure in a high-diversity bivalve fauna from an early Campanian rocky shore, Ivõ Klack (Sweden). Cretaceous Research 33, 21-41.

Sørensen, A. M., Surlyk, F. \& Lindgren, J. 2013. Food resources and habitat selection of a diverse vertebrate fauna from the upper lower Campanian of the Kristianstad Basin, southern Sweden. Cretaceous Research 42, 85-92.

Southward, A.J. 2006. Barnacles. Keys and notes for the Identification of British Species. Synopses of the British Fauna (New Series) no. 57. Field Studies Council. 137pp. 
Sowerby, J. de C. 1836. Descriptive Notes respecting the Shells figured in Plates 11-23 (pp. 335-348). Appendix A, to Fitton, ,W.H., Observations on some of the Strata between the Chalk and the Oxford Oolite in the South-East of England. Transactions of the Geological Society of London, (2) 4 ,103-389, pls 11-23.

Stanley, S.M. \& Newman, W.A. 1980. Competitive exclusion in evolutionary time: the case of the acorn barnacles. Paleobiology 6, 173-83.

Steenstrup, J. 1839. Bidrag til Cirripedernes Historie i Fortid og Nutid. Forste Bidrag. Anatiferidae og Pollicipedidae fra Kritperioden. Kroyer, Naturhist Tidsskrift 11, 396-415.

Surlyk, F. \& Christensen, W.K. 1974. Epifaunal zonation on an Upper Cretaceous rocky coast. Geology, 2, 529-34.

Surlyk, F. \& Sørensen, A.M. 2010. An early Campanian rocky shore at Ivo Klack, southern Sweden. Cretaceous Research, 31, 567-576.

Withers, T.H. 1912a. The cirripede 'Brachylepas cretacea', H. Woodward. Geological Magazine, Decade 5, 9, 321-6.

Withers, T.H. 1912b. The cirripede 'Brachylepas cretacea', H. Woodward. Geological Magazine, Decade 5, 9, 353-360.

Withers, T. H. 1914a. Some Cretaceous and Tertiary cirripedes referred to Pollicipes. Annals and Magazine of Natural History 8, 14, 167-206.

Withers, T.H. 1914b. A remarkable new cirripede from Chalk of Surrey and Hertfordshire. Proceedings of the Zoological Society London. 945-53.

Withers, T.H. 1923. Die Cirripedien der Kreide Rügens. Abhandlungen aus dem Geologisch-Paläontologischen Institut der Universität zu Greifswald 3, 1-54, 3 pls. 
Withers, T.H. 1928. British Museum (Natural History). Catalogue of the Fossil Cirripedia in the Department of Geology Vol. 1. Triassic and Jurassic. 154pp., 12 pls. London, Dulau \& Co.

Withers, T.H. 1935. British Museum (Natural History). Catalogue of the Fossil Cirripedia in the Department of Geology Vol. 2. Cretaceous. 534pp, 50pls. Adlard \& Sons Ltd., London.

Withers, T.H. 1953. British Museum (Natural History). Catalogue of the Fossil Cirripedia in the Department of Geology Vol. 3. Tertiary. 396pp, 64pls. Bartholomew Press, Dorking.

Van Syoc, R.J., Fernandes, J.N., Carrison, D.A. \& Grosberg, R.K. 2010.

Molecular genetics and biogeography of Pollicipes (Crustacea, Cirripedia), a Tethyan relict. Journal of Experimental Marine Biology and Ecology 392, 193-99.

Woodward, H.B. 1901. On "Pyrgoma cretacea", a cirripede from the Upper Chalk of Norwich and Margate. Geological Magazine, Decade 4, 8, 145-152.

Yamaguchi, T. \& Newman, W.N. 1990. The hydrothermal vent barnacle Eochionelasmus (Cirripedia, Balanomorpha) from the North Fiji, Lay and Manus Basins, South-West Pacific. Zoosystema 19: 623-49.

Young, P. 2001. Redescription of Scalpellopsis striatociliata, with a discussion on its phylogenetic position and the peduncular plate pattern in scalpellids. Journal of Crustacean Biology 21, 456-468.

Zullo, V.A. 1987. Scalpelloid and brachylepadomorph barnacles (Cirripedia, Thoracica) from the Upper Cretaceous Mt Laurel Sand, Delaware. Journal of Paleontology 61, 333-345. 
Zullo, V. A., Russell, E.E. \& Mellen, F.F. 1987. Brachylepas Woodward and Virgiscalpellum Withers (Cirripedia) from the Upper Cretaceous of Arkansas. Journal of Paleontology 61, 101-111.

Figure Captions

Fig. 1. Proposed homologies between scalpellomorphs and balanomorphs, illustrated by Recent Arcoscalpellum (A) and Catomerus polymerus (B). B1 follows Darwin (1854) and Anderson (1983), and indicates homologies between the carinolatus (cl, red), laterals ( $\mathrm{ul}, \mathrm{ll}$, yellow) and rostrolatus (rl) of scalpellomorphs. B2 shows the interpretation of Yamaguchi \& Newman (1990) interpreting the lateral plate of Darwin as a replication of the carinolatus (CL1, CL2). B3 shows the homologies suggested here, where the lateral plates are interpreted as new structures, carinomarginals (CM), marginal (M) and rostromarginals (RM).

Fig. 2. Comparative morphology of of Capitulum mitella (A), Etcheslepas durotrigensis Gale, 2014, (B), Pycnolepas articulata Collins (C), Brachylepas naissanti (D), Parabrachylepas ifoensis (Withers) gen nov. (E), Epibrachylepas newmani gen et sp nov. (F), Pachydiadema cretacea Withers (G). A-D, lateral aspect of individuals, homologies coloured as for Fig. 1. E1,F1, G1 shows opercula in lateral aspect; E2, F2, G2 show wall plates without surrounding imbricating plates, E3,F3 and G3 show lateral aspect of reconstructed individuals, details described in Systematic Palaeontology (see below). Note progressive loss of all laterals except upper latus (yellow) in A-D, which remains incorporated in the operculum (E-G). A new wall plate, (M, pale blue) evolves in E. newmani and $P$. ifoensis, and two further plates, RM and CM, in P. cretacea which are thought to be homologous with the eight plates of some balanomorphs. Compare with Figs. 4-6.

Fig. 3. Brachylepas naissanti (Hébert, 1855). Lateral (A) and apical views of articulated specimen, lacking opercular valves. B. mucronata Zone, Beeston Chalk, 
Upper Campanian, pit no. 153, Thorpe, Norwich, UK, Rowe Collection, NHM, In. 27160. Scale bar in mm. This is the only articulated Brachylepas known. Arrow indicates sites of addition of new plates.

Fig. 4. Diagrammatic representation of wall plate development in horizontal section in Epibrachylepas newmani (A), Pachydiadema cretacea (B) and Catomerus polymerus $(\mathrm{C})$. A new plate, the marginal $(\mathrm{M})$ is present between the rostrum and carina in E. newmani, but does not articulate closely with these plates. In P. cretacea, two further new plates, the rostromarginal (RM) and carinomarginal (CM) are intercalated into the wall, but only overlap weakly (see Fig. 7 for detailed articulations). In C. polymerus, the plates have become imbricated deeply, and a sheath and specialized articulation surfaces have developed (see also Figs. 5,6). Note that the imbrication direction of two surfaces have reversed in C. polymerus (r).

Fig. 5,6. Development and evolution of wall plates in basal balanomorph Pachydiadema cretacea Withers, 1935 (Cretaceous, Ivö Klack), and crown group neobalanomorphs Catomerus polymerus (Darwin, 1854), Recent, S. Australia, and Chirona hameri (Ascanius, 1767) Recent, North Sea. Note strong overlaps, coloured blue, between alae on the carinae and carinomarginals, and corresponding radii on the carinomarginals and marginals ( $\mathrm{x}-\mathrm{x}, \mathrm{y}-\mathrm{y}, \mathrm{z}-\mathrm{z})$. Sheath coloured green. Overlap is only very weak in P. cretacea (Fig. 7), but surfaces homologous with $\mathrm{x}-\mathrm{x}, \mathrm{y}-\mathrm{y}$ and $\mathrm{z}-\mathrm{z}$ are present (marked in black letters), and became articular surfaces (alae, radii) in the transition between P. cretacea and crown group balanomorphs. Also, the sheath is not present in P. cretacea, but the surfaces which subsequently united to form a sheath are clearly shown. Compare with Fig. 4. Note that the rostromarginal and rostrum are fused in C. hameri. NHM IC 792 (marginal), 793 (rostromarginal), 794 (carina), 795 (carinomarginal).

Fig. 7. Articulation between wall plates in Pachydiadema cretacea Withers, 1935 from Campanian, Ivõ Klack, Sweden. A, B, external and oblique external views of marginal plates (M) to show short lateral flanges (f) overlapped by rounded 
ridges $(\mathrm{r})$ respectively the rostromarginals ( $\mathrm{r}$ on F) and carinomarginals. NHM IC 796, 792, AX4.5, BX3.6. C, carinomarginal to show flange (f) overlapped by ridge on carina ( $\mathrm{r}$ on E), NHM IC 797, X4.5. D, rostrum, external aspect, to show asymmetrical flanges (f) overlapped by rostromarginal plates, NHM IC 798, X3.3. E, interior view of carina, to show rounded margin (r) overlapping adjacent carinomarginal (flange f on C). NHM IC 799, X3.8. F, interior of carinomarginal to show rounded margin r overlapping flange on marginal (f on A). NHM IC 798, X9. G, small marginal plate, to show single articular flange (f). NHM IC 801, X4.5. H,I, reconstruction of wall and articulation of imbricating plates; $\mathrm{H}$, shows marginal and rostromarginal plates, overlain by innermost of imbricating plates (i). RM NHM IC 795; M IC 792; i IC 802, X3. I, interior of imbricating plate to show broad articular surfaces. NHM IC 802, X4.2. Although the primary wall plates showed only very limited overlap, they were strongly imbricated by the innermost of the very robust imbricating plates.

Figs. 8,9. Proposed homologies and nomenclatorial modifications for scuta and terga of balanomorphs and stem group Sessilia. This demonstrates the progressive increase in size, number and complexity of articular structures, permitting closer articulation and subsequent loss of the upper latus, and illustrates the homologies proposed in this paper. Key features are the 1) development of a tergal notch (te $n$ ) on the scutum, which articulates with the scutal auricle (sc a) of the tergum (green), and 2) the progressive decrease in size and change in orientation of the tergal region of the scutum (sc $t$ ), which inflexes to become the tergal slip (te s), and articulates with the inner side of the upper latus (y-y) in Brachylepas and Epibrachylepas. The tergal slip is homologous with the articular furrow (art f) of balanomorphs in which the upper latus is lost. The weak oblique ridge between the scutal notch and articular furrow seen in Brachylepas and Epibrachylepas strengthens in balanomorphs to become the articular ridge (art r). In the tergum, the scutal wall (sc w) provides articulation for the upper latus in Brachylepas and Epibrachylepas (x-x); in balanomorphs the scutal wall and scutal groove (sc g) combine and deepen to become the articular furrow (Octomeris and Solidobalanus). Colours represent 1 ) the apical articulation of the tergal notch 
and scutal auricle (green), 2) the scutal articular ridge-tergal groove (purple) and 3) the scutal wall-upper latus and subsequent scutal wall-articular furrow articulation (orange). A, Calantica sp., W. Australia, Recent; B, Capitulum mitella, Hong Kong, Recent; C, Pycnolepas bruennichi (Withers), Danian, Palaeocene, Faxe, Denmark (NHM IC scutum 1019, tergum 1020, upper latus 1021); D, Brachylepas naissanti (Hébert), tergum NHM IC 1028, higher upper latus 1029, lower from the Lower Maastrictian, Rugen, Germany; scutum from the Upper Campanian of Lüneburg, Hanover, Germany, NHM In. 27424; E, Brachylepas guascoi (Bosquet), higher scutum, NHM IC 823, lower scutum, 827, tergum 825, higher upper latus 826, lower 826, lower Upper Campanian, Ivö Klack, Sweden; Epibrachylepas newmani gen et sp. nov., upper scutum, NHM IC 825, lower scutum, IC 828, tergum IC 862, upper lata IC 830-1, Campanian, Ivö Klack Sweden; G, Octomeris brunnea, south east Asia, Recent; H, Solidobalanus fallax, Recent, Devon UK. 1A, interior view of scutum; $1 \mathrm{~B}$ external view of scutum; $2 \mathrm{~A}$, interior view of upper latus; $2 \mathrm{~B}$, interior view of upper latus; $3 \mathrm{~A}$, external view of tergum; $3 \mathrm{~B}$ oblique view of tergum. Recent material listed in Table 1.

Fig. 10. Consensus cladogram of inferred relationships between the 12 taxa studied herein, with changes at nodes shown. Values to the left of nodes in bold are Bremer support valves for each node.

Fig. 11 Proposed phylogeny and classification of basal sessilians, based largely upon the cladogram in Fig. 10. The Sessilia are defined by the absence of a peduncle, which was lost within in the genus Pycnolepas. Verrucomorphs evolved from Pycnolepas. Balanomorpha are defined by the presence of at least one enlarged wall plate, and Parabrachylepas, Epibrachylepas and Pachydiadema constitute the stem group; crown group balanomorphans (Palaeocene-Recent) are named the Neobalanomorpha. Note that Pycnolepas, Brachylepas (and therefore, the Brachylepadidae and Brachylepadomorpha) are paraphyletic.

Fig. 12. Muscle attachments in fossil and recent thoracican cirripedes. A, scalpellomorph Calantica villosa, B, basal balanomorph Catomerus polymerus, after Anderson 1983; C, Parabrachylepas ivoensis, D, Epibrachylepas newmani, E, 
Pachydiadema cretacea (all from the lower upper Campanian of Ivõ Klack); F, Eochionelasmus ohati, Recent, Fiji; Catomerus polymerus (Recent, South Australia). Scutal adductor blue, tergal depressor pink, lateral scutal depressor, green, rostro-scutal depressor, yellow. In C. villosa (a), numerous longitudinal peduncular muscles run from the basal margins of the scuta and terga to the base of the peduncle, whereas in C. polymerus (b) three specialized depressor muscles, used in closing the aperture, run from the basis to the tergum (tergal depressor) and scutum (lateral scutal depressor, rostro-scutal depressor). In $P$. ifoensis (c), an enlarged rostro-scutal depressor attachment site is present, but otherwise the musculature resembles that of $C$. villosa (a). In E. newmani and $P$. cretacea $(\mathrm{d}, \mathrm{e})$, both enlarged scutal depressors are present, but smaller attachment sites for depressor muscles are found on the basal scutal margin between these. A specialized tergal depressor site is also present. In E. ohati and P. polymerus (f,g), the smaller scutal muscles between the depressors are absent, and specialized insertion sites for a powerful tergal depressor are present.

Fig. 13. Reconstructions of Brachylepas species; B. fallax (a) B. guascoi (b), B. naissanti (c). B. fallax is based on associated valves from the Maastrichtian of Rugen (M. Kutscher coll.), B. guascoi on isolated valves from Ivö Klack (Figs $14,15)$, and B. naissanti on the articulated specimen from the Late Campanian of Norwich, Norfolk, (BMNH In. 27160) figured herein (Fig. 3).

Fig. 14. A-P, Brachylepas guascoi (Bosquet, 1857), Lower Upper Campanian, Ivö Klack, (Röper Lense), Sweden. A,B large scutum, exterior and interior views. NHM IC 827, X5. C, exterior of large tergum, NHM IC 825, X4.6. D, exterior of small tergum, NHM IC 832, X21. E, oblique view of scutum, to show tergal slip see also Fig. 9E. NHM IC 823, X7. F, very small scutum, exterior view, NHM IC 833, X25.7. G, exterior and $\mathrm{H}$, interior views of small terga; note exfoliation of outer layer in G. NHM IC 834-5, GX17, HX21. I-L, upper lata, in oblique (I), external (J,L) and internal (K) views. I, NHM IC 826, J, 824, K, 836, L, 837. IX11, JX13, KX15, LX18. N, rostrum in oblique interior view; M, enlargement of interior surface of same specimen, to show slit-like pores. NHM IC 838, MX100, NX17. 0,P, 
small carinae in apical aspect, to show distinctive external sculpture. NHM IC 839,840, Both X15.

Fig.15. A-R, Brachylepas guascoi (Bosquet, 1857), Lower Upper Campanian, Ivö Klack, (Röper Lense), Sweden. A-C, large carina in external, oblique lateral , and interior views. NHM IC 841, X 4.4. D,E, large rostrum in external and internal views with in-life damage to apex, NHM IC 842, X4. F-H, large rostrum in external, oblique and internal views, with in-life microborings which have damaged the apical region. NHM IC 843, X4. I-R, imbricating plates, external views (I-K, M,R); internal views $(\mathrm{N}, \mathrm{Q})$ and lateral view $(\mathrm{L}, \mathrm{P})$. I-L,Q are from the lower whorls of plates; M,0,P from upper whorls. NHM IC 908-914, 1X19, JX15, KX18, LX24, MX11, NX25, OX9, PX20, QX26, RX15. S,T, Brachylepas fallax (Darwin, 1851) Maastrichtian, Rugen, Germany, imbricating plate, in external (S) and internal (T) views. NHM IC 1165.

Fig. 16.A-R, Epibrachylepas newmani gen et sp .nov. Lower Upper Campanian, Ivö Klack (Röper Lense), Sweden. A-D, scuta, in external (A-C) and oblique internal (D) aspect, NHM IC 855-857, 825, AX11, BX15, CX21, DX14. E-H, terga, in external (E-G) and internal (H) aspects, NHM IC 858-861, EX36, FX22, GX21, HX24. I-K, upper lata, in external (I,J) and internal (K) views. I, NHM IC 830, J-K 831, IX10, J,KX16. L,0,P, carinae, in apical and internal views. NHM IC 863,866-7, L,14X17, 0,PX15. M,N, rostra, in internal and apical views, with in-life wear on apex, NHM IC 864-5, MX11, NX18. Q,R, rostrum, in lateral view, and enlargement to show external sculpture. NHM IC 868, QX28, RX100.

Fig. 17. A-L, Epibrachylepas newmani gen. et sp. nov.; A,B, marginal plate in external and internal views. NHM IC 869, X25. E,F,I, scuta in external (E,F) and internal (I) aspects. Note gastropod boring in F which passes into site of scutal adductor. NHM IC 872,3, 876, EX41, FX29, IX20. C,D,G,H,J-L, imbricating plates, all in external view except $K$, internal. C,D, and $G$ are from lower rows, H,J and L, from upper rows (see Fig. 2). NHM IC 870-1, 874-5, 877-9, CX25, DX28, GX20, HX23, JX27, KX23, LX22. M-0, Brachylepas naissanti (Hébert,1855) rostrum in 
external, apical and internal views. NHM IC 880, X26. All from Lower Upper Campanian, Ivö Klack (Röper Lense), Sweden.

Fig. 18. A-0, Parabrachylepas ifoensis (Withers, 1935). Lower Upper Campanian, Ivö Klack (Röper Lense), Sweden. A-E, scuta. A, E scuta of small individuals in external view, NHM IC 881, 884, AX16, EX33. C,D, internal and external views of scutum of large individual, IC 883, X3.5. B, internal view of medium sized scutum, IC 882, X20. F-H,L, terga. F,G, external and internal views of small tergum, IC 885, X14. H, external view of large tergum, IC 886, X3.3. L, external view of very small tergum, IC 890, X27. Note the strong allometry in the opercular plates. I-K, marginal plates. I,J, marginal plate in external and internal views, IC 887, X16. K, Smaller marginal plate, external view, IC 889, X28.M, enlargement of surface sculpture of scutum in E. X200. N,O, upper latus in external and internal aspects, CI 890, X23.

Fig. 19. A-R, Parabrachylepas ifoensis (Withers, 1935). Lower Upper Campanian, Ivö Klack (Röper Lense), Sweden. A-H, L, are small carinae and rostra. A,H, carinae, in apical and internal views, NHM IC 892, 898, AX23, HX9. B-D, E-H, L, Rostra, in apical (E), external (B), internal (C,F,L) and lateral (D) views. B, IC 893, C, 894, E, 896, D,G, 895, E, 896, L, 901, BX21, CX18, DX20, EX28, FX18, GX25, LX15. I-J, large rostra, in external, lateral and internal views, I,K (same specimen), IC 899, X5, J, IC 900, X3.75. M-R, imbricating plates, in external $(\mathrm{M}, \mathrm{O}, \mathrm{R})$ and internal aspects $(\mathrm{N}, \mathrm{P}, \mathrm{Q})$. Plates with a flat base and strong articular structures are from the lower whorls (P-R); more oval plates with notches and weak articular structures from the upper whorls (M-0). IC 902-907, MX15, NX19, OX11, PX13, QX19, RX18. S,T, Brachylepas naissanti (Hébert, 1855), Late Campanian chalk, Luneburg, Hanover, Germany. Imbricating plates in external aspect. NHM In. 27433. SX17, TX12.

Fig. 20. Pachydiadema cretacea (Withers, 1935). Lower Upper Campanian, Ivö Klack, (Röper Lense), Sweden. A,E, carinomarginal in external and internal views, NHM IC 795, X2.5. B, F marginal plate in internal and external views, IC 792, X3.4. C,G, rostromarginal in external and internal views, IC 793, X 2.7. 4,8, D,H, O, 
carina in external, internal and lateral views, IC 794, X3. I, carinomarginal in lateral view, IC 797, X4. J-L, rostrum in external, internal and lateral aspects, IC 798, X3.1. M,N, outer imbricating plate in apical and internal views, IC 803, X2. $\mathrm{P}, \mathrm{T}$, scutum in external and internal views, IC 804, X3.5. Q,U, tergum in external and internal views, IC $805, \mathrm{X} 4.2$. R,V, upper latus in lateral and internal views, IC 806, X11. S,W, inner imbricating plate in lateral and internal aspects, IC 802, X2.6.

Fig. 21. Pachydiadema cretacea (Withers, 1935). Lower Upper Campanian, Ivö Klack, (Röper Lense), Sweden. A-C, carina of small individual in external, internal and lateral views. Note prominent growth line, which probably represents a preferred line for spalling of the early stages. NHM IC 807, X 6.7. D,E, rostra of small individuals in external and internal views, IC 808-9, X5. F,G, Small carina, in external and internal views, IC 810, X8. H,I, tergum in external and internal views, IC 811, X5. Note in life borings (acrothoracican) on external surface. J, external view of well preserved tergum with smooth spalled external surface, 812, X3.6. K, tall narrow imbricating plate, in external view, IC 813, X5.6. L, rostromarginal of medium sized individual, external view, IC 814, X4.6. M, rostromarginal of large individual to show colour banding, IC 815, X3.8. N,P, marginal plate of juvenile individual, external and internal views, IC 816, X8. 0,Q, rostromarginal of juvenile individual, external and internal views, IC 817, X8. R,S, well preserved carina in external and lateral views, IC 818, X3.4. T, carina in external aspect, IC 819, X2.6. U, rostromarginal, in external aspect, IC 820, X3. T and U represent a variant with closely spaced, strong ribbing.

Fig. 22. Ontogeny in reconstruction of Pachydiadema cretacea. A-F, ontogenetic succession of marginal plates, Campanian, Ivö Klack (Röper Lense), Sweden. Note that the apical angle becomes progressively more acute with size, and the apical portion has spalled away in larger plates (D-F). G,H, reconstruction, showing oval outline and rather depressed profile; the outer surface of all plates (except the scuta) comprises a concave to flat surface where the apical portion of the plate has spalled away (see Figs 20,21). Compare with extant species Catolasmus pilsbryi Broch (Fig.23), which also has a low profile and spalled plates. A, NHM IC 816, B, IC 821, C, IC 822, D, IC 801, E, IC 792, F, IC 796. 
Fig. 23. Catolasmus pilsbryi (Broch, 1922). Recent, Isla Taboga, Panama (847’N, 79033’W). Specimens from type series, University of Copenhagen Zoology Museum. Taxon with superficial similarity to Pachydiadema cretacea; note the low profile (c), and spalled/bioeroded apical portions of the opercular, wall and imbricating plates $(\mathrm{A}-\mathrm{C})$. However, the alternating imbricating plates are concavo-convex (D,E) with a significant space between successive whorls. Note that the plates decrease in size towards the periphery, indicating that outer plates are the last formed.

Table 1. Recent material examined

\begin{tabular}{|l|l|l|l|l|}
\hline Major group & Genus/species & locality & Collector/source & Reg. no. \\
\hline Scalpellomorpha & Calantica sp. & $\begin{array}{l}\text { Western } \\
\text { Australia }\end{array}$ & W.A. Newman & $\begin{array}{l}\text { NHM } \\
\text { IC } 1144\end{array}$ \\
\hline Scalpellomorpha & $\begin{array}{l}\text { Capitulum } \\
\text { mitella }\end{array}$ & $\begin{array}{l}\text { Hong } \\
\text { Kong }\end{array}$ & W.A. Newman & $\begin{array}{l}\text { NHM } \\
\text { IC } 1145\end{array}$ \\
\hline Balanomorpha & $\begin{array}{l}\text { Octomeris } \\
\text { brunnea }\end{array}$ & SE Asia & A.S. Gale & $\begin{array}{l}\text { NHM } \\
\text { IC } 1148\end{array}$ \\
\hline Balanomorpha & $\begin{array}{l}\text { Eochionelasmus } \\
\text { ohati }\end{array}$ & $\begin{array}{l}\text { Fiji } \\
\text { trench }\end{array}$ & Newman & $\begin{array}{l}\text { NHM } \\
\text { IC } 1149\end{array}$ \\
\hline Balanomorpha & $\begin{array}{l}\text { Catophragmus } \\
\text { polymerus }\end{array}$ & $\begin{array}{l}\text { S } \\
\text { Australia }\end{array}$ & W.A. Newman & $\begin{array}{l}\text { NHM } \\
\text { IC } 1150\end{array}$ \\
\hline Balanomorpha & $\begin{array}{l}\text { Chirona hameri } \\
\text { North } \\
\text { Sea }\end{array}$ & A S Gale & $\begin{array}{l}\text { NHM } \\
\text { IC } 1151\end{array}$ \\
\hline Balanomorpha & $\begin{array}{l}\text { Solidobalanus } \\
\text { fallax }\end{array}$ & $\begin{array}{l}\text { Devon, } \\
\text { UK }\end{array}$ & A S Gale & $\begin{array}{l}\text { NHM } \\
\text { IC } 1152\end{array}$ \\
\hline
\end{tabular}

\section{Table 2 Character list - origin of balanomorphs}

1) flexible plated peduncle present (0); low skirt of imbricating plates present (1) 
2) peduncular plates added proximal to capitulum (0); added peripherally (1)

3) peduncular plates lack specialized articulation (0); interiorly directed basal shelf present (1); mortis and tenon articulation present (2)

4) RL, CL, UL, LL present (0); only UL present (1); all laterals lost (2)

5) Primary wall lacking (0); M plate present (1); RM and CM present (2)

6) Articulation between wall plates weak (0); specialized articulation structures present (1)

7) Overlap between wall plates very small (0); extensive imbrication (1)

8) M overlapped by CM (0); M overlaps CM (1)

9) C overlaps CM (0); CM overlaps C (1)

10)T and S firmly attached to other capitular plates (0); form mobile operculum (1)

11) Operculum tall, laterally compressed (0); low, mound-like (1)

12) Opercular sheath absent (0); present (1)

13) Accessory laterals present (0); absent (1)

14) Upper latus equi-triangular (0); tall triangular (1); small, oval (2); absent (3)

15) Upper latus fixed in capitulum (0); UL part of operculum(1)

16) Tergum outline rhombic (0); triangular (1)

17) Scutal and carinal areas of tergum equal-subequal size (0); carinal area > scutal (1)

18) Scutal area of tergum flat (0); forms vertical wall set beneath apicobasal line (1)

19) Angle between upper and lower carinal margins of tergum obtuse (0); approximates to right angle (1)

20) Apicobasal ridge on tergum weakly defined (0); forms sharp ridge (1)

21) Scutum outline approximates to isosceles triangle with short basal margin (0); right triangle, with occludent margin forming hypotenuse (1)

22) angle between basal and occludent margins of scutum $70-90^{\circ}(0)$; acute, $40-60^{\circ}(1)$

23)tergal area of scutum subequal/equal to rostral (0); tergal area smaller than rostral (1) 
$24)$ tergal region of scutum visible on exterior of valve (0); inset beneath apicobasal ridge (1)

25) apicobasal ridge absent (0); present (1)

26) apex of scutum weakly inclined towards tergum (0); strongly inclined (1)

27) scutum simply rests on tergum (0); tergal notch and scutal auricle weakly developed (1); auricle and notch well developed, form firm concavoconvex articulation (2)

28) tergal slip absent (0); present, articulates with upper latus (1); articulates with tergum (2)

29) tergal slip simple concave depression (0); divided to articular furrow and tergal wall (1)

30) articular ridge absent (0); present, weakly developed (1); strongly developed, prominent, articulates with articular furrow (2)

31 ) tergal notch subapical in position (0); apical (1)

32 ) carina larger than rostrum (0); both of approximately equal size(1)

33 ) carina and rostrum curved towards tergum and scutum respectively (0); not inclined (1)

34) carina triangular in outline, $>2.5 \mathrm{X}$ taller than broad (0); triangular, height equal to or slightly greater than breadth (1); outline irregular trapezoid (2)

35 ) cross section of carina and rostrum subtends angle of $<120^{\circ}(0)$; subtends angle of $180-240^{\circ}(1)$

36) articular surface of carina with terga, and rostrum with scuta forms inverted V (0); transverse line across interior of plate (1)

37 ) carina with rounded exterior (0); with raised median ridge (1)

38) rostrum low inverted isosceles triangle with lateral wings (0); triangular outline (1); trapezoidal-rectangular outline (2)

39 ) height of rostrum $>2 X$ breadth (0); height equal to or slightly greater than breadth (1)

40) rostrum with rounded exterior (0); with raised median ridge (1)

Table 3. Character matrix 
See separate file 
R

RM

M

C
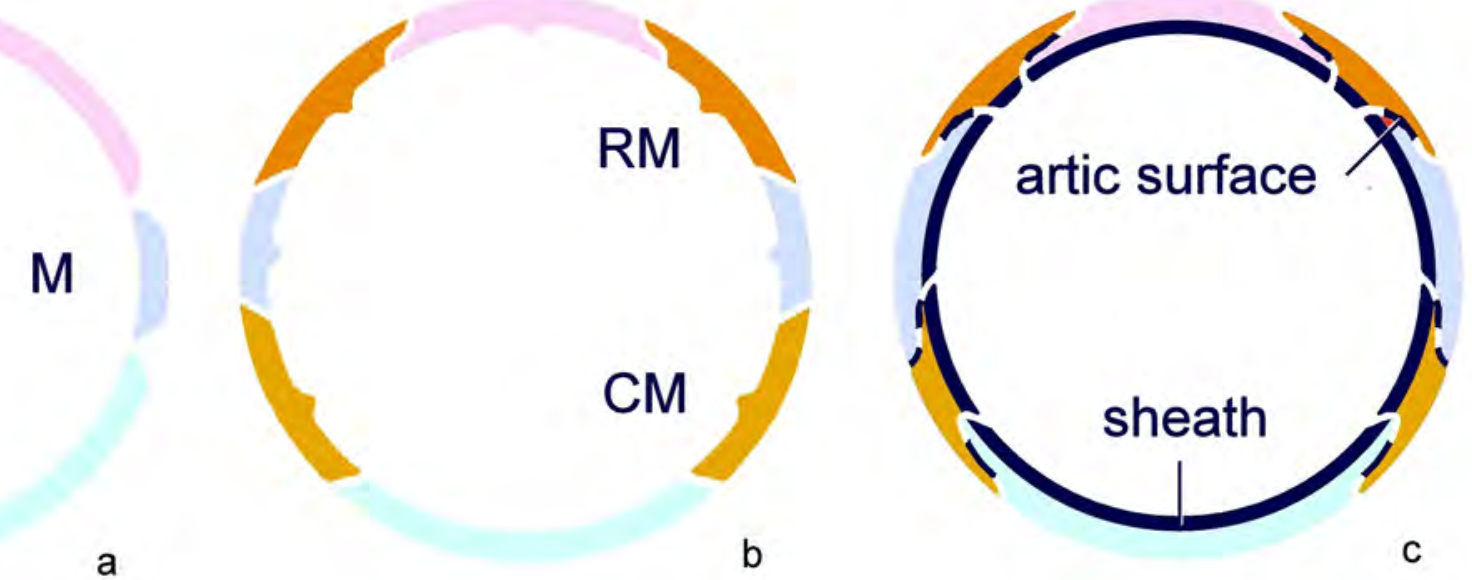

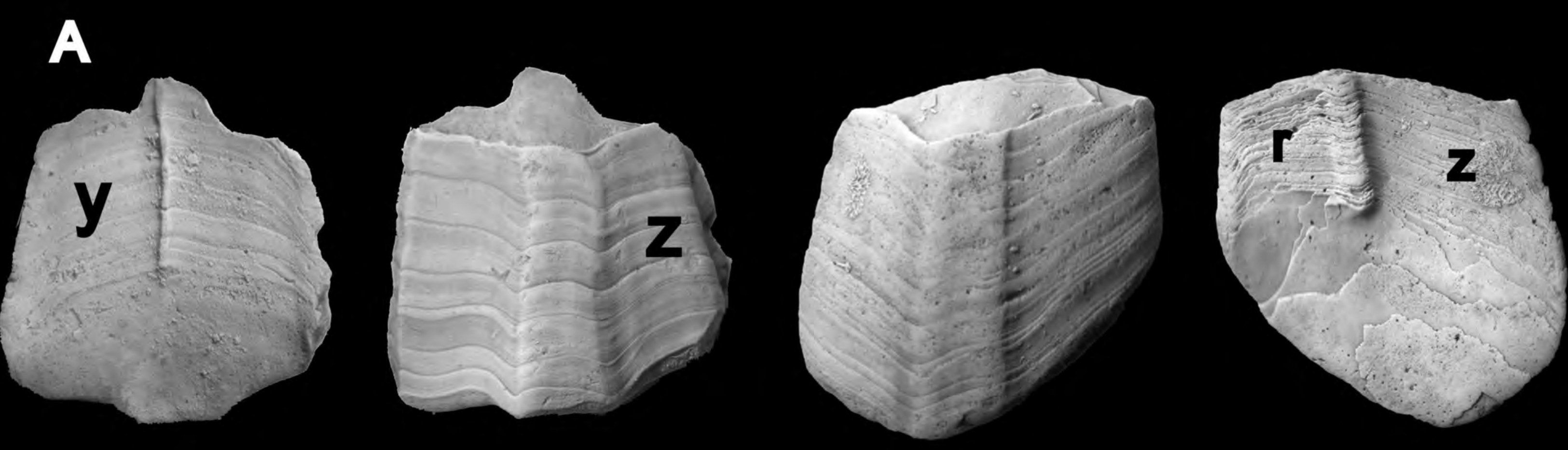

B
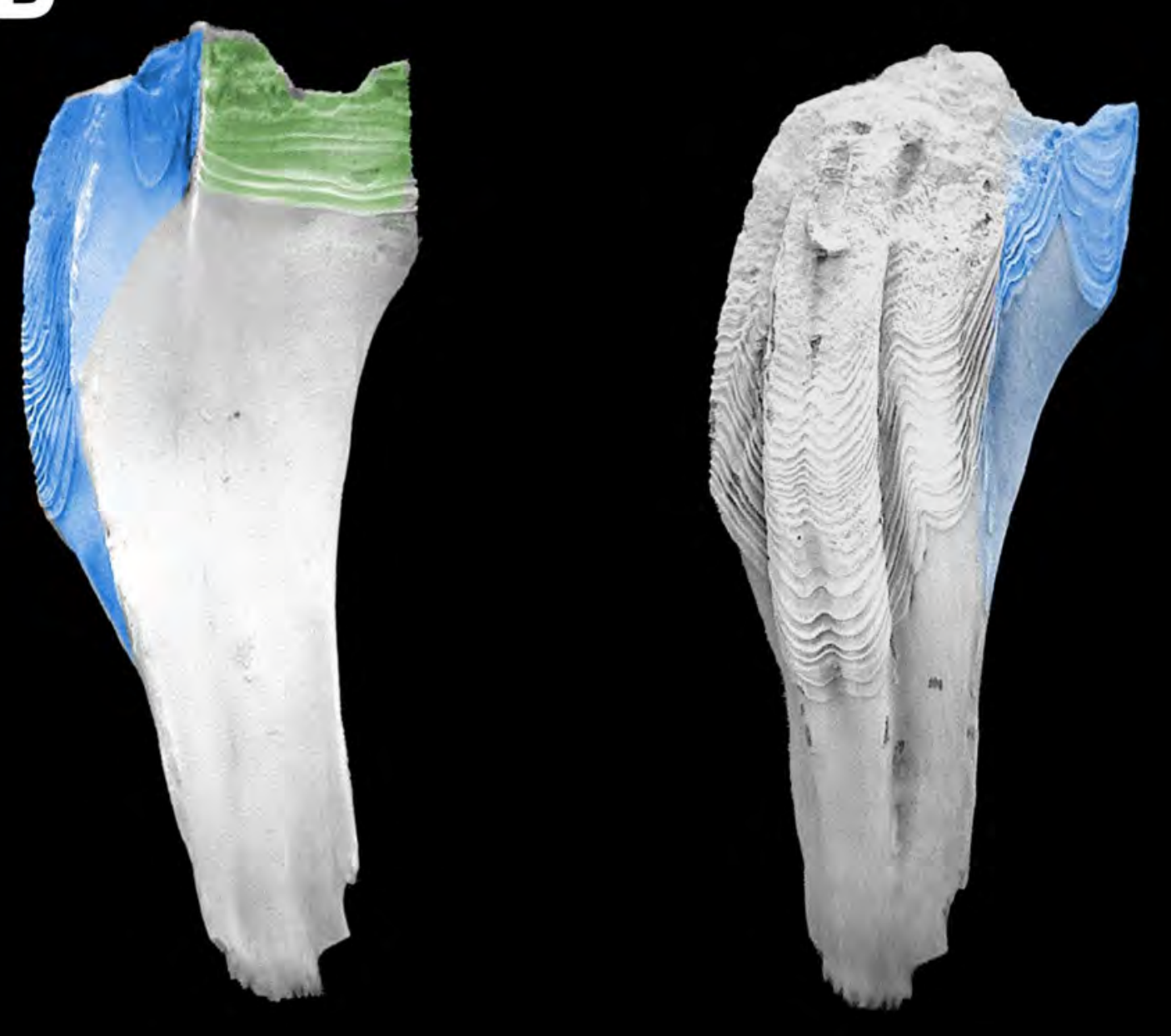

c
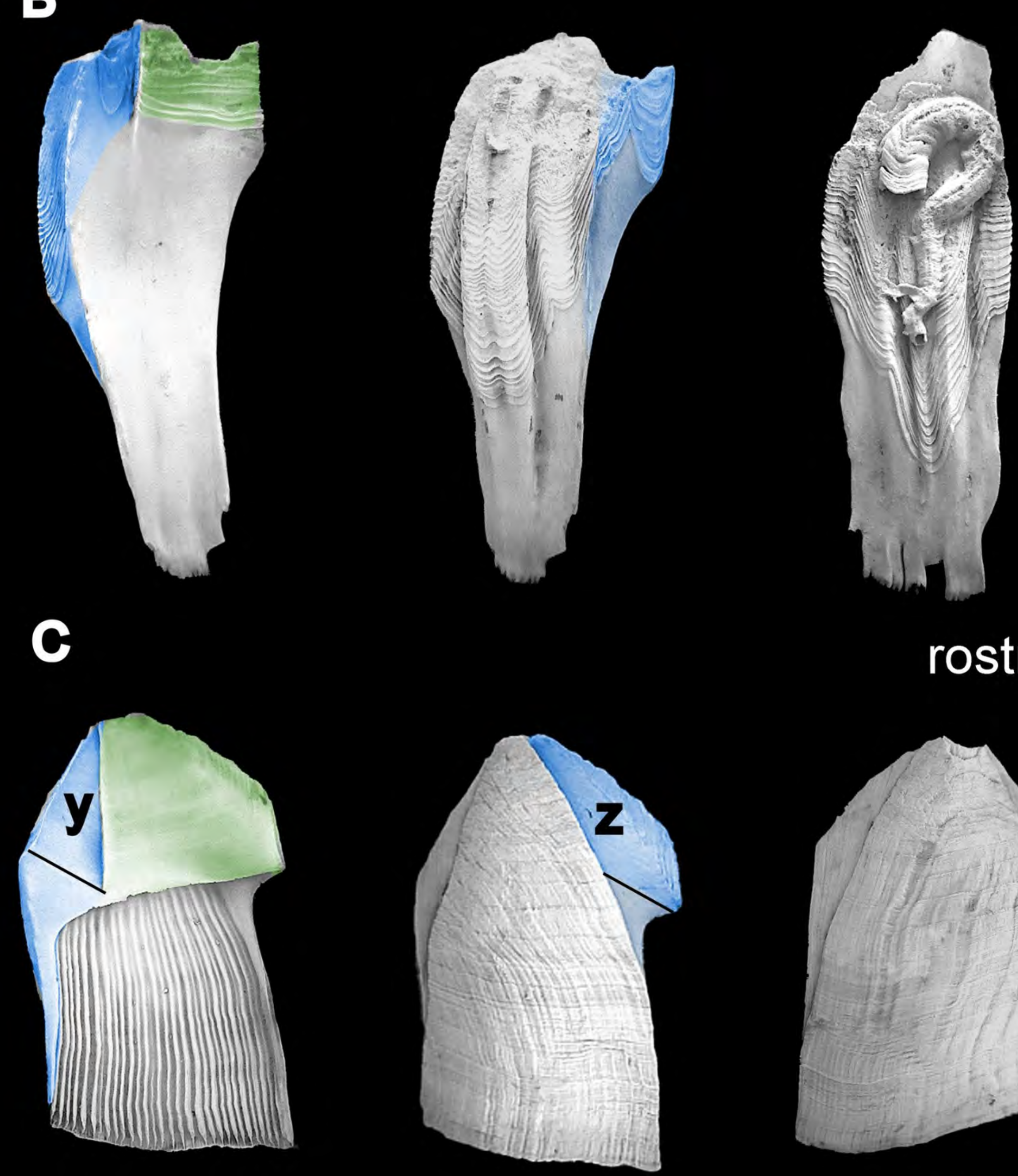

to rostrum

\section{rostromarginal}
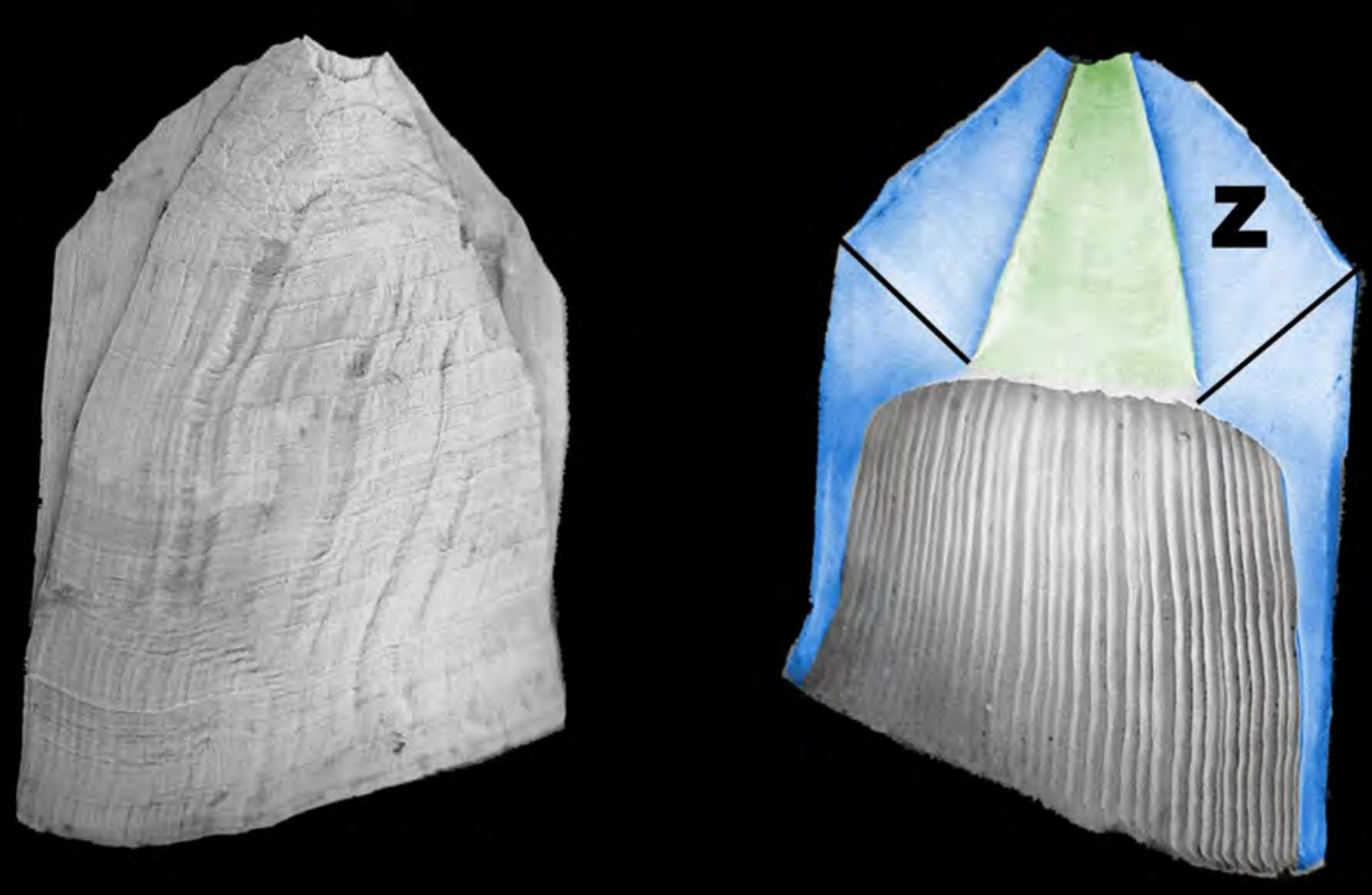

marginal rostrum + rostromarginal 

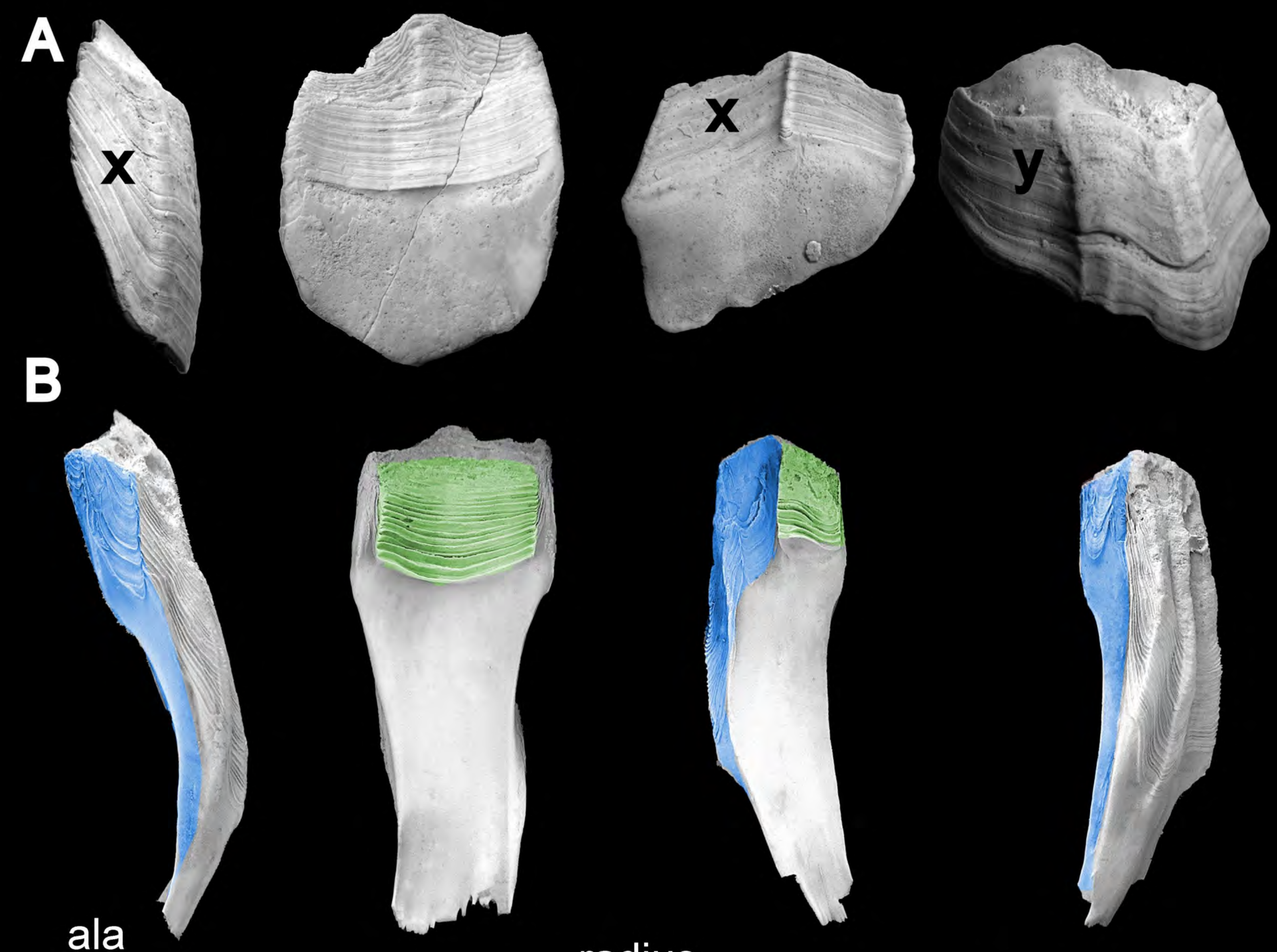

\section{radius}
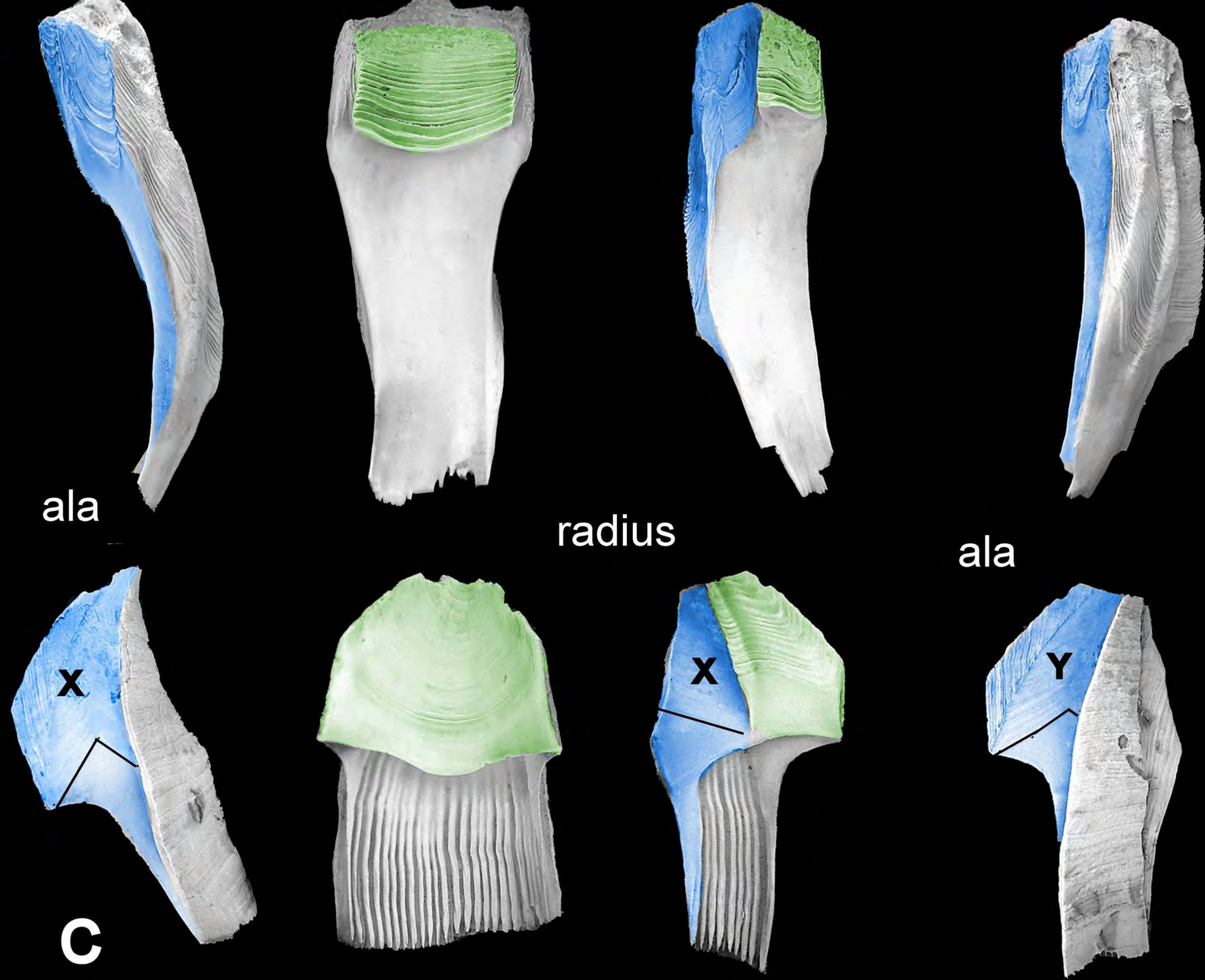

ala

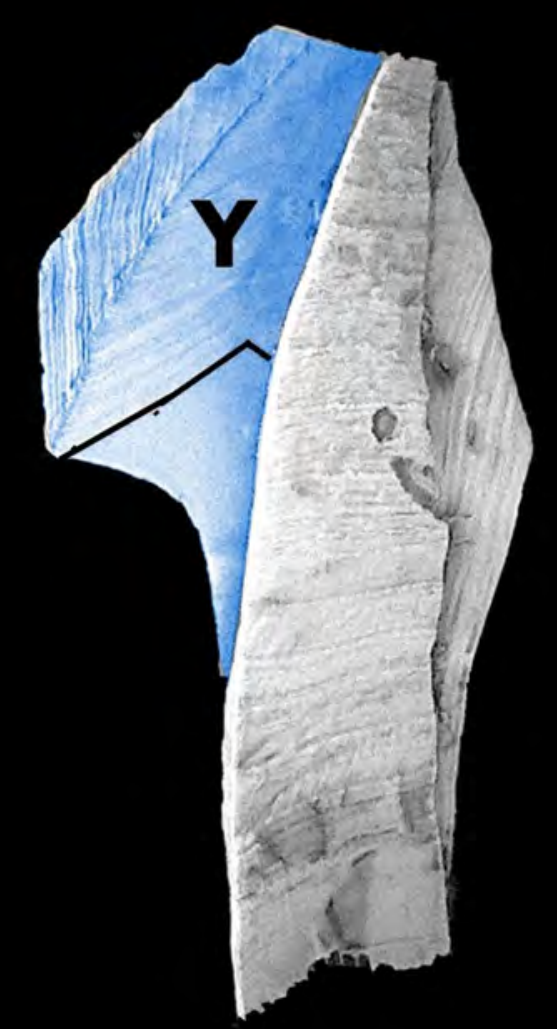

carina 


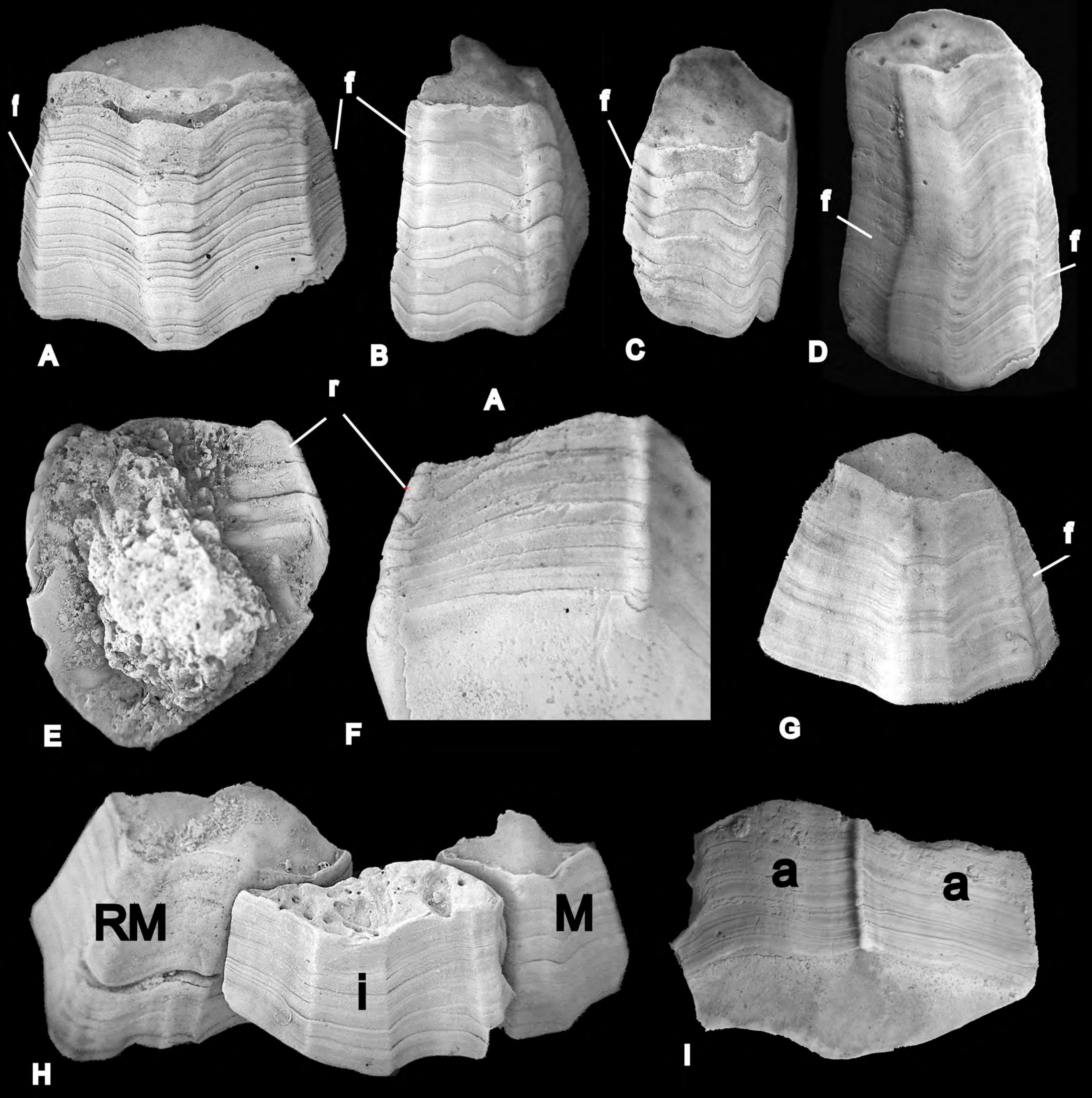




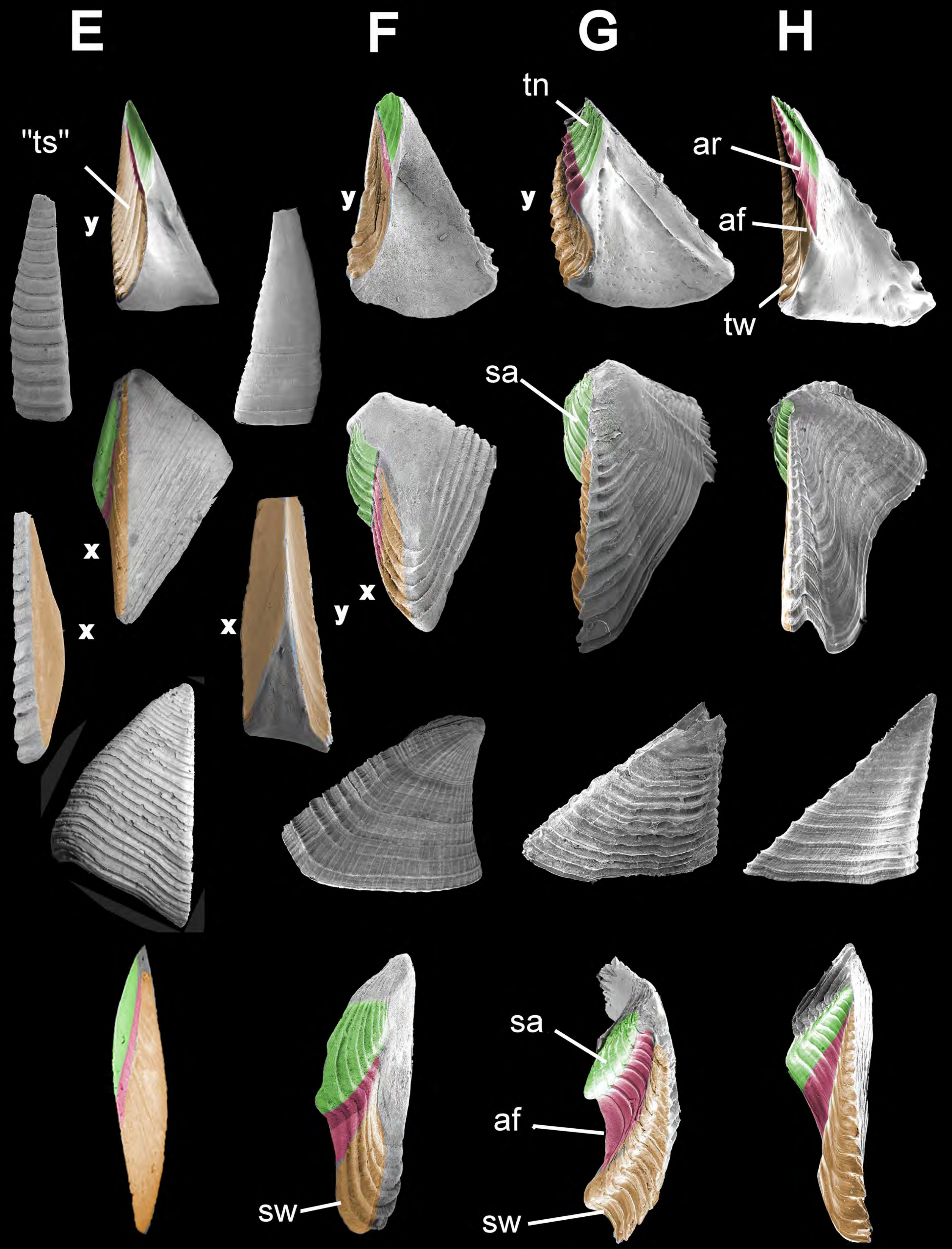




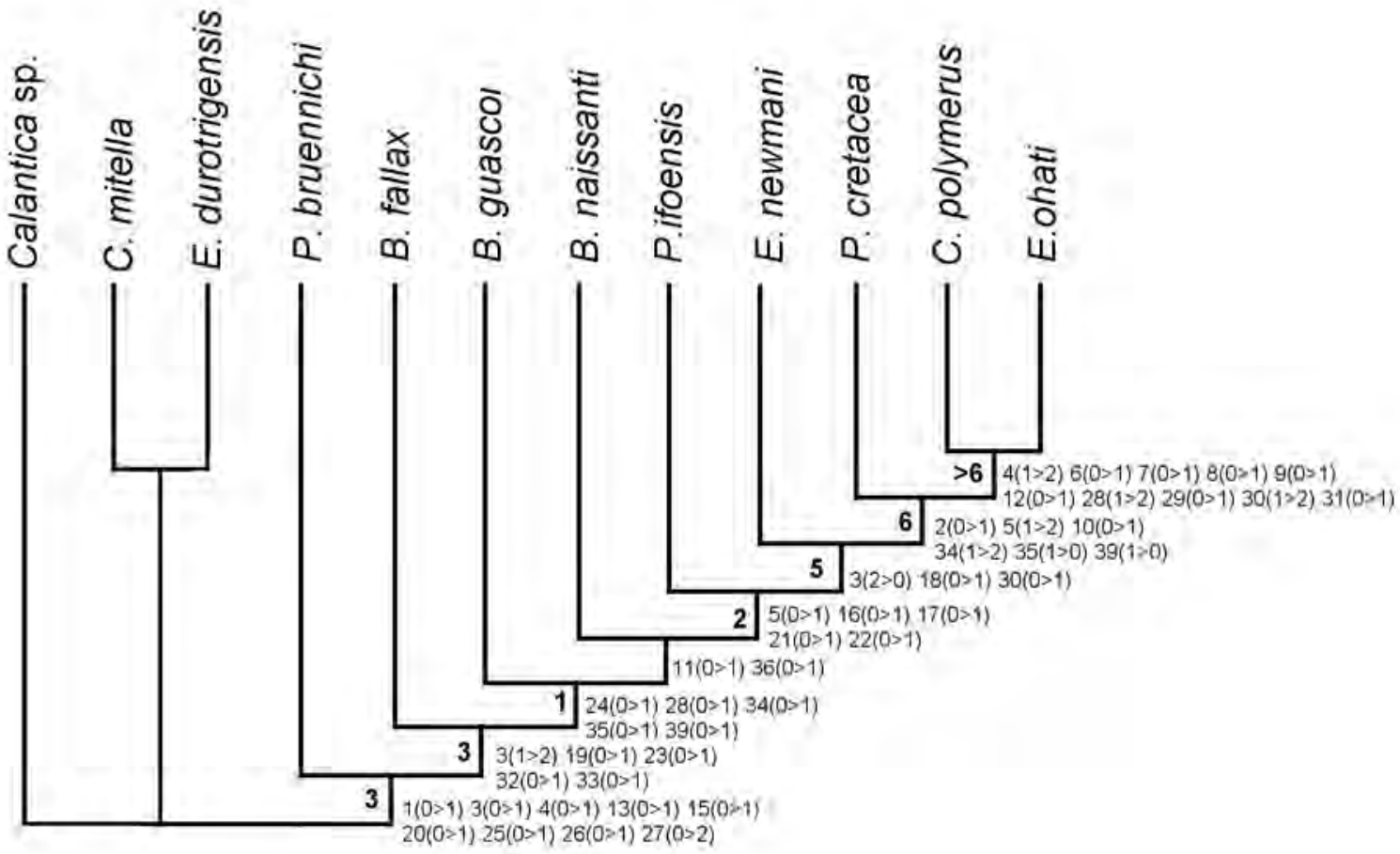




\section{SESSILIA}

\section{VERRUCOMORPHA}

\section{BALANOMORPHA}

Pycnolepas Brachylepas

NEOBALANOMORPHA

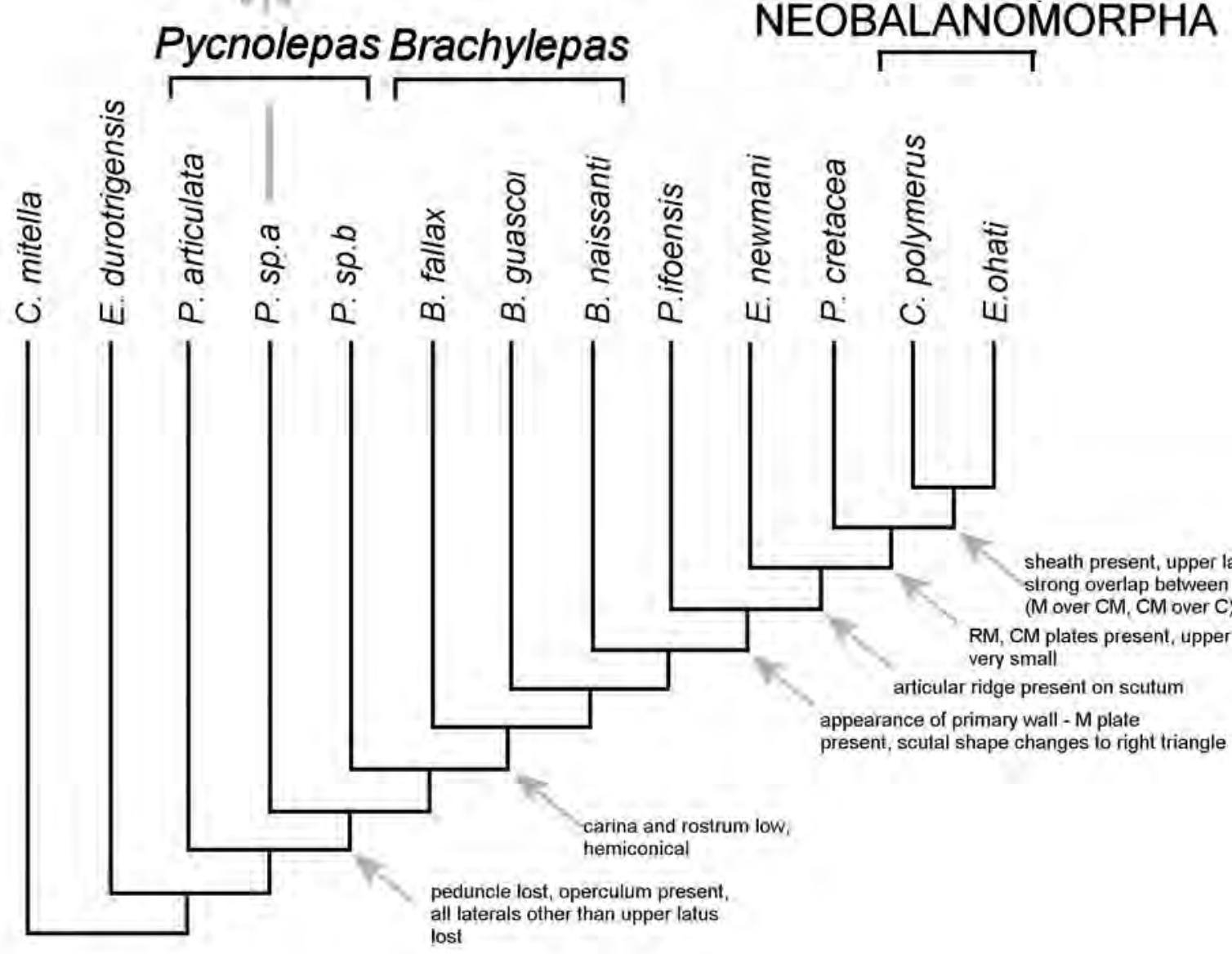




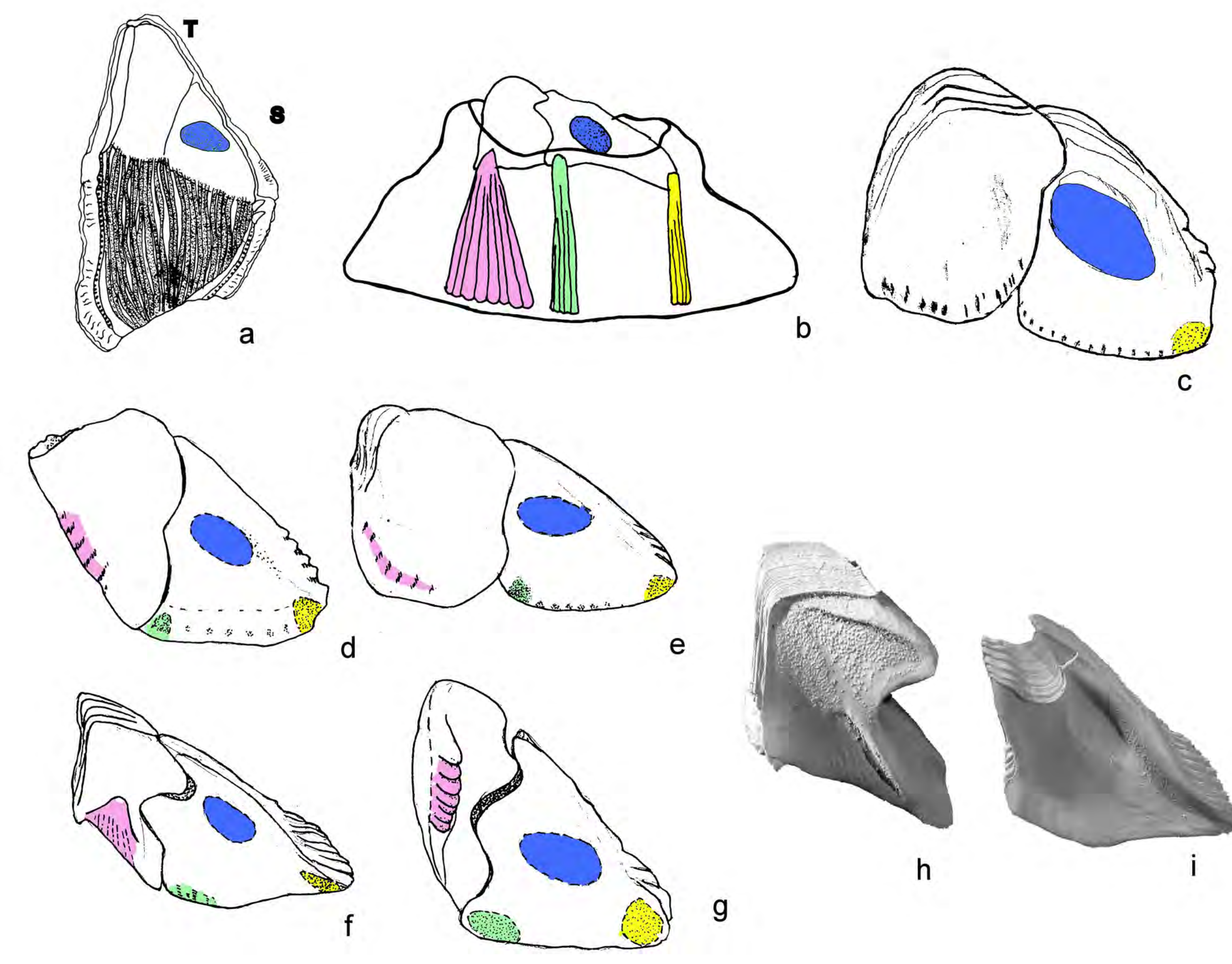




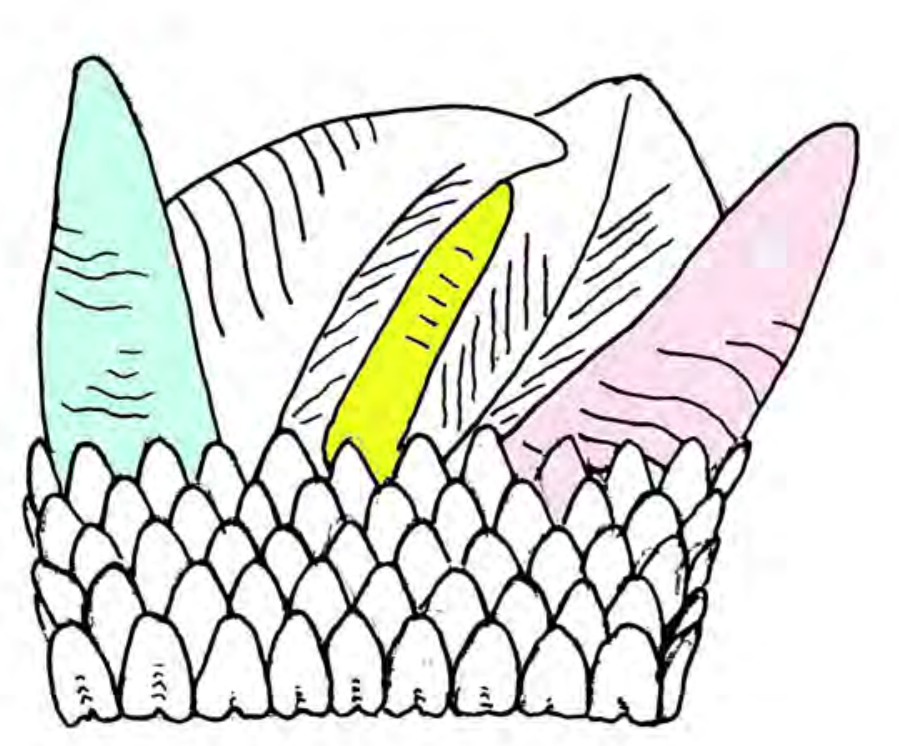

a

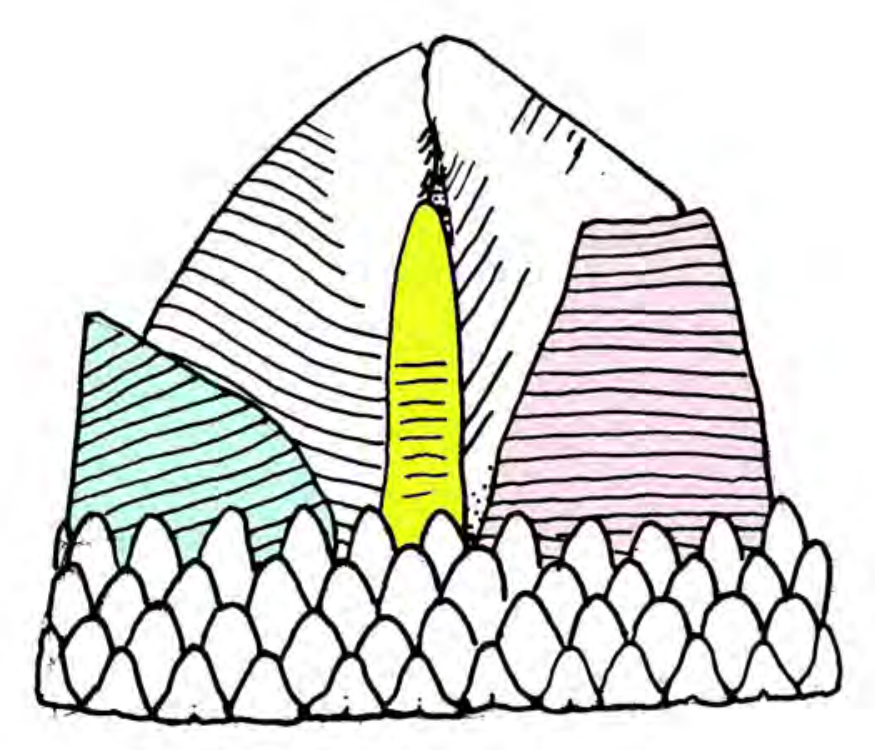

b

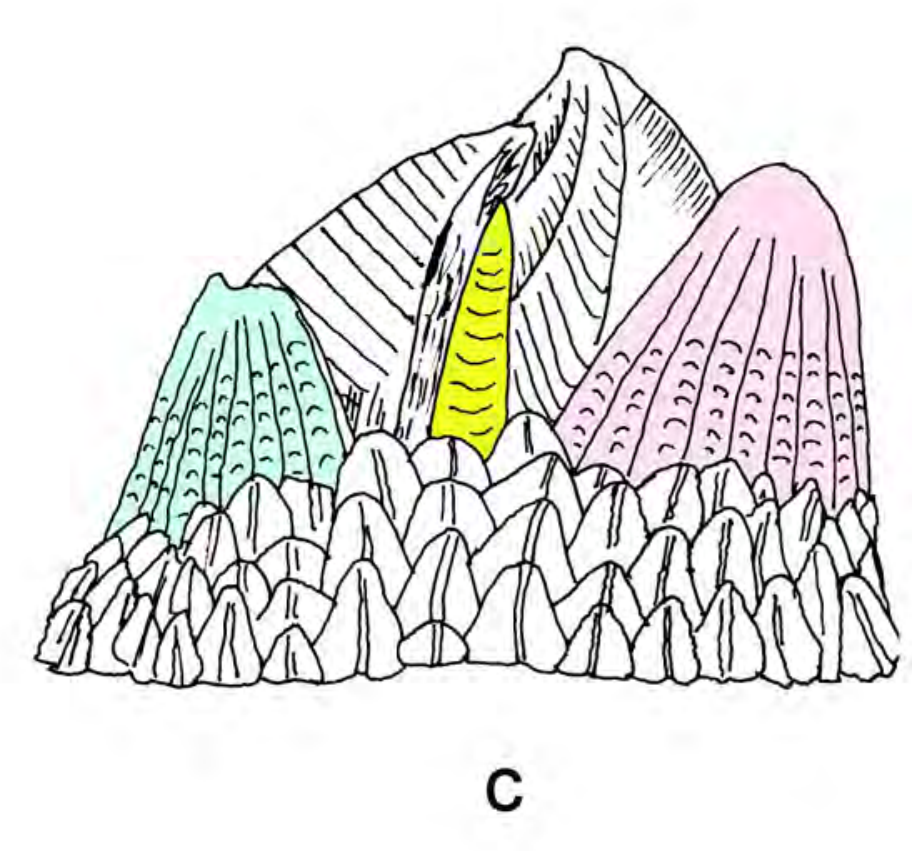



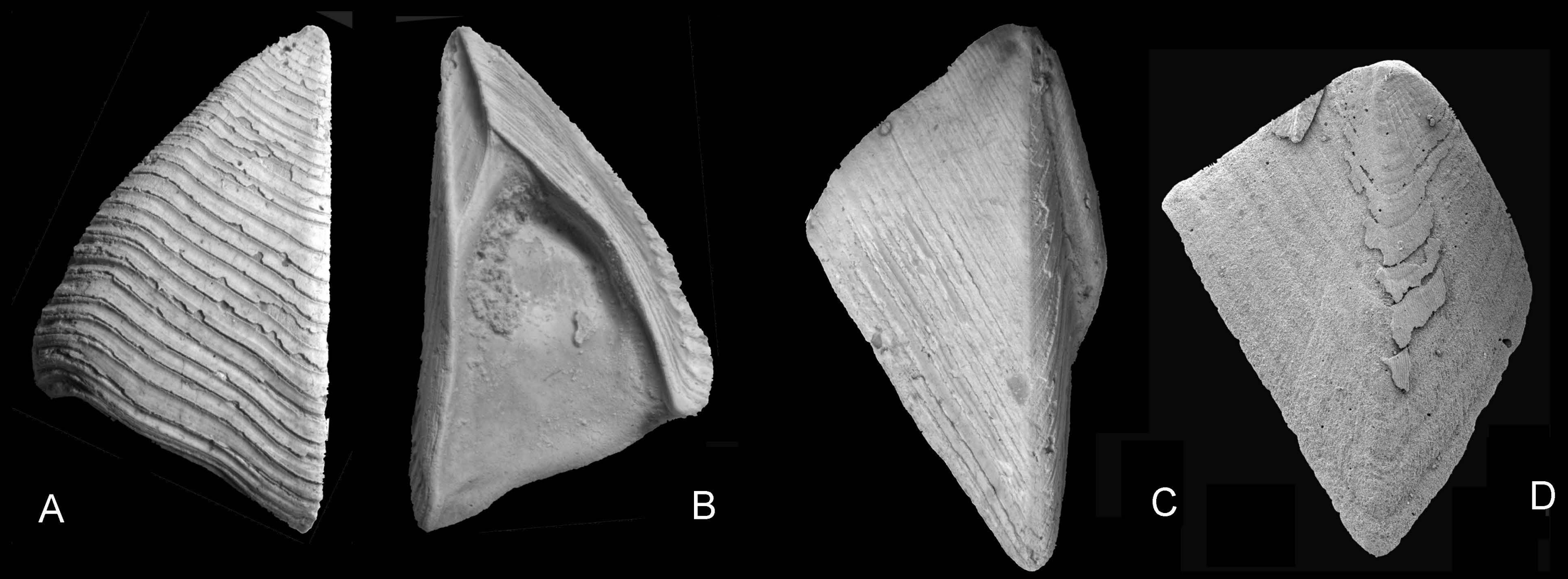

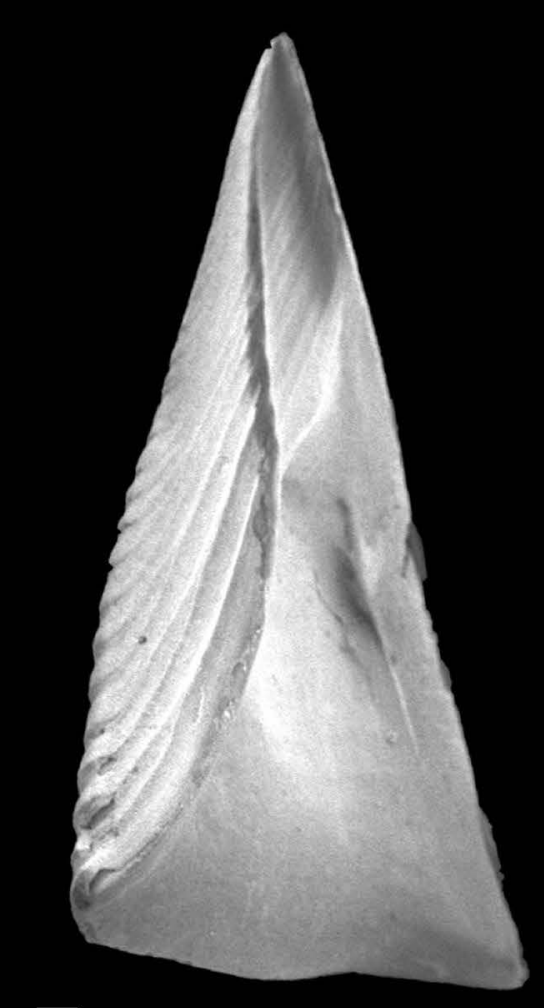

E

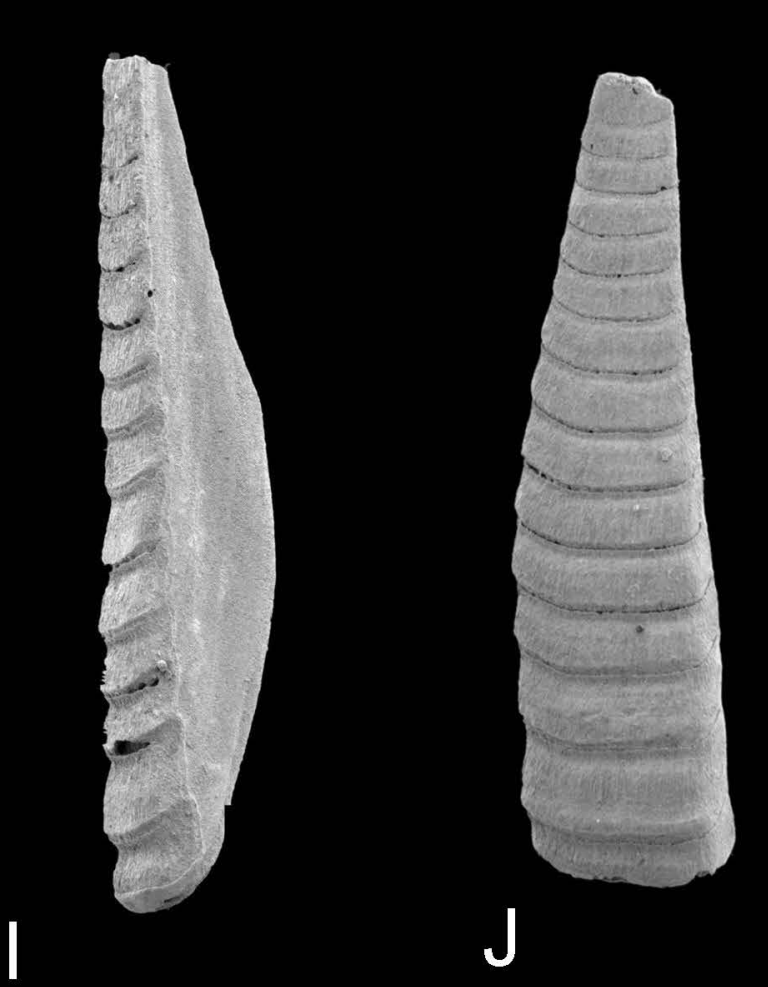

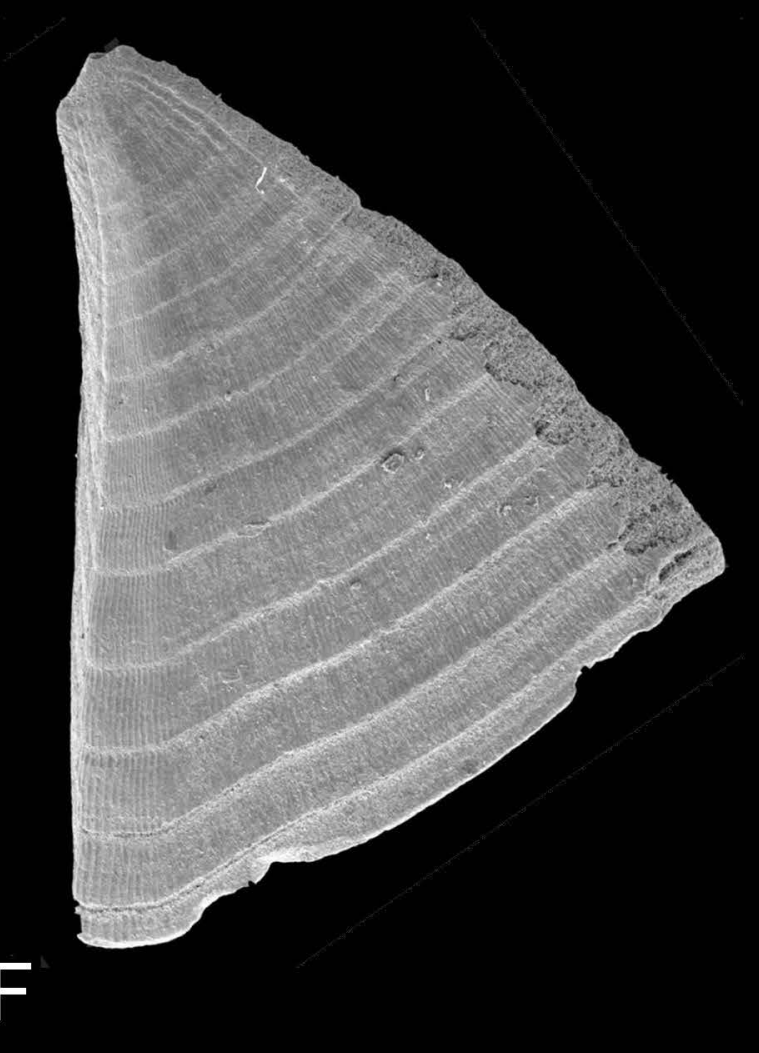
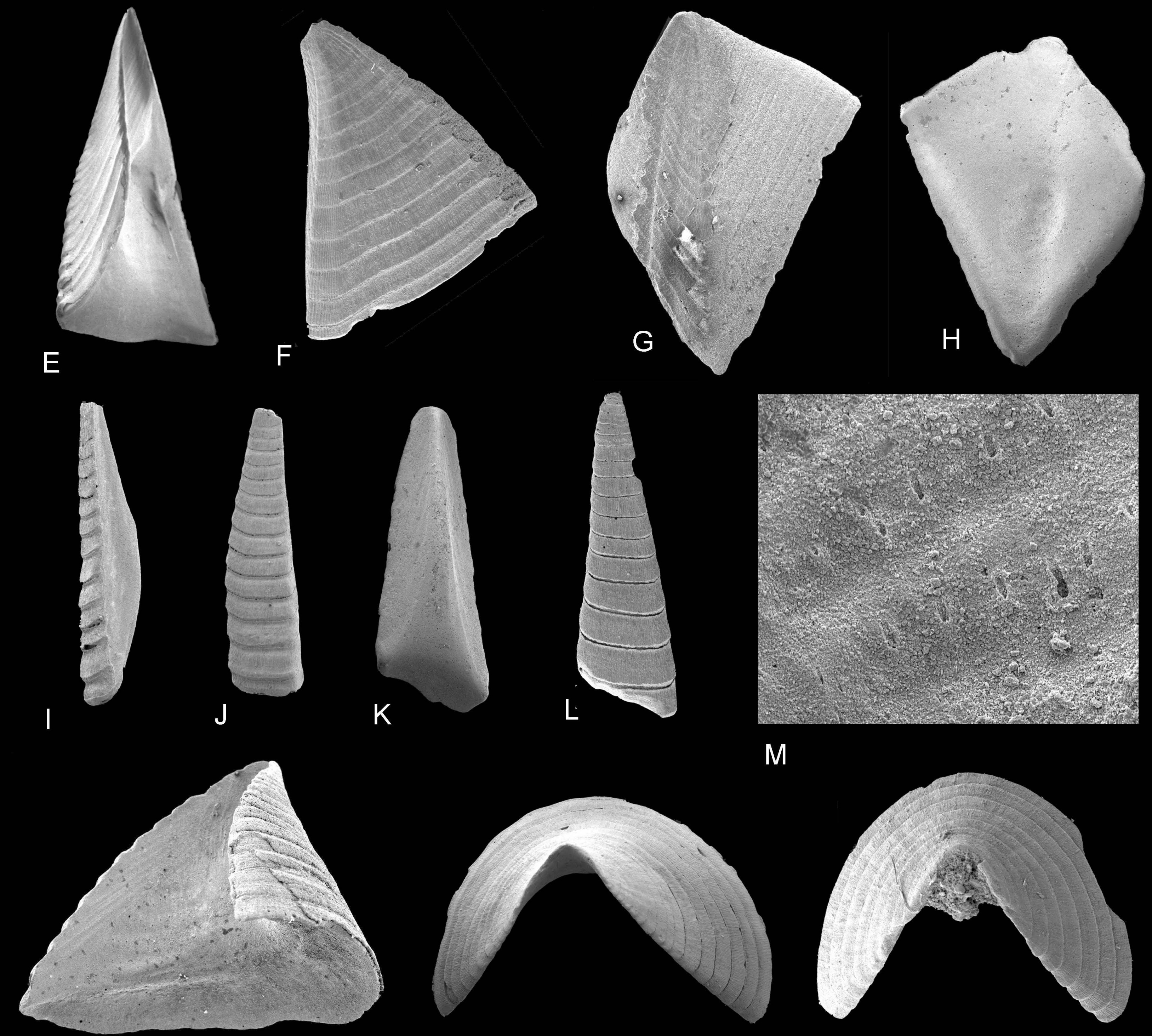

O

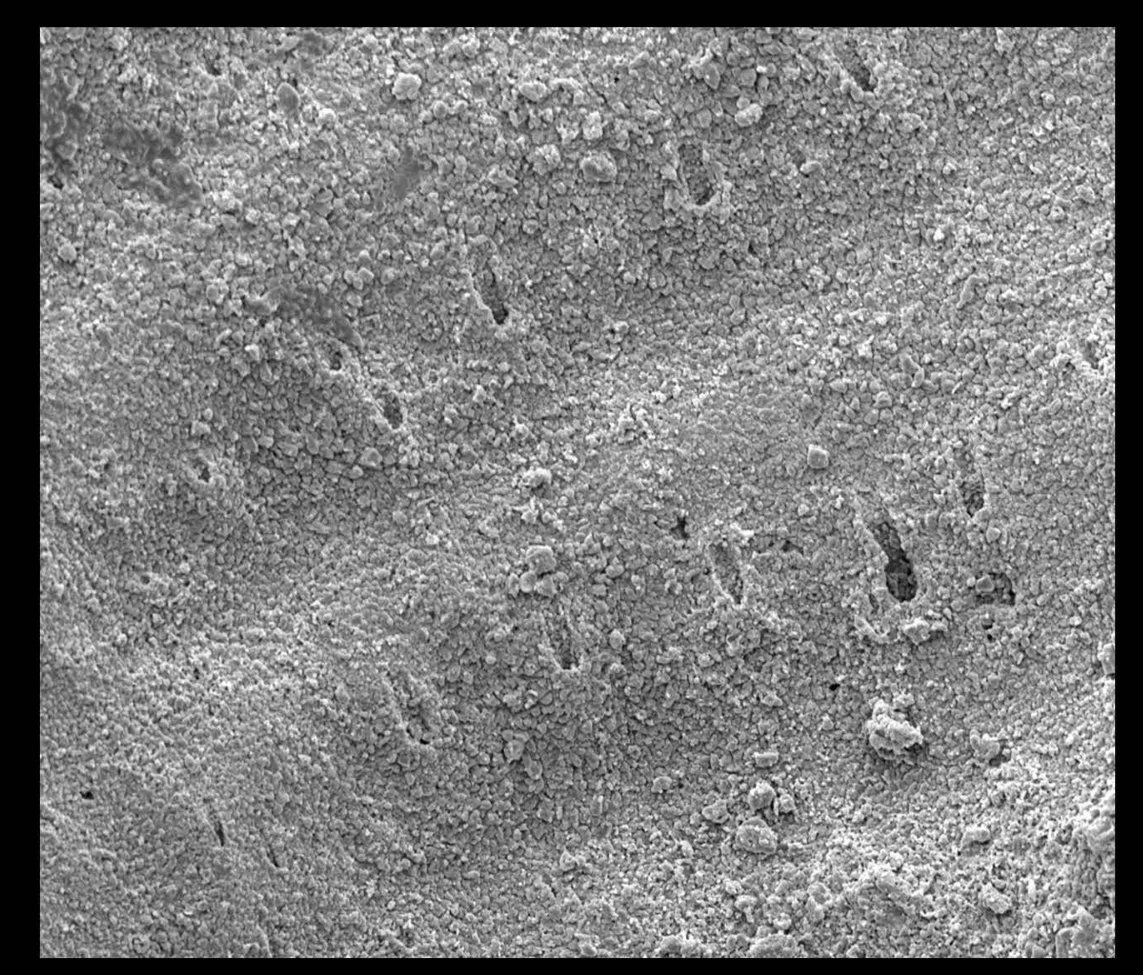

M

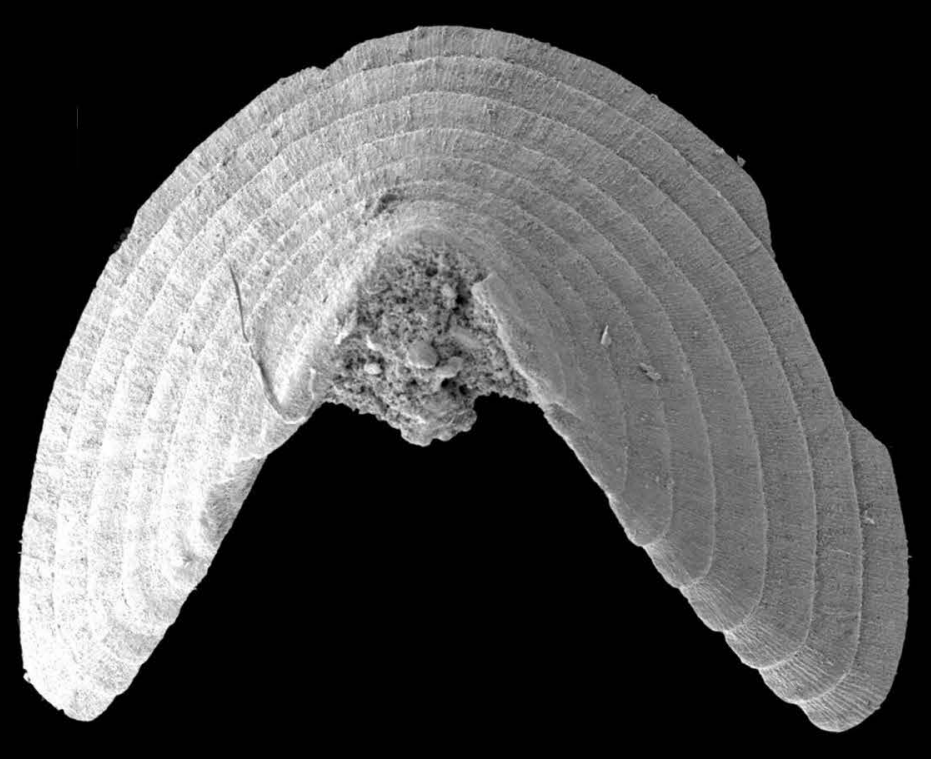

P 

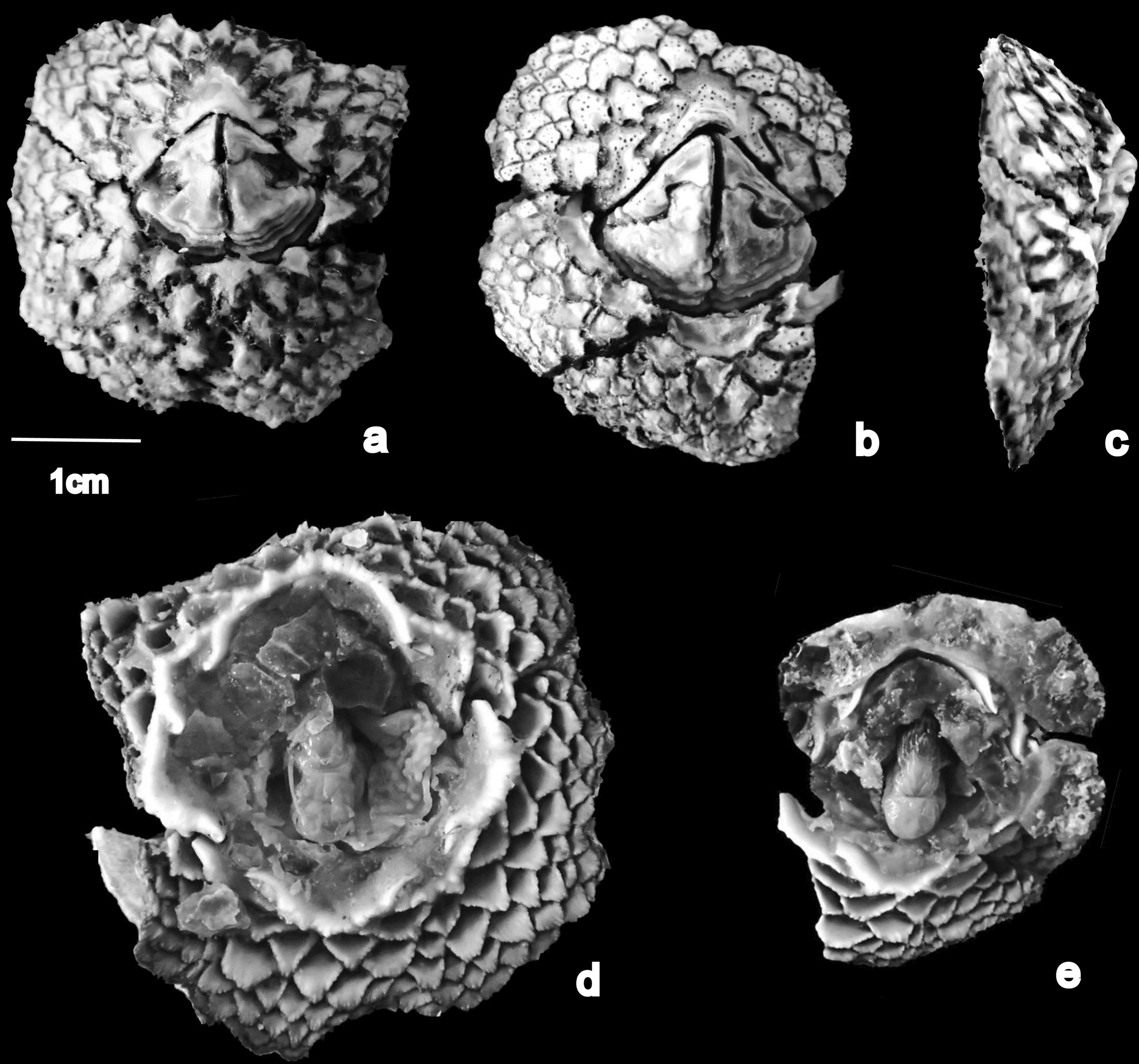


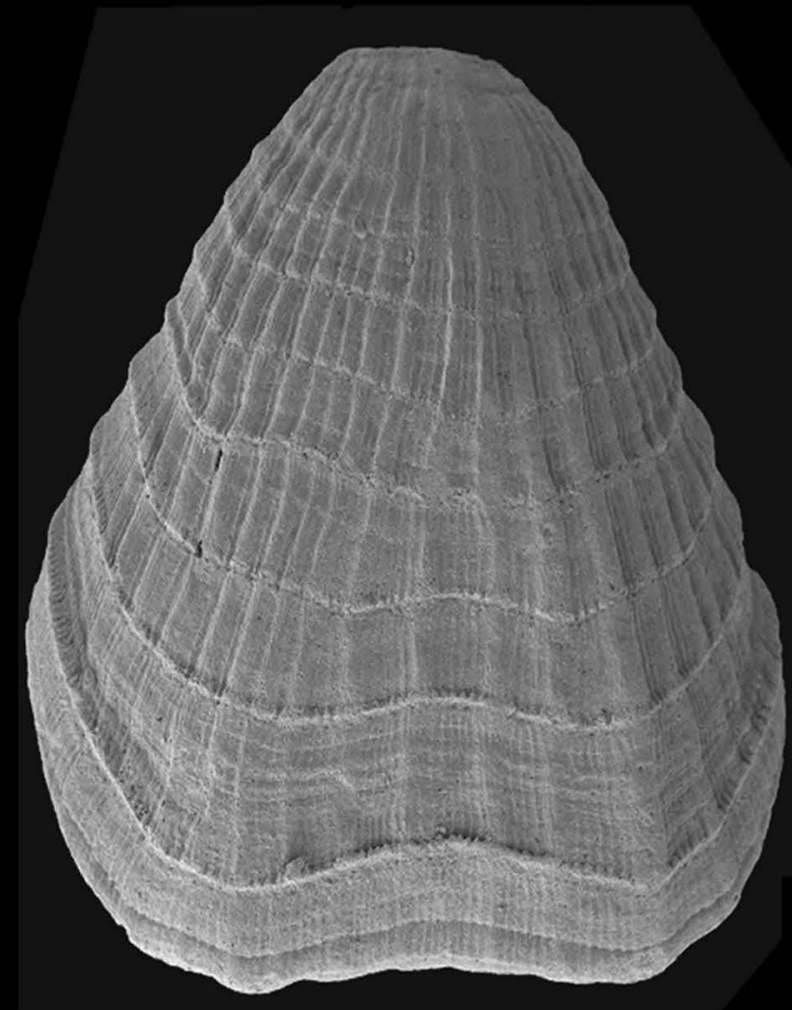

A

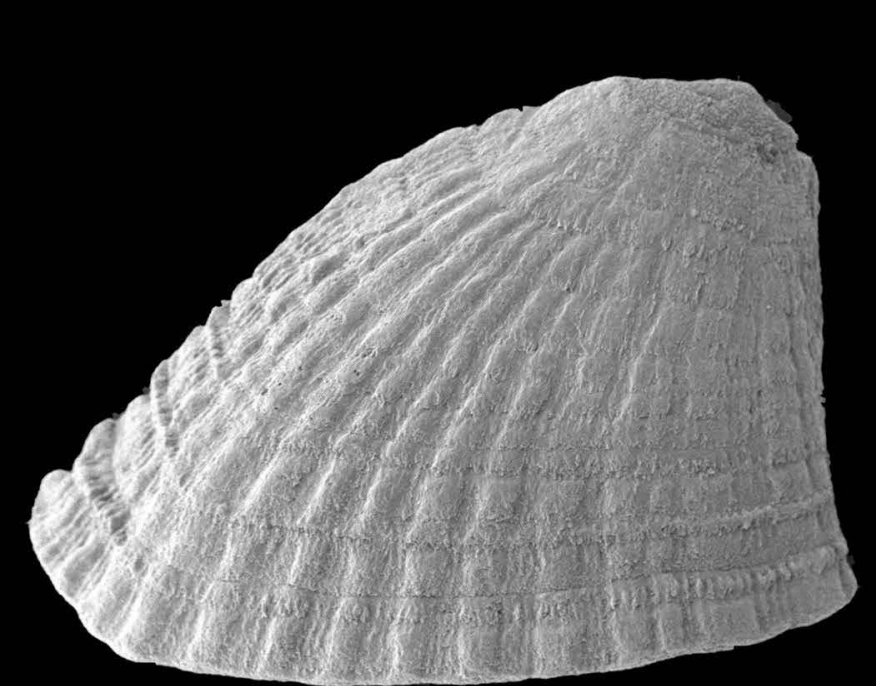

E

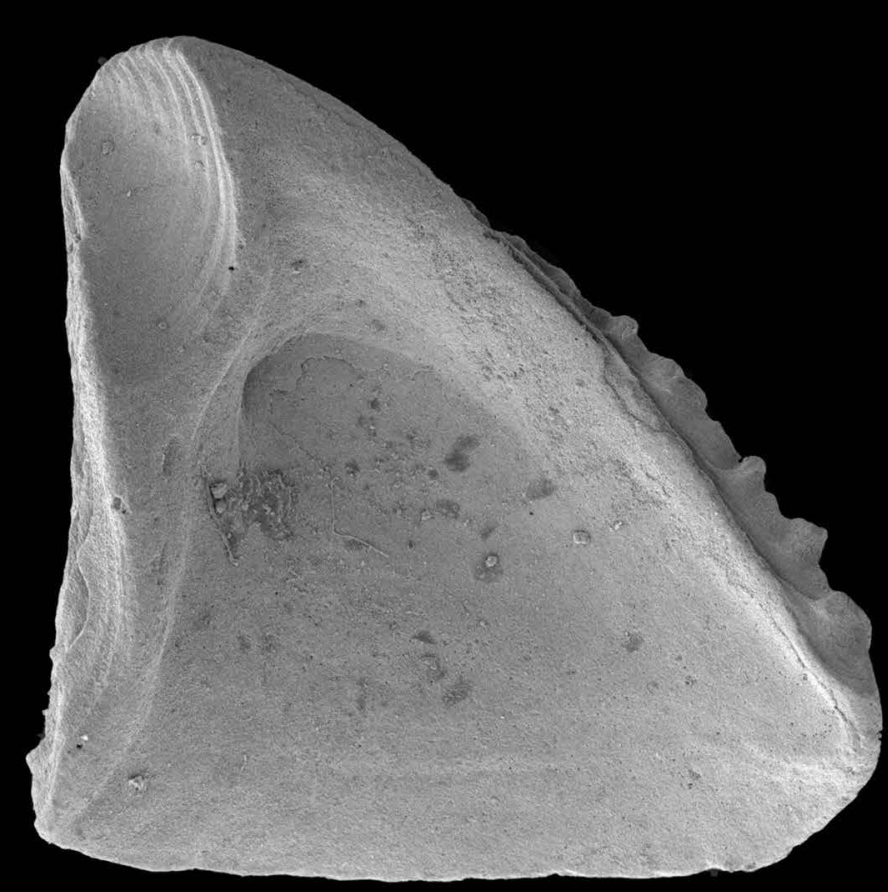

I

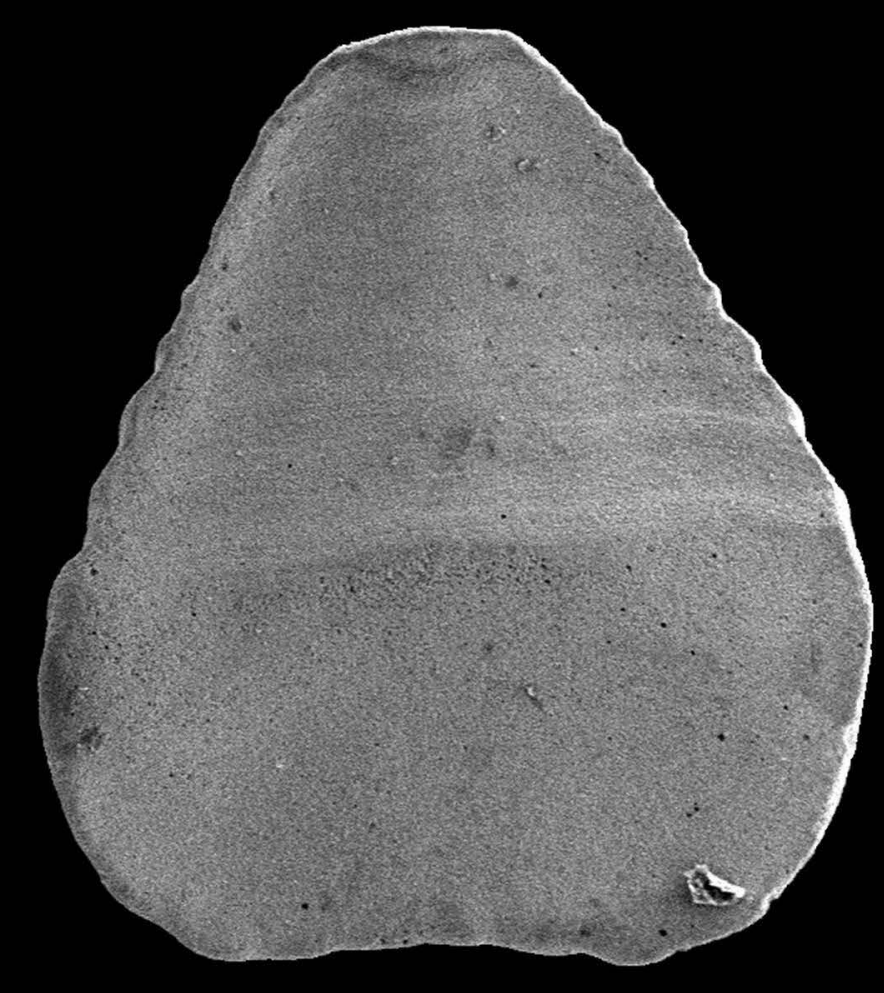

B

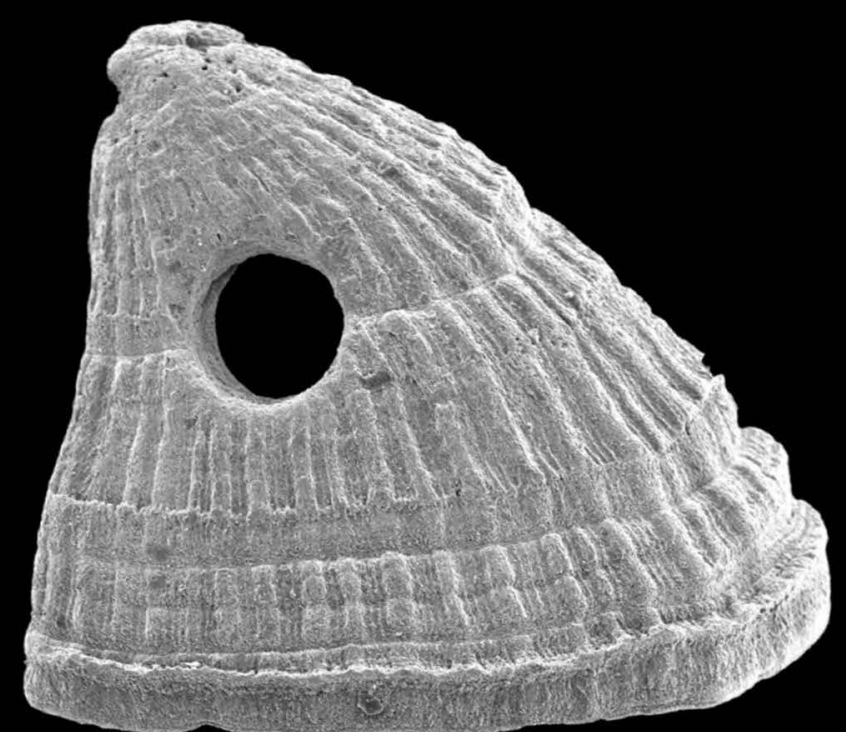

F

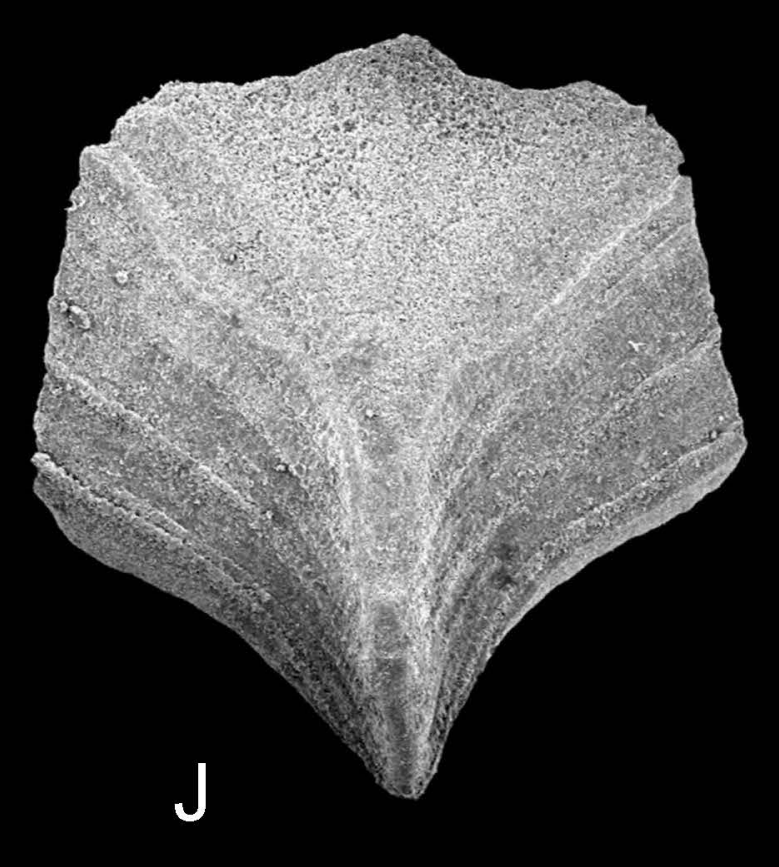

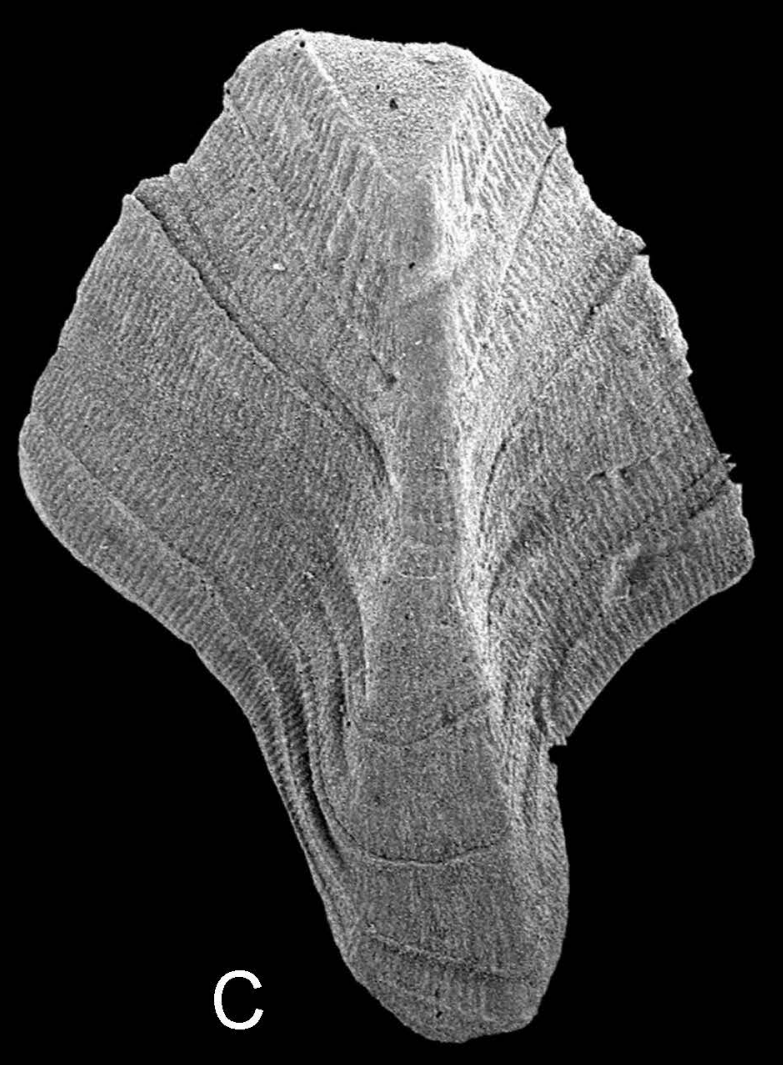
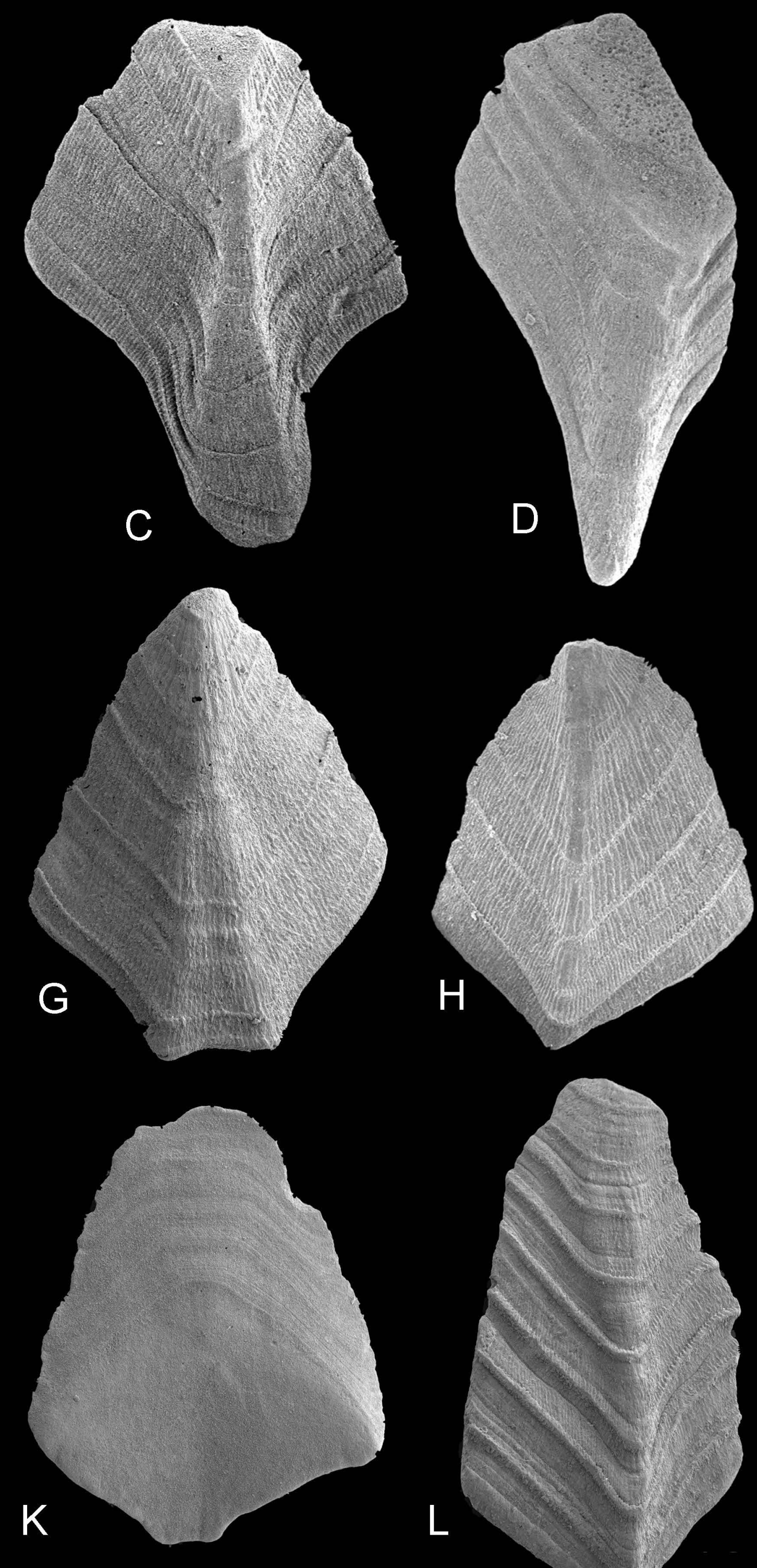

L
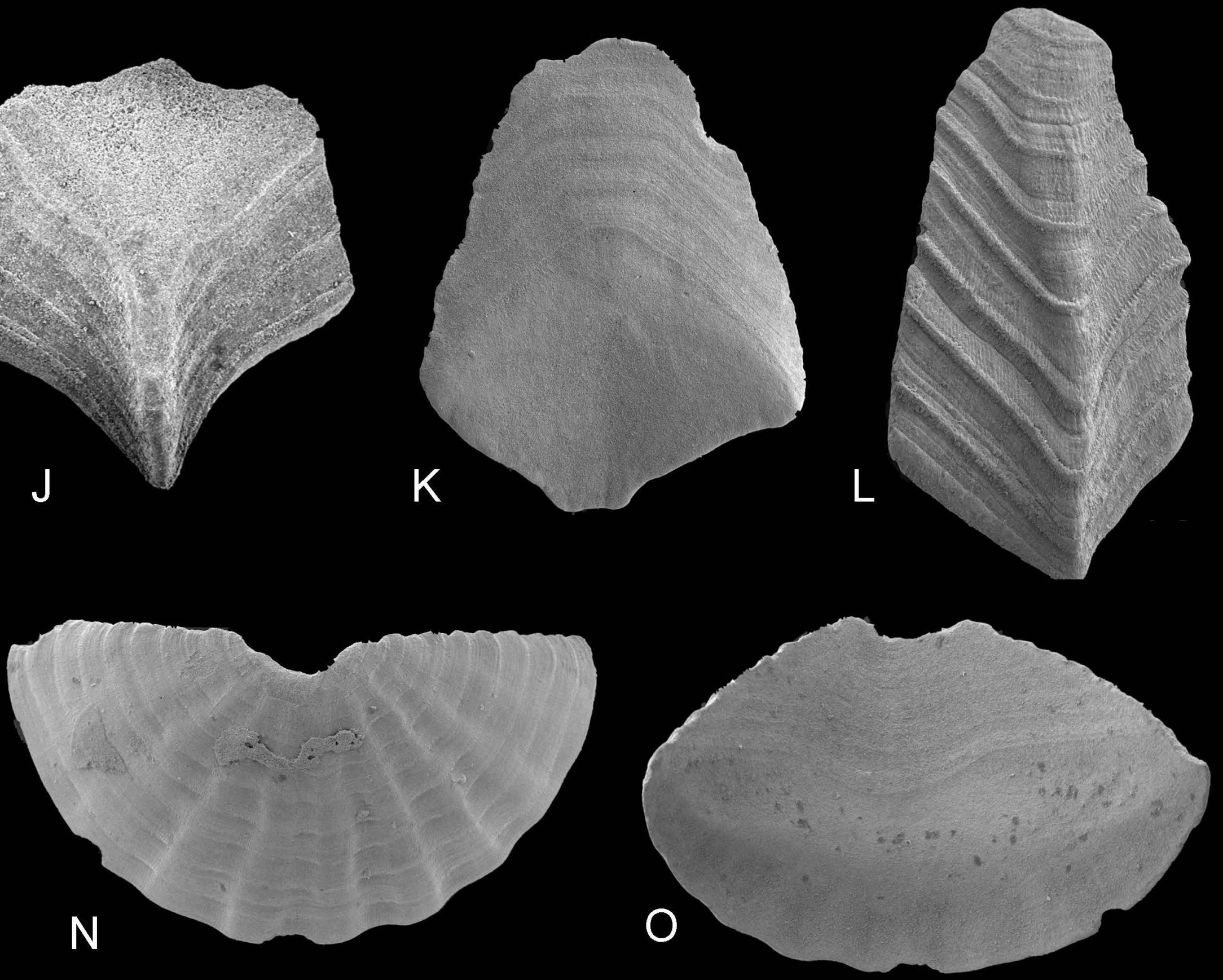


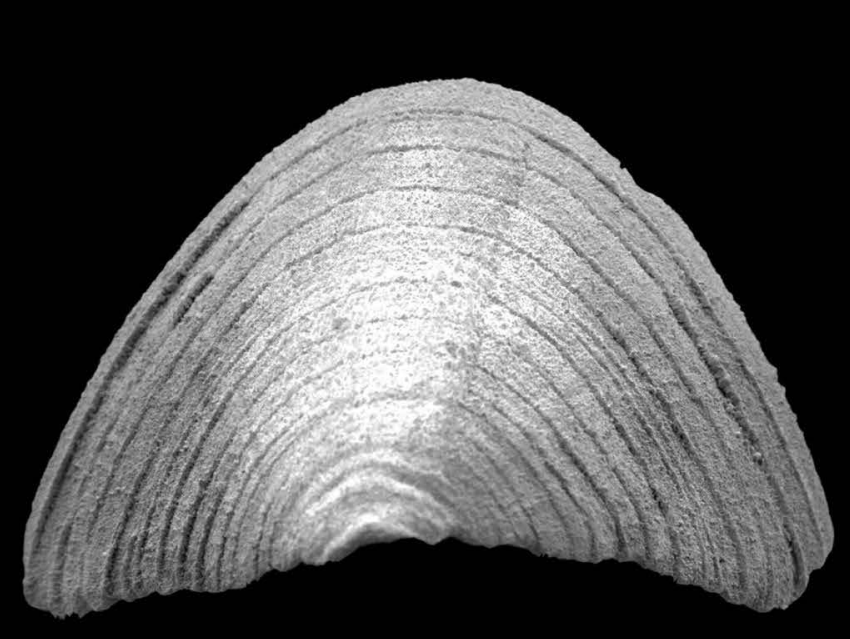

A

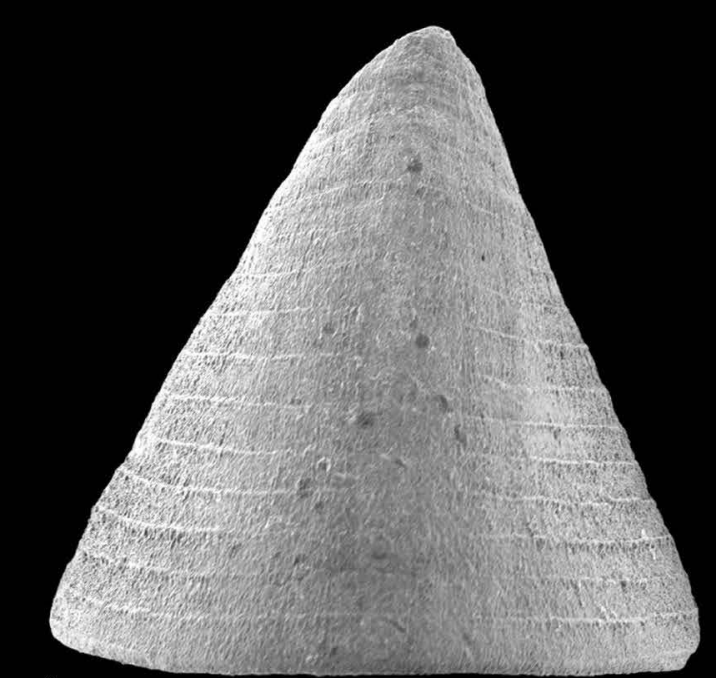

B
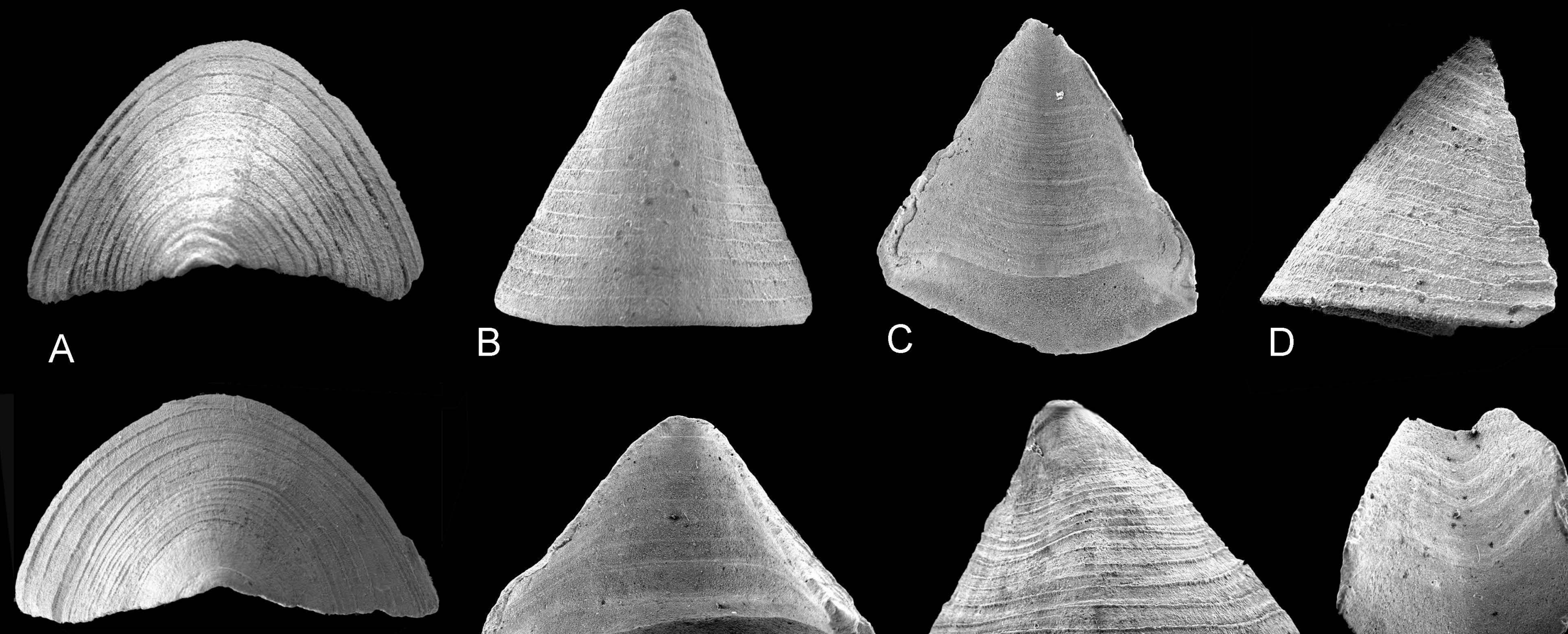

E
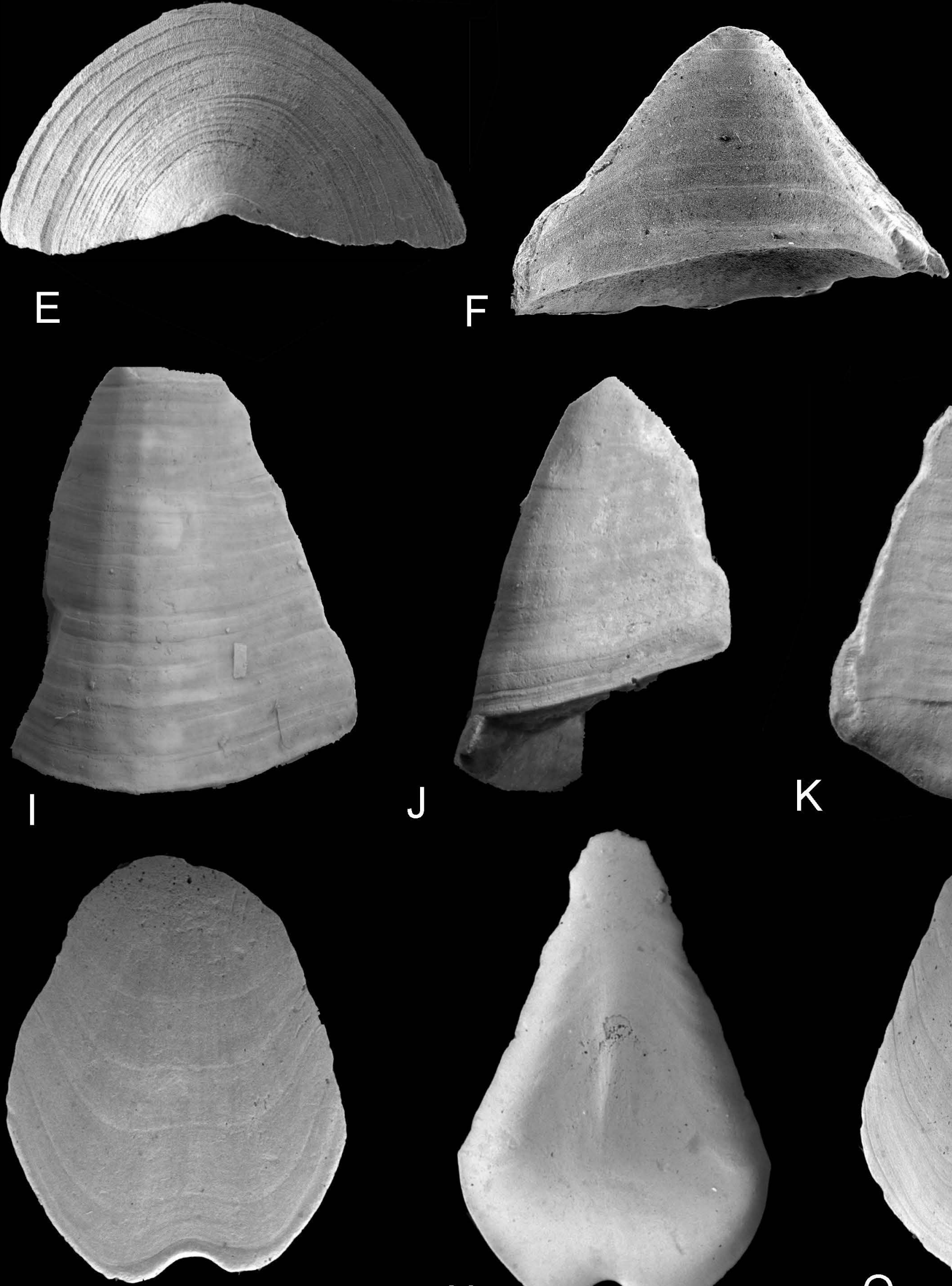

M

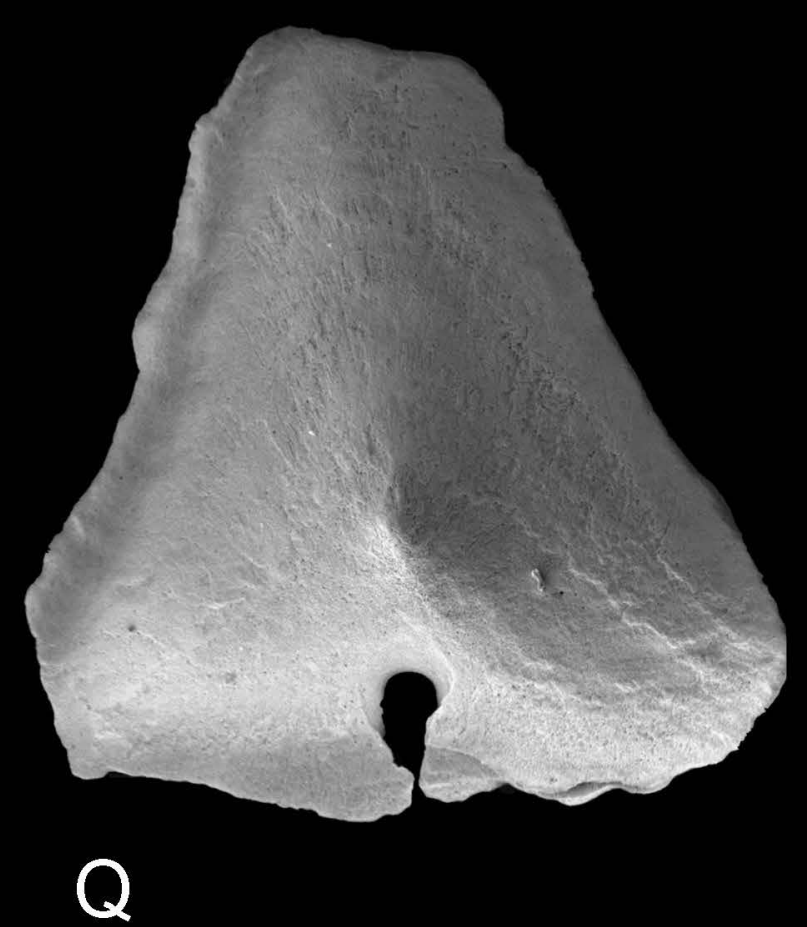

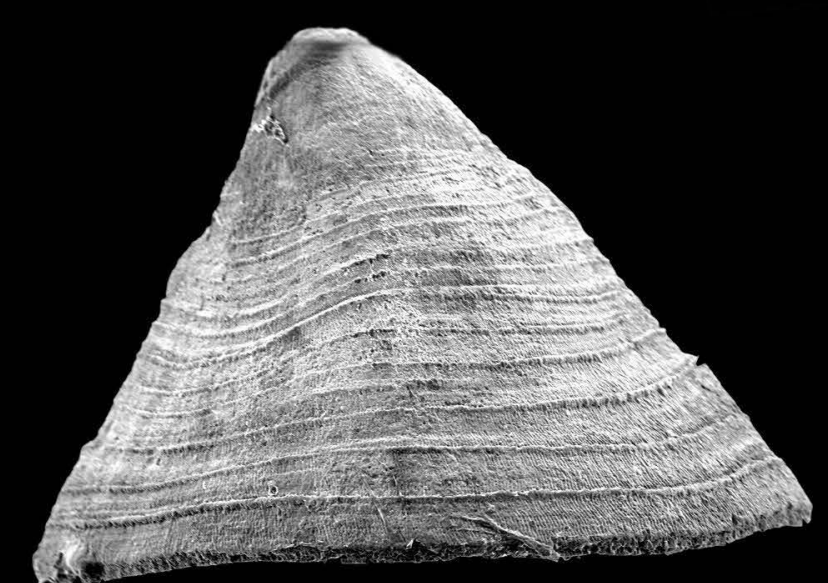

G
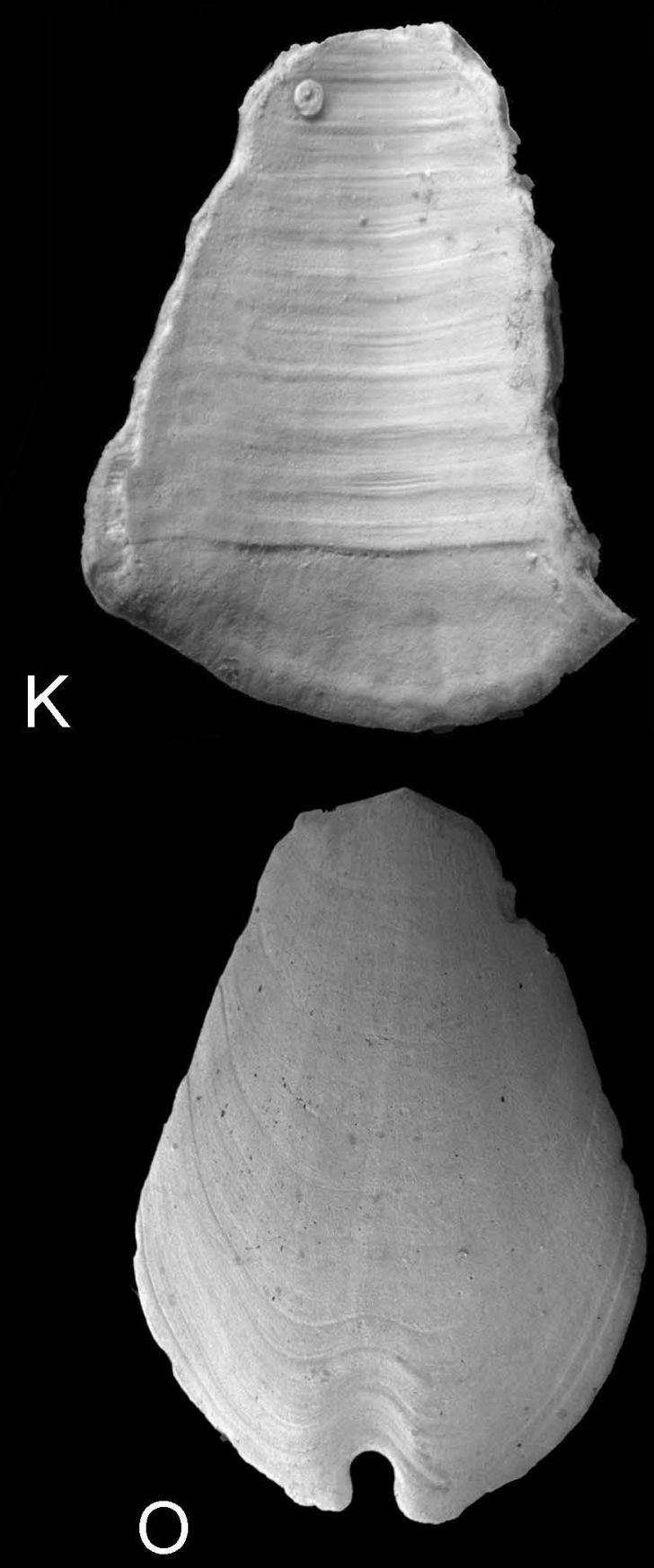
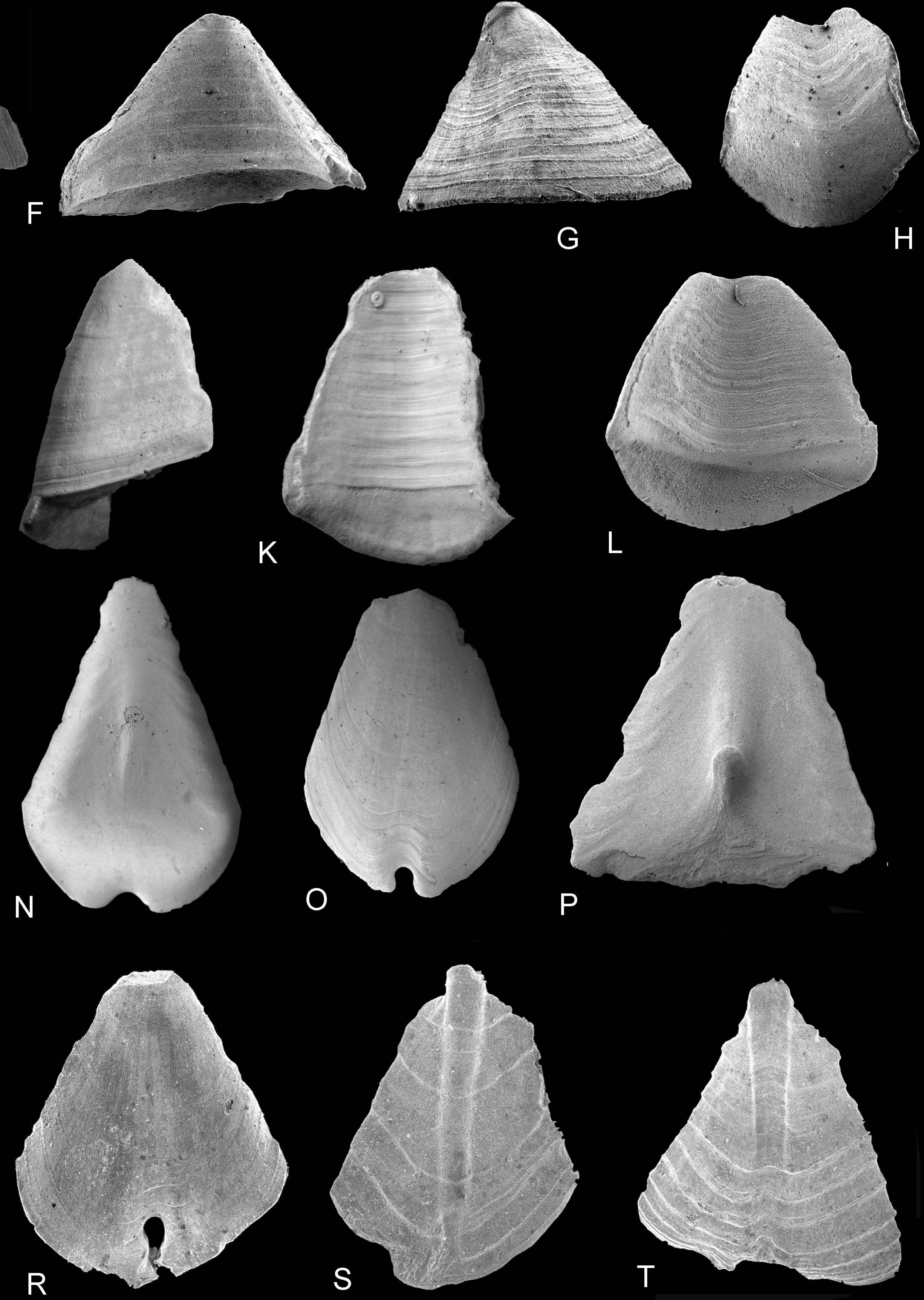


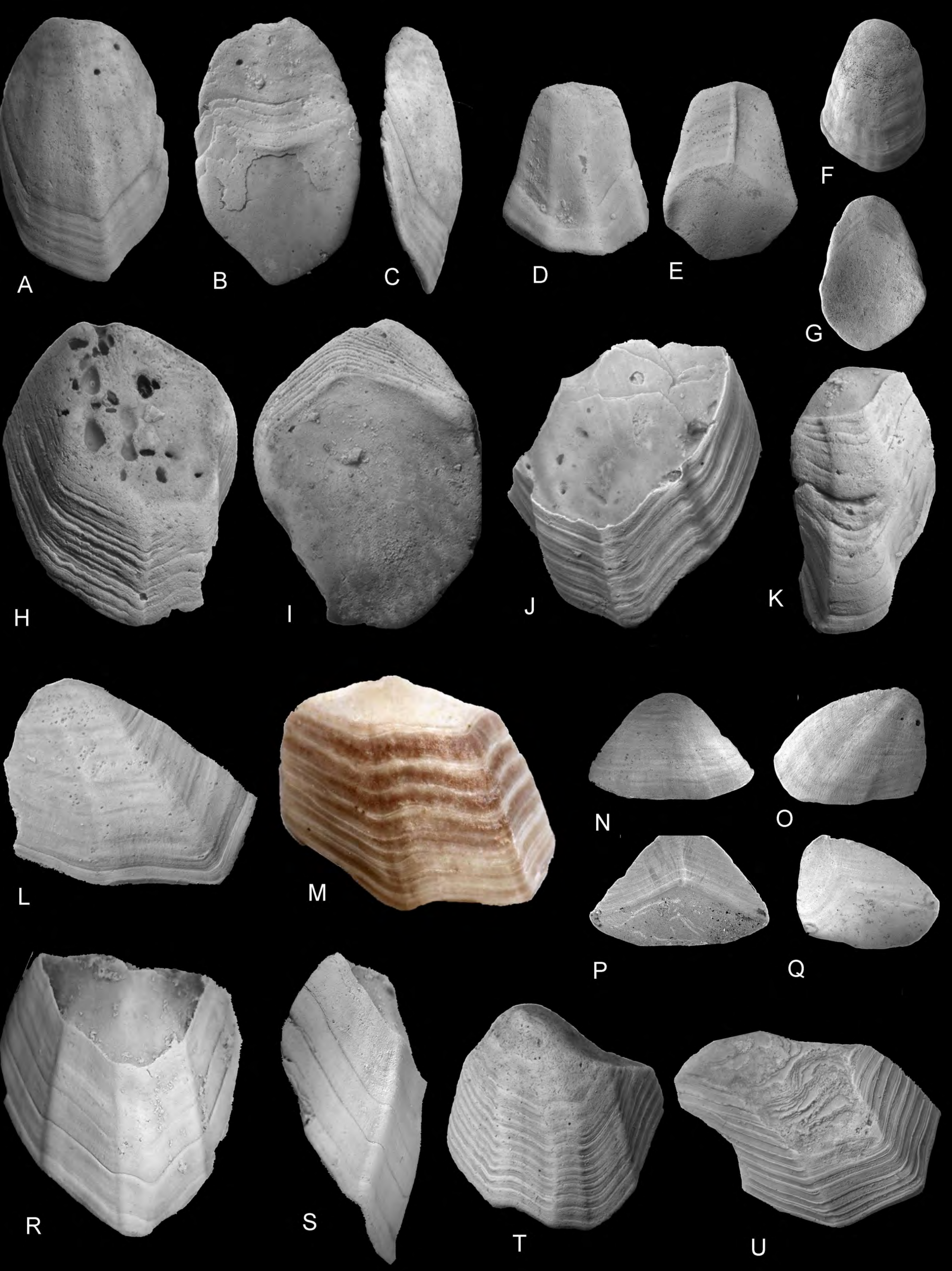




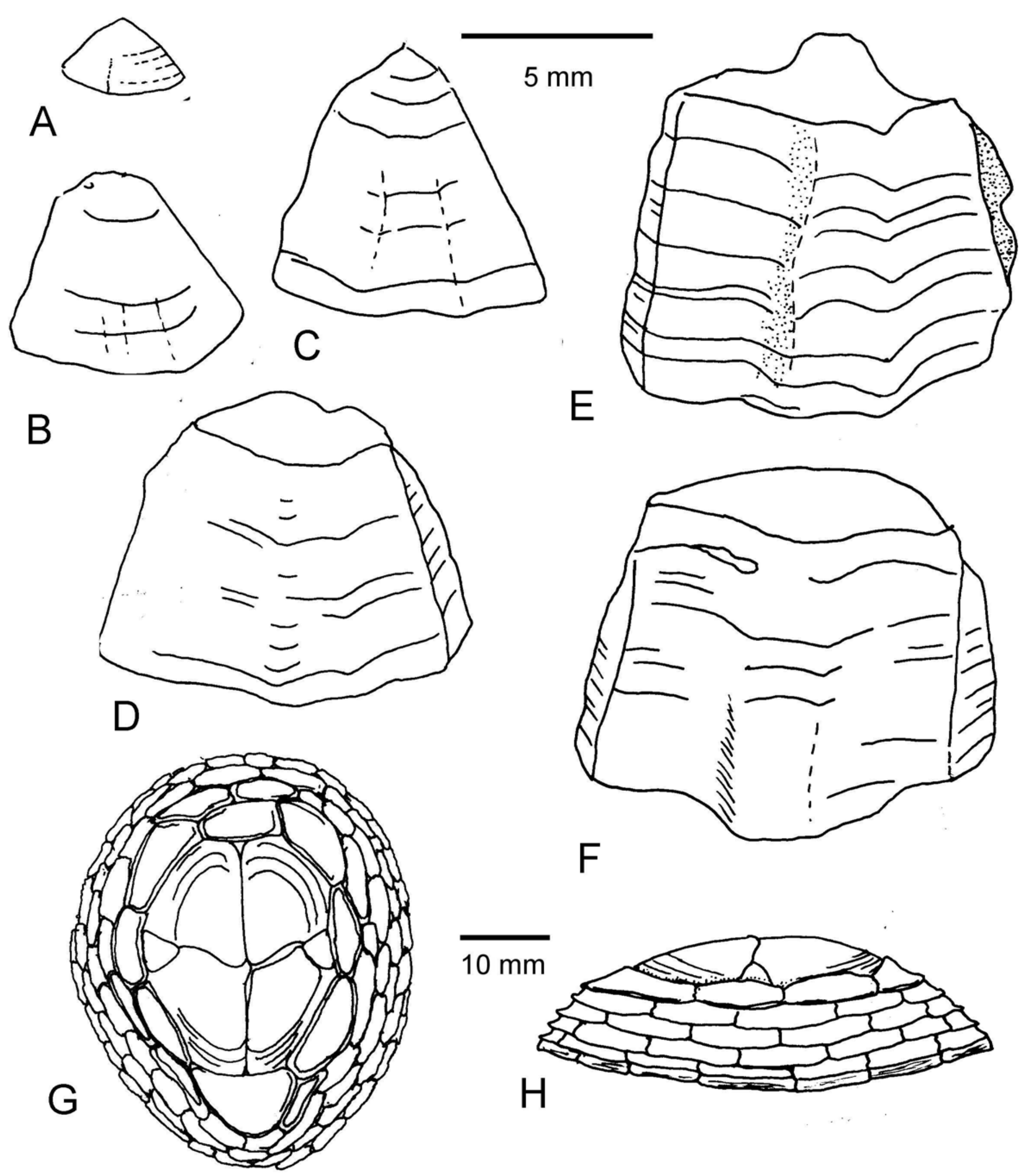



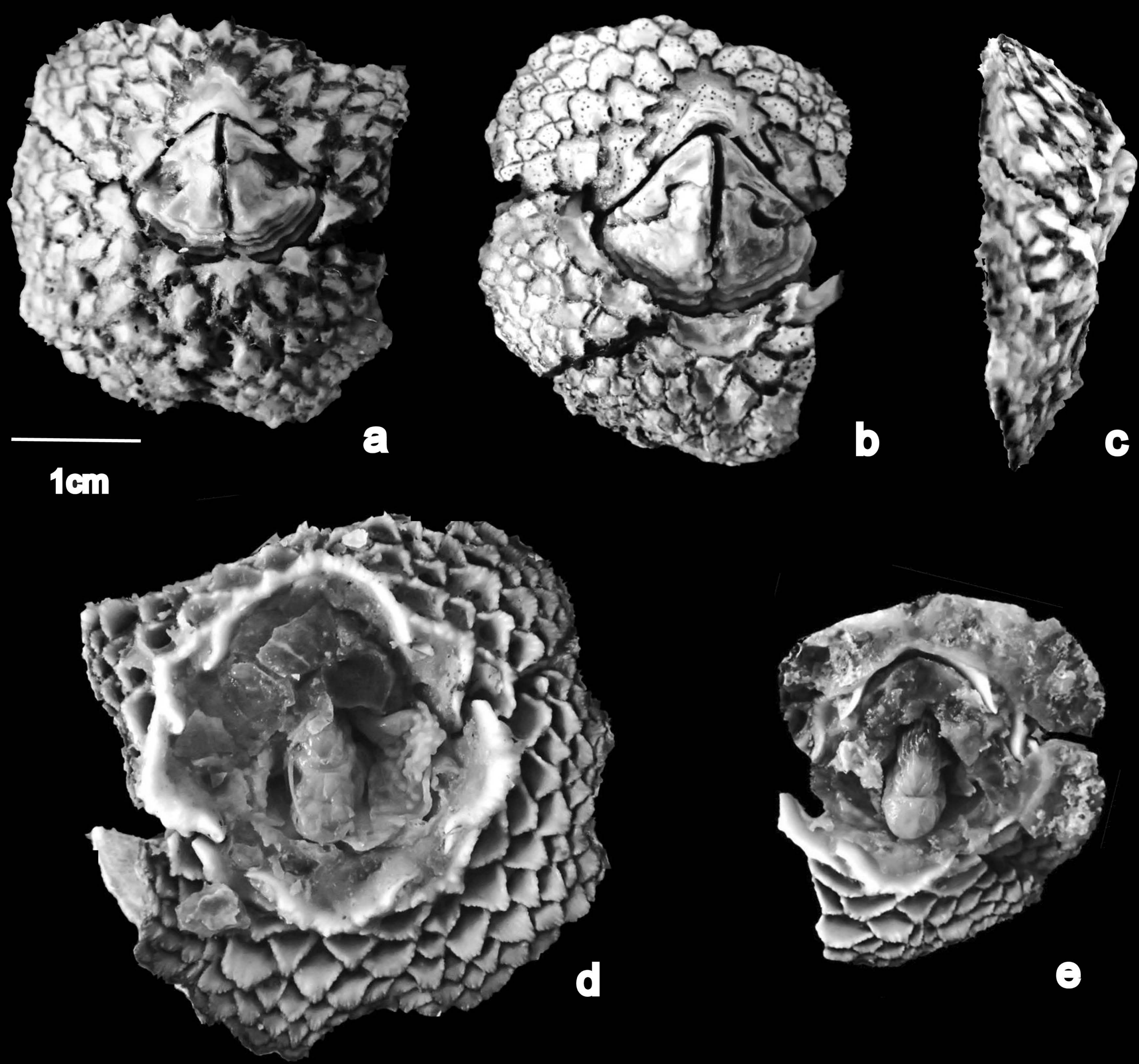